\title{
Short-term prey field lability constrains individual specialisation in resource selection and foraging site fidelity in a marine predator
}

\author{
Courbin Nicolas ${ }^{1,{ }^{*}}$, Besnard Aurélien ${ }^{1}$, Péron Clara ${ }^{2}$, Saraux Claire ${ }^{3}$, Fort Jérôme ${ }^{4}$, Perret Samuel ${ }^{1}$, \\ Tornos Jérémy ${ }^{1}$, Grémillet David ${ }^{1,5}$, Nathan Ran
}

${ }^{1}$ Centre d'Ecologie Fonctionnelle et Evolutive (CEFE); UMR 5175; Centre National de la Recherche Scientifique (CNRS); Université de Montpellier; Université Paul Valéry Montpellier; Ecole Pratiques des Hautes Etudes (EPHE); 1919 Route de Mende 34293 Montpellier Cedex 5, France

${ }^{2}$ Marine Biodiversity Exploitation and Conservation (MARBEC); UMR 248; Institut de Recherche pour le Développement (IRD); Université de Montpellier; Place Eugène Bataillon - bât 24 - CC093 34095 Montpellier Cedex 5 ,France

${ }^{3}$ Institut Français de Recherche pour l'Exploitation de la Mer (IFREMER); UMR 248 MARBEC; Avenue Jean Monnet CS 301734203 Sète, France

${ }^{4}$ Littoral, Environnement et Sociétés (LIENSs); UMR 7266; Centre National de la Recherche Scientifique (CNRS); Université La Rochelle; 2 rue Olympe de Gouges 17000 La Rochelle ,France

${ }^{5}$ FitzPatrick Institute; DST/NRF Excellence Centre at the University of Cape Town; Rondebosch 7701 ,South Africa

* Corresponding author : Nicolas Courbin, email addresses : nicolas.courbin@cefe.cnrs.fr ; ncourbin@gmail.com

\begin{abstract}
:
Spatio-temporally stable prey distributions coupled with individual foraging site fidelity are predicted to favour individual resource specialisation. Conversely, predators coping with dynamic prey distributions should diversify their individual diet and/or shift foraging areas to increase net intake. We studied individual specialisation in Scopoli's shearwaters (Calonectris diomedea) from the highly dynamic Western Mediterranean, using daily prey distributions together with resource selection, site fidelity and trophic-level analyses. As hypothesised, we found dietary diversification, low foraging site fidelity and almost no individual specialisation in resource selection. Crucially, shearwaters switched daily foraging tactics, selecting areas with contrasting prey of varying trophic levels. Overall, information use and plastic resource selection of individuals with reduced short-term foraging site fidelity allow predators to overcome prey field lability. Our study is an essential step towards a better understanding of individual responses to enhanced environmental stochasticity driven by global changes, and of pathways favouring population persistence.
\end{abstract}

Keywords: Behavioural consistency, Calonectris diomedea, foraging site fidelity, resource selection, Scopoli's shearwater, temporal resource dynamic, Western Mediterranean 


\section{Introduction}

Individual specialization (i.e. consistent trait variations among individuals [Sutherland 1987; Araújo et al. 2011]) shapes population-level behavioral diversity (Woo et al. 2008; Potier et al. 2015), and has strong implications for evolutionary processes and ecological interactions, affecting population and community dynamics (Araújo et al. 2011; Bolnick et al. 2011; Violle et al. 2012; Wolf \& Weissing 2012; Spiegel et al. 2017). Individual specialization is related to differences in physiological, behavioral and ecological mechanisms (Sutherland 1987; Fortin et al. 2008; Araújo et al. 2011; Bolnick et al. 2011; Spiegel et al. 2017) and is found across terrestrial and marine taxa (Bell et al. 2009; Araújo et al. 2011; e.g. fish: Allgeier et al. 2017; mammals: Duchesne et al. 2010; Leclerc et al. 2016; birds: Phillips et al. 2017). Studying the mechanisms by which individual specialization arises is critical to test theoretical approaches (Bolnick et al. 2011), and develop relevant conservation strategies (Duchesne et al. 2010; Wakefield et al. 2011; Merrick \& Koprowski 2017), especially in the context of rapid global change.

Individual specialization in resource selection (ISRS) is the within-individual consistency in selection of a subset within a range of available resources that differs from selection by other individuals. Mechanistic models suggested that individual resource specialization increases with intra-specific competition, to mitigate reduction in availability of the preferred prey, and decreases in dense populations to yield low resource levels and high fitness costs for specialists (Svanbäck \& Bolnick 2005; Fortin et al. 2008). Empirical studies confirmed these predictions (Araújo et al. 2011; e.g. fish: Svanbäck \& Bolnick 2007; sea otter: Tinker et al. 2012; seabirds: Navarro et al. 2017). For example, inter-individual variations in resource selection within a red deer (Cervus elaphus) population on the Isle of Rum (Scotland) reflected selective pressures for density- and frequency-dependent foraging tactics (Fortin et al. 2008). Individual specialization in foraging was also related to spatio- 
temporal changes in resource availability and prey predictability (Woo et al. 2008; Phillips et al. 2017). Most empirical studies (e.g. reviewed for seabirds in Ceia \& Ramos 2015) found reduced individual specialization in diet and habitat use in years with lower resource accessibility (Catry et al. 2014). In systems with rapid (day to week) changes in abiotic conditions, high prey patchiness and low prey predictability (e.g. Weimerskirch 2007; Fernandez et al. 2017), low ISRS is expected. Indeed, in such a situation, the costs of tracking one elusive resource could outweigh foraging benefits of specialization related to predator abilities and prey features.

ISRS offers a selective advantage if individuals increase foraging efficiency by reducing search times, and this is related to their abilities to locate prey (Spiegel \& Crofoot 2016) and to prey predictability (Phillips et al. 2017). When prey distributions are predictable, predators can reduce search time using memory (Weimerskirch 2007; Wakefield et al. 2013) and/or public information (Weimerskirch et al. 2010; Wells et al. 2016). In contrast, if prey distributions are unpredictable, information cannot allow maintaining ISRS. Individuals may overcome low spatio-temporal prey predictability by diversifying their diet, either through generalist foraging tactics (no selection) or by alternating foraging tactics targeting specific prey items (narrow short-term resource selection). In colonial species, this is promoted by the breeding site functioning as an information centre (Harel et al. 2017). Previous studies showed predator specialization on resources that are temporally dynamic but predictable in space and/or time. For instance, Nile crocodiles (Crocodylus niloticus) prey on migrating wildebeest (Connochaetes taurinus) at predictable times (Subalusky et al. 2017). However, the relative effect of the two main contrasting drivers, intra-specific competition and prey predictability, acting upon ISRS remains largely unknown.

To tackle such question, we must consider behaviours that distort the interplay between resource selection, ISRS and prey predictability. Individual foraging site fidelity 
(IFSF, i.e. consistent use of the same foraging areas by an individual, Wakefield et al. 2015) is a widespread behaviour within colonial marine predator populations (Arthur et al. 2015; Baylis et al. 2015; Wakefield et al. 2015), probably selected for the benefit of site familiarity (Wakefield et al. 2015) or because predators go where their preferred prey usually occur. IFSF increases with environmental stability (Switzer 1993) and should be positively correlated with resource selection and ISRS when prey distribution is stable and not depleted (Fig. 1). Accordingly, seabirds show both IFSF and individual specialization in habitat use (reviewed in Ceia \& Ramos 2015; e.g. Grémillet et al. 1999; Patrick et al. 2014; Wakefield et al. 2015). The determinants of ISRS remain nevertheless unclear: Does individual specialization on a given prey type occur because of IFSF, or do individuals track specific prey types occurring systematically at the same place (ISRS as well as IFSF)? Theoretically, prey predictability should enforce a trade-off between IFSF and ISRS. In environments with rapidly changing spatio-temporal prey distribution, visits to the same foraging areas should promote generalist foraging tactics (dietary diversification) and low ISRS, while low IFSF allows specialized foraging tactics and high ISRS (Fig. 1). If specialization costs in prey type (ISRS) or site (IFSF) are too high, individuals may use generalist or short-term specialized foraging tactics and switch among foraging areas leading to low ISRS and low IFSF. Understanding if and how ISRS arises in environments with low prey predictability thus requires to simultaneously consider IFSF and ISRS in a dynamic habitat selection framework including prey availability fluctuations (i.e. disproportionate use relative to resource availability; Manly et al. 2002).

We studied the ecological drivers of ISRS in Scopoli's shearwaters (Calonectris diomedea) using an analytical framework combining modelling of prey field lability, spatial and trophic ecology of shearwaters (see Appendix S1). We tracked birds with GPS loggers during four chick-rearing seasons within the Gulf of Lions (Western Mediterranean, Fig. 2), a 
marine system associated with daily to yearly environmental stochasticity (Saraux et al. 2014; Appendix S2, Fig. S2.1). We used hydro-acoustic estimations of biomass (summed individual masses) and net sampling estimations of abundance (number of individuals) of prey targeted by shearwaters, to develop dynamic prey habitat models and predict prey daily spatial distributions according to shifting oceanographic conditions. We then assessed resource selection for shearwaters, based on daily prey fields, to test the following predictions: 1) Shearwaters show low ISRS and low IFSF at the individual level, and switch between specialized foraging tactics (selection related to trophic level and/or prey type over the shortterm). 2) IFSF is uncoupled from ISRS and resource selection at the individual level. 3) Information use for prey localization partly drives ISRS. Finally, we confronted our findings with seabird trophic analyses. Overall, our study aimed at determining how short-term predictability in prey distribution shapes ISRS and its mechanisms within foraging populations.

\section{Material and Methods}

\section{Study system}

Our study was carried out during four chick-rearing seasons (in 2011, 2012, 2014 and 2015) at two Marseille islands (Frioul and Riou, $43^{\circ} 11^{\prime} 00^{\prime}{ }^{\prime}, 05^{\circ} 23^{\prime} 00^{\prime} \mathrm{E}$ ) located in the Western Mediterranean Sea (Fig. 2). Marseille's archipelago hosts one of the largest French breeding colonies of Scopoli’s shearwater (Anselme \& Durand 2012), with approximately 520 breeding pairs. During the chick-rearing period, Scopoli's shearwaters are known to feed on a wide range of prey, from zooplankton to small pelagic fish and squid (Sarà 1993; Ramos et al. 2009). The dynamic spatial distribution of these prey mainly relies on stochastic inputs of nutrients associated with the Rhône River discharge, on coastal upwelling due to northerly winds, and on the spatial extent of the Rhône freshwater plume induced by wind forcing. 
Consequently, small pelagic fish show strong inter-annual heterogeneity in their summer spatial distribution (Saraux et al. 2014). Additionally, we demonstrated high spatio-temporal variations in fish and zooplankton distribution on a daily scale (Fig. S2.1).

\section{GPS tracking and feather sampling}

We tracked the foraging movements of 75 breeding Scopoli's shearwaters of both sexes during the chick-rearing period using GPS loggers between the $29^{\text {th }}$ July and the $18^{\text {th }}$ August in four years $(\mathrm{n}=18,27,19$ and 20 birds in 2011, 2012, 2014 and 2015, respectively; see Appendix S3). Individuals were caught at the nest at night. We equipped birds with GPS loggers (Perthold Engineering LCC) encapsulated in heat-shrink tubing and attached to back feathers with Tesa tape. Tagged birds weighted $604 \mathrm{~g}$ on average (range: 500 to $753 \mathrm{~g}$ ), and tagging load $(22.7 \mathrm{~g})$ represented $\sim 3.8 \%$ of individual's body mass (range: 3.0 to $4.5 \%$ ). GPSs recorded a location every 1.5, 2 or 3 min depending on individuals and all GPS tracks were interpolated to regular 2 min intervals. Birds were recaptured and loggers were retrieved after 1 to 5 days. At recapture, and before releasing birds, we collected the tip $(1-2 \mathrm{~cm})$ of the first primary feather to assess their trophic position using stable isotopic analyses (see Appendix S4). Through GPS-tracking, we thus had information on the foraging ecology of shearwaters for periods of up to 5 days, and for approximately two-week periods (feather growth period) through isotopic analyses. No effect of manipulation and instrumentation was found on the breeding performance and divorce rate of shearwaters at this study site (Authier et al. 2013). Also, device and exposure to stress potentially affecting short-term behavior was standardized, as all birds were handled in exactly the same manner.

\section{Identification of foraging locations}


175 We considered a foraging trip as a round trip between colony/colony or colony/raft because sometimes shearwaters stopped at rafts localized within $4 \mathrm{~km}$ of the colony before starting a new trip. We identified the foraging locations of each trip using the residence in space and time method (Torres et al. 2017). This method discriminates between behavioural states by calculating the amount of space and time occupied by an individual in an area of constant surface (a circle of radius $r$ ): Movement across long distances and protracted residency time within an area reflect foraging behaviour; short movement distances and long residency time reflect resting, and short distance and time correspond to travelling. The radius $r$ was determined with an automated dynamic scaling process for each foraging trip (Torres et al. 2017). Its average value was $0.52 \pm 0.14 \mathrm{~km}( \pm \mathrm{SD})$. Foraging locations corresponding to surface pecking behavior may have been omitted, yet previous studies showed that this behavior is marginal in shearwaters (Camphuysen \& Van Der Meer 2001).

\section{Prey field modelling}

To obtain daily shearwater prey distributions (zooplankton and pelagic fish; Sarà 1993; Ramos et al. 2009) across our entire study area, we modelled biomasses (tonnes) of European anchovies (Engraulis encrasicolus), sardines (Sardina pilchardus) and sprats (Sprattus sprattus) of both juvenile and adult stages. We also modelled the abundance (ind. $\mathrm{m}^{-3}$ ) of two zooplankton groups: 'preferred zooplankton prey' (copepods, euphausiids, fish eggs and fish larvae) and 'others', based on shearwater dietary preferences (Appendix S2). Empirical data for potential prey were collected each year in July during PELMED oceanographic campaigns (Appendix S2, Fig. S2.2). We used spatial generalized linear mixed models with a Horseshoe prior in a Bayesian framework (Authier et al. 2017) and models were fitted with daily dynamic oceanographic predictors (Fernandez et al. 2017, see Appendix S2). Such models make robust and accurate predictions for fish biomass in the Gulf of Lions, including 
extrapolations (Authier et al. 2017). We assessed zooplankton model robustness using leaveone-out cross-validation (see Appendix S2). The ecological niches of small pelagic fish and zooplankton are sustained across the summer period in the Gulf of Lions (Plounevez \& Champalbert 2000), and the slight temporal mismatch between prey field assessment and bird tracking was not an issue.

\section{Resource selection of shearwaters}

We assessed Scopoli's shearwater resource selection functions (RSF; Manly et al. 2002) based on daily prey distributions. Such analyses are rarely performed in marine ecology (but see Wakefield et al. 2009; Raymond et al. 2015) because direct information on prey availability is particularly difficult to obtain (Grémillet et al. 2004; Torres et al. 2008). RSF compared the daily predictions for the six fish biomasses, the two zooplankton abundances and their predictability (i.e. variance of biomasses or abundances calculated over the previous seven days) at foraging locations and at available locations where birds could potentially forage. Prey-related variables were standardized, and availability was determined in two steps. First, for each observed foraging trip, we simulated 10 tracks that started at the same location as the observed trip using a first-order vector autoregressive model (Raymond et al. 2015). Simulated tracks considered no habitat preference, while respecting constraints on trip structure (duration and travel speed; Raymond et al. 2015). We then identified available foraging locations for each simulated track using the residence in space and time method described previously (Torres et al. 2017). Foraging locations and their associated available locations occurred at the same spatio-temporal scale and we therefore controlled for shortterm variability in prey spatial distribution. Additionally, with simulated tracks being spatially anchored to the colony, we used a non-uniform spatial distribution of availability adapted to 
study central-place foragers that use areas close to the colony more frequently than elsewhere (Wakefield et al. 2009; Monsarrat et al. 2013).

We fitted one RSF for each of the 16 prey-related variables, and estimated RSF coefficients using mixed-effects logistic regressions (Gillies et al. 2006; Hebblewhite \& Merrill 2008; Courbin et al. 2013). We used nested random intercepts to accommodate the three-level hierarchical structure of our data: foraging locations $(n=56945)$ within foraging trips $(\mathrm{n}=182)$ within individuals $(\mathrm{n}=75)$ (Hebblewhite \& Merrill 2008). Random intercepts corrected for differences in sample size between foraging trips and individuals (Gillies et al. 2006). We added random coefficients (one slope per individual and per trip) to assess differences in resource selection between individuals and trips (conditional estimates) in addition to estimate population-level responses (marginal estimate; Gillies et al. 2006; Hebblewhite \& Merrill 2008; Leclerc et al. 2016; Carneiro et al. 2017). We tested the added value of using random coefficients based on the Akaike Information Criterion (AIC). RSF modelled for foraging location $i$, trip $j$ and shearwater $k$ took the form:

$$
w\left(\mathbf{x}_{i j k}\right)=\exp \left(\beta_{0}+\mathbf{X} \boldsymbol{\beta}+\gamma_{0 j k}^{(t r i p)}+\gamma_{0 k}^{(b i r d)}+\gamma_{x j k}^{(t r i p)} x_{i j k}+\gamma_{x k}^{(b i r d)} x_{i j k}\right)
$$

where $w\left(\mathbf{x}_{i j k}\right)$ is the relative probability of selecting resources for shearwaters, $\mathbf{x}$ is a vector, $\beta_{0}$ is the mean intercept, $\mathbf{X} \boldsymbol{\beta}$ is the vector of the fixed-effect resource selection coefficients for the set of covariate (i.e. the standardized fish biomasses, standardized zooplankton abundances or their standardized variances, year [four levels] and islands [two levels]), $\gamma_{0 j k}^{(\text {trip })}$ and $\gamma_{0 k}^{(\text {bird })}$ are the random intercepts at the trip and individual levels, respectively, $\gamma_{x j k}^{(t r i p)}$ is the random coefficient of prey-related variable $x$ for trip $j$ and shearwater $k$, and $\gamma_{x k}^{(b i r d)}$ is the random coefficient of $x$ for shearwater $k$. No multicollinearity 
between variables was detected (variance inflation factor being <2; Dormann et al. 2013).

We accounted for multiple comparisons by adjusting the $95 \%$ confidence interval of RSF coefficients with Benjamini-Yekutieli correction (Benjamini \& Yekutieli 2001). RSFs were performed with the lme4 package (Bates et al. 2015) of the R software (R Development Core Team 2016).

Assessing individual specialization in resource selection (ISRS)

We quantified ISRS, i.e. within-individual consistency in resource selection, by calculating an adjusted repeatability index $R_{k}$ for each shearwater $k$ between its different trips (47 birds were tracked for multiple trips) and each prey-related variable. We adapted the population-level repeatability index $R$ developed for logistic regression with random coefficients (Johnson 2014; Nakagawa et al. 2017) at the individual-level, by partitioning the global observationlevel (GPS location level) variance $\sigma_{\varepsilon}^{2}$ at the individual level, as usually done for linear models (Potier et al. 2015; Wakefield et al. 2015; see Appendix S5). In a mixed RSF for foraging location $i$, trip $j$ and shearwater $k, R_{k}$ took the form:

$$
R_{k}=\frac{\sigma_{x, \text { between }}^{2}}{\sigma_{x, \text { between }}^{2}+\sigma_{x, \text { within }}^{2}+\sigma_{\varepsilon k}^{2}}
$$

where $\sigma_{x, \text { between }}^{2}$ and $\sigma_{x, \text { within }}^{2}$ are the between- and within-individual variances (bird and trip level, respectively) estimated from Eq. 1 with a random effect for the prey-related variable $x$, $\sigma_{\varepsilon k}^{2}$ is the partitioned observation-level variance for the $k^{\text {th }}$ bird given a logit link. $R_{k}$ values range between 0 and 1 , with 1 meaning high consistency in resource selection for shearwater $k$ between its different trips. Low $R_{k}$ values arise from heterogeneous resource selection among foraging trips or locations of shearwater $k$ (i.e. high within- 
272 individual and/or partitioned observation-level variance). Analyses were performed with the

$273 r p t R$ package (Stoffel et al. 2017) of the R software (R Development Core Team 2016).

274

275

276

277

278

279

280

281

282

283

284

285

\section{Assessing individual foraging site fidelity (IFSF)}

We quantified within-individual consistency in the use of space, an index of IFSF (Wakefield et al. 2015). For each shearwater $k$ in each year $(n=47$ individuals and 154 trips), we calculated the $95 \%$ utilization distributions (UDs) for each of its trips based on foraging locations only, and assessed the mean overlap between all pairwise combinations of consecutive UDs using Bhattacharyya's affinity ( $B A_{k}$, Fieberg \& Kochanny 2005). $B A_{k}$ ranges between 0 (no spatial overlap) and 1 (perfect spatial overlap). All UDs were calculated with a fixed bandwidth (Wakefield et al. 2015) of $0.5 \mathrm{~km}$ that encompassed the extent of almost all bandwidth estimations ( $h r e f$ ) calculated for a random sample of foraging areas and individuals ( $\mathrm{n}=32$, c.a. 93 -quantile of href $=0.5 \mathrm{~km})$, on a $0.3 \mathrm{~km}$ resolution grid.

We determined if overlap among foraging areas of different trips of a given individual $k\left(B A_{k}\right)$ differed from a random expectation, $B A_{k, \text { random. }} B A_{k \text {,random }}$ was the average overlap between each UD for observed trips and each UD for the immediate previous and next simulated tracks. We compared $B A_{k}$ and $B A_{k, \text { random }}$ with a paired t-test. We also tested if $B A_{k}$ differed from overlap among foraging areas of different individuals, $B A_{k, \text { between }} . B A_{k, \text { between }}$ was the average overlap for individual $k$ between each of its UD and the UDs of other individuals occurring within \pm 1 day. We contrasted $B A_{k}$ and $B A_{k, \text { between }}$ with a paired t-test. Analyses were performed with the adehabitat package (Calenge 2006) of the R software (R Development Core Team 2016).

Finally, we used Spearman rank correlation to investigate the relationships between $\operatorname{IFSF}\left(B A_{k}\right)$ and ISRS $\left(R_{k}\right)$, and between IFSF $\left(B A_{k}\right)$ and individual selection coefficients 
$\left(\gamma_{x k}^{(\text {bird })}\right.$ in Eq. 1) for each prey-related variable. P-values were adjusted with BenjaminiYekutieli correction (Benjamini \& Yekutieli 2001).

\section{Identifying foraging trip tactics}

In order to identify the main foraging trip tactics within the shearwater population, reflecting a potential gradient of specialization with respect to trophic level and/or prey type, we discriminated between groups of trips (cluster) with similar resource selection. We conducted the analysis at the trip level because of higher heterogeneity within, than between individuals (Fig. 3). We ran a hierarchical cluster analysis with a Ward clustering method using selection coefficients of 182 trips ( $\gamma_{x j k}^{(\text {trip })}$ in Eq. 1) for biomasses of adult anchovies, adult sprats and abundances of both zooplankton groups. The selection coefficients for other variables of biomass had low variations around 0 and were not considered in the cluster analysis (Fig. 3B).

\section{Results}

We collected $2.4 \pm 1.8$ trips per bird (mean \pm SD, ranging from 1 to 11 trips), characterized by an average trip range of $59 \pm 46 \mathrm{~km}$ from the colony, a total travelled distance of $218 \pm 167$ $\mathrm{km}$, and a duration of $22.2 \pm 11.9$ hours (Appendix S6, Fig. S6.1). Foraging areas mostly occurred within the continental shelf of the Gulf of Lions and along the continental slope, generally within a $40 \mathrm{~km}$-radius from the colony and over the $-100 \mathrm{~m}$ isobath (Fig. 2, Fig. S6.2).

\section{Rapid changes in resource selection feature low ISRS}

Random coefficients for prey-related variables improved fit of RSFs ( $\triangle \mathrm{AIC}>6652$ for all models). RSFs including the variance of biomasses of all juvenile fish and adult sardines failed to converge. At the population-level, shearwaters selected foraging areas with higher 
abundances of both zooplankton groups and generally lower fish biomass than expected randomly (Appendix S6, Table S6.1). However, this apparent habitat selection pattern resulted from heterogeneous selection among individuals, and to a greater extent, from heterogeneous selection across trips of the same individuals (Table S6.1, Fig. 3). The relatively high within-individual variability in selection featured a low ISRS for each preyrelated variable $\left(R_{k}<0.3\right.$, Fig. $4 \mathrm{~A}$, Table S6.2).

At the trip level, clustering revealed two foraging trip tactics (Fig. S6.3). Shearwaters selected different prey and trophic levels among their trips, which entailed rapid changes in their resource selection (Table S6.3). During most trips (54\%), shearwaters selected areas with higher abundances of both zooplankton groups, as well as areas with higher biomasses of adult anchovies and adult sprats, than expected randomly (Fig. 5A). The biomass of pelagic fish increased along the shelf edge and at the Cassis canyon head close to the colony, while zooplankton-preferred group was associated with coastal areas, the plume of the Rhône river, and canyons (Appendix S2, Table S2.1, S2.5, S2.7, Fig. S2.3). Selection of high zooplanktonother abundance required cautious interpretation due to the poor prediction ability of its model, while zooplankton-preferred abundance was correctly predicted (Fig. S2.4).

Shearwaters used zooplankton-only specialist trips to a lesser extent (46\%), selecting areas with a higher zooplankton-preferred abundance and lower fish biomasses than randomly expected (Fig. 5B). Birds always avoided the most coastal foraging areas with high biomass of sardines and juvenile sprats (Fig. 5, Table S2.3, S2.4, S2.6, Fig. S2.3). Isotopic analyses revealed that the trophic position of shearwaters was $3.30 \pm 0.25$ (median \pm IQR, Appendix S4, Fig. S4.1), and confirmed that most birds used both foraging tactics and foraged on different trophic levels including zooplankton (trophic position = 2) and small pelagic fish (trophic position = 3, Fig. 6). 
Low individual foraging site fidelity

Shearwaters showed low IFSF between consecutive trips, with values only slightly higher than for a random process (mean $B A_{k}=0.135$, mean $B A_{k, \text { random }}=0.084$, t-test: $\mathrm{t}_{46}=5.43, \mathrm{P}<$ 0.001, Fig. 4B). Different individuals shared some foraging areas, with similar $B A$ index found within and between birds (mean $B A_{k, \text { between }}=0.131$, t-test: $\mathrm{t}_{46}=0.39, \mathrm{P}=0.70$, Fig. 4B). IFSF was not related to the number of trips performed by single individuals $\left(\mathrm{r}^{2}<0.01, \mathrm{P}=\right.$ 0.51). IFSF was uncoupled from shearwater resource selection and its within-individual consistency (ISRS).

\section{Prey predictability shapes search patterns in shearwaters}

Shearwaters used directional search to find fish as they selected foraging areas with high predictability (i.e. lower variance) of biomasses of adult anchovies and sprats (Fig. 5A). In contrast, they selected areas with high zooplankton abundance independently from their predictability (Fig. 5). Interestingly, zooplankton abundances were less predictable than fish biomasses and temporal autocorrelation in zooplankton abundances was low after only one day, the mean trip duration (Fig. S2.1).

\section{Discussion}

As theoretically expected, our broad analytical framework allowed us to demonstrate that short-term prey predictability induces low individual specialization in resource selection (ISRS) and low individual foraging site fidelity (IFSF) within a predator population. According to RSF and isotopic analyses, breeding Scopoli's shearwaters searched for zooplankton and fish within the Gulf of Lions, where we showed daily changes in prey distribution. To overcome prey field lability, we found that shearwaters searched for zooplankton patches, which they detect remotely via olfactory cues (Dell'Ariccia et al. 2014). 
Such tactics do not require previous information on prey distributions. Indeed, RSFs showed that shearwaters selected zooplankton patches independently from their predictability. However, environmental variation (e.g. wind conditions, low prey availability) and lack of luck (stochastic noise) may prevent shearwaters from detecting distant zooplankton patches. Consequently, we found that shearwaters frequently switched between alternative foraging tactics, and their selection of predictable fish patches may suggest memory/public information use. Crucially, we demonstrated how low prey predictability shaped specialized foraging tactics over the short-term and potentially information use, and resulted in the use of varied foraging sites and diet items.

\section{Prey field lability constrains individual specialization in resource selection}

Costs associated with intra-specific competition and niche overlap favour individual specialization (Araújo et al. 2011; Bolnick et al. 2011; Wolf \& Weissing 2012; Wakefield et al. 2013), and lead to the emergence of competing density-dependent foraging behaviours and diet (Fortin et al. 2008; Tinker et al. 2012). This is true in stable environments, but when prey distributions vary spatio-temporally and become temporarily inaccessible, fitness costs associated with narrow resource selection can increase (Fortin et al. 2008; Woo et al. 2008). To increase net intake when tracking highly mobile prey, predators can diversify their diet and use selection patterns allowing them to exploit different prey simultaneously, as demonstrated for wolves (Canis lupus; Courbin et al. 2013). Low ISRS is thus expected if behavioural plasticity is not dramatically constrained (Sih et al. 2004, Hendry 2016) and if higher encounter rates favoured by behavioural plasticity overcome the potential benefits of specialization (improved search image and handling technique). As hypothesized, shearwaters had low short-term ISRS, and isotopic analyses confirmed that most individuals consumed various prey at different trophic levels (Fig. 6; median individual trophic position was 3.30; 
Fig. S4.1). Zooplankton-based diets are common in seabirds (Savoca \& Nevitt 2014) and, in our study system, fish and zooplankton-preferred have close calorific contents (HarmelinVivien et al. 2012). Hence, diet diversification and low ISRS should not be promoted by a low zooplankton nutritional value. Overall, low spatio-temporal predictability in prey distributions constrained predators to diversify their diet at the individual level, thereby diminishing inter-individual differences. However, trophic position appeared more heterogeneous among individuals in some years (2010 and 2011; Fig. S4.1), revealing that competing foraging strategies may emerge (at low frequency) in dynamic systems. Seabird populations can switch diets between years (Garthe et al. 2011; Tew Kai et al. 2013), ultimately limiting negative effects on population dynamics (Cury et al. 2011).

Whether such dietary plasticity arises from variability in prey availability, or from predator behavioural changes is often unclear (Hunsicker et al. 2011). In our study system, we showed that inter-annual dietary switches can arise from changes in resource selection, rather than in prey availability (Table S6.5). Thereby, changes in prey distribution and availability occurring at multiple temporal scales (day to year) shaped individual specialization: Short-term changes prevented short- and long-term specialization, while long-term changes tended to favour individual specialization in the shorter-term.

\section{Relaxing individual foraging site fidelity is not sufficient in dynamic prey fields}

In systems with low prey predictability, low ISRS should arise when individuals use a generalist foraging tactic (no selection), or each individual uses different short-term specialized foraging tactics. IFSF is common in colonial central-place predators (Arthur et al. 2015; Baylis et al. 2015; Ceia \& Ramos 2015; Wakefield et al. 2015). When prey distribution varies daily, as observed in our studied system, individuals have to balance ISRS and IFSF, and IFSF should imply generalising of diet and habitat use, while preventing specialization 
(Fig. 1). As theoretically expected, by relaxing IFSF only, Scopoli's shearwaters were able to track daily changes in prey distribution, selecting foraging areas with high biomasses of adult anchovies and adult sprats, and high zooplankton abundance. Antarctic fur seals (Arctocephalus gazella) tracking changes in prey distribution during the winter also showed low IFSF (Arthur et al. 2015).

Our dynamic study area and associated low predictability in prey distributions implied, however, that shearwaters switched foraging tactics on a daily basis. This resulted in rapid changes in individual resource selection. Birds used 1-day trips, either focusing on nearby areas with high zooplankton abundance, or also searching more distant waters harbouring adult anchovies or sprats. Short-term resource selection by shearwaters highlighted their foraging plasticity when exposed to changes in prey distributions. This strategy, which could allow predators to maintain their foraging efficiency, requires some capacity to predict prey distributions (Pettex et al. 2010), and/or to reduce search time with the prospect of exploring alternative prey patches.

\section{Linking prey predictability, information use and ISRS}

Our study emphasizes how the coupling between the frequency of prey redistribution and the frequency at which information on prey location can be updated and reused by the predator shapes search patterns of predators and IRSR. Thereby, it sheds light on the mechanisms linking prey predictability and narrow resource selection. Shearwaters searched for zooplankton-rich areas independently of their predictability. Autocorrelation in zooplankton abundance was low after only one day and birds were unlikely to use memory/public information on zooplankton distribution between daily trips. In this context, sensory cues available over long distances seem a far more efficient way to locate shifting resources than public information (Savoca \& Nevitt 2014; Spiegel \& Crofoot 2016). Recent investigations 
confirm that shearwaters use long to medium-scale olfactory cues to find zooplankton (Dell'Ariccia et al. 2014). However, combination of unstable olfactory landscapes and quickly outdated information on zooplankton distribution limits ISRS and requires alternative foraging tactics. Further investigations should verify if the increase of individual specialization in the capacity to use sensory cues according to age and experience (Harel et al. 2016) is balanced by prey unpredictability.

During trips specialized on zooplankton and fish, shearwaters selected areas with the most predictable biomasses of adult anchovies and sprats. Fish biomasses being autocorrelated for longer periods than shearwater daily trips (Fig. S2.1), shearwaters may gain information on prey locations using short-term memory (Wakefield et al. 2013; Spiegel \& Crofoot 2016) or public information (Weimerskirch et al. 2010; Spiegel \& Crofoot 2016; Wells et al. 2016). Our results confirm that both mechanisms can occur in parallel, as shearwaters shared a limited number of foraging areas across their consecutives trips, and different individuals shared some foraging areas at similar time. Although information on patch location can reduce search times and could favour foraging efficiency and ISRS, we found almost no ISRS. Prey predictability being generally low, individuals rather used public information to locate prey patches independently of the species, probably following their peers (Harel et al. 2017). We found low overlap values among birds but the small proportion of tracked individuals probably led to underestimating shared space use. Additional sources of information may also be involved, such as the visual detection of tuna chasing smaller pelagic fish, or knowledge of the most predictable fishing areas through long-term memory (Weimerskirch 2007; Monsarrat et al. 2013). Interestingly, moderate ISRS for predictable anchovy patches revealed individual differences in bird ability to use available information (Fig. 4A; Spiegel \& Crofoot 2016). 


\section{Conclusions}

472 Our study demonstrates that colonial predator populations preying on relatively unpredictable 473 prey are subjected to ecological drivers leading to contrasting effects on ISRS. Thereby, the

474 negative effect of prey unpredictability and patchiness on ISRS, overrides the positive effect of intra-specific competition (Fortin et al. 2008; Araújo et al. 2011). Prey unpredictability also seems to limit potential inter-sexual differences in individual specialization (both sexes were tracked here). Prey variability may further constrain the expected enhancement of individual specialization with age/experience due to longer sampling of environmental variation and development of specific skills (see also Woo et al. 2008). Future work explicitly considering age and sex of tagged birds should therefore quantify the opposite effects of low prey predictability and internal states on individual specialization. Moreover, individual specialization could vary among phases of the annual cycle, especially if birds migrate and/or encounter different foraging conditions.

Importantly, our study shows how individual responses to enhanced environmental stochasticity driven by global change could potentially impact population persistence. A population requires some degree of non-specialization to overcome novel conditions, e.g. generalist populations consisting of specialized individuals (Wolf \& Weissing 2012; Merrick \& Koprowski 2017). Here, we reinforce the idea that individual plasticity in foraging movements (low individual specialization and inter-annual variation in tactics used) could be a globally important pathway to cope with changing conditions and maintain population density, in the presence of limited behavioural plasticity (Dall et al. 2004, Sih et al. 2004, Hendry 2016). Finally, individual foraging plasticity may prevent the use of apex predators as ecological indicators of lower trophic levels (Grémillet \& Charmantier 2010). This is particularly relevant as seabird populations are being flagged as indicators of food supplies within marine systems (Boyd et al. 2015, Brisson-Curadeau et al. 2017). 


\section{Acknowledgements}

498

499

500

501

502

503

504

505

506

507

508

509

510

511

512

513

514

515

516

517

518

519

This study was funded by the French Agency for Biodiversity (AFB) within the program PACOMM-Natura2000 en mer and INDEXPUF, and by the OSU OREME Montpellier. Handling protocols for shearwaters were approved by the boards of the 'Parc National des Calanques' (permit number: 2014-068, 2016-111), the French 'Direction Départementale de la Protection des Populations' (permit number: 34-369, \#A34-505), the French 'Direction Départementale des Territoires et de la Mer des Bouches-du-Rhône' (permit number: 1700010, 184-0017) and the 'Comité d'Ethique pour l'Expérimentation Animale LanguedocRousillon' (permit number: 1170). Thanks to O. Spiegel, R. Nathan and one anonymous reviewer for their helpful comments. We are very grateful to M. Authier for his help with Bayesian models for prey, S. Benhamou for our fruitful discussions and A. Kibler for revising the manuscript. Thanks to all fieldworkers involved in this study: P. Giraudet, L. Martin, A. Gaborit Loret, M. Kriloff, J.-B. Pons, C. de Franceschi. We also thank the agents from 'Parc National des Calanques' of Marseille for providing support during the fieldwork (J.-P.

Durand, C. Pastorelli and A. Mante), N. El Ksabi for the preparation of feather samples, Plateforme d'Analyses Chimiques en Ecologie at CEFE for logistic support, and Plateforme 'Spectrométrie isotopique' (University of La Rochelle - LIENSs) for isotopic analyses of feathers samples. Thanks to the staff of PELagic MEDiterranean oceanographic campaigns to share with us empirical data on fish and zooplankton (doi: http://dx.doi.org/10.18142/19) and to Directive Cadre Stratégie pour le Milieu Marin for providing fish isotopic values in 2015. We are grateful to B. Raymond from the Australian Antarctic Division for sharing his track simulation R package. We finally are very grateful to NASA (Ocean Color project), CNES (Aviso+ project), IEDA (Marine Geoscience Data System), IFREMER, SHOM and Meteo 
France (PREVIMER project), and EUSeaMap European project for sharing oceanographic data and satellite images.

\section{References}

Allgeier, J.E., Adam, T.C. \& Burkepile, D.E. (2017). The importance of individual and species-level traits for trophic niches among herbivorous coral reef fishes. Proc. R. Soc. $B, 284,20170307$.

Anselme, L. \& Durand, J.P. (2012). Le puffin cendré Calonectris diomedea diomedea, Etat des connaissances et de conservation actualisés, des populations nicheuses des petites îles de Méditerranée, pp 1-17.

Araújo, M.S., Bolnick, D.I. \& Layman, C.A. (2011). The ecological causes of individual specialization. Ecol. Lett., 14, 948-958.

Arthur, B. et al. (2015). Return customers: Foraging site fidelity and the effect of environmental variability in wide-ranging Antarctic fur seals. PLoS ONE, 10, e0120888. Authier, M., Péron, C., Mante, A., Vidal, P. \& Grémillet, D. (2013). Designing observational biologging studies to assess the causal effect of instrumentation. Methods Ecol. Evol., 4, 802810.

Authier, M., Saraux, C. \& Péron, C. (2017). Variable selection and accurate predictions in habitat modelling: a shrinkage approach. Ecography, 40, 549-560.

Bates, D., Maechler, M., Bolker, B. \& Walker, S. (2015). Fitting Linear Mixed-Effects Models Using lme4. J. Stat. Softw., 67, 1-48.

Baylis, A.M.M. et al. (2015). Diving deeper into individual foraging specializations of a large marine predator, the southern sea lion. Oecologia, 179, 1053-1065.

Bell, A.M., Hankison, S.J. \& Laskowski, K.L. (2009) The repeatability of behaviour: a metaanalysis. Anim. Behav., 77, 771-783. 
Benjamini, Y. \& Yekutieli, D. (2001). The control of the false discovery rate in multiple testing under dependency. Ann. Stat., 29, 1165-1188.

Bolnick, D.I. et al. (2011). Why intraspecific trait variation matters in community ecology.

Trends Ecol. Evol., 26, 183-192.

Boyd, C. et al. (2015). Predictive modelling of habitat selection by marine predators with respect to the abundance and depth distribution of pelagic prey. J. Anim. Ecol., 84, 575-1588.

Brisson-Curadeau, E., Patterson, A., Whelan, S., Lazarus, T. \& Elliott, K.H. (2017). Tracking cairns: Biologging improves the use of seabirds as sentinels of the sea. Front. Mar. Sci., 4, 357.

Calenge, C. (2006). The package "adehabitat" for the R software: a tool for the analysis of space and habitat use by animals. Ecol. Modell., 197, 516-519.

Camphuysen, K. \& Van Der Meer, J. (2001). Pelagic distribution, moult and (sub-)specific status of Cory's shearwaters Calonectris [D.] diomedea/borealis wintering off Southern Africa. Mar. Ornithol., 29, 89-96.

Carneiro, A.P.B., Bonnet-Lebrun, A.S., Manica, A., Staniland, I.J. \& Phillips, R.A. (2017). Methods for detecting and quantifying individual specialisation in movement and foraging strategies of marine predators. Mar. Ecol. Prog. Ser., 578, 151-166.

Catry, T., Alves, J.A., Gill, J.A., Gunnarsson, T.G. \& Granadeiro, J.P. (2014) Individual specialization in a shorebird population with narrow foraging niche. Acta Oecol., 56, 56-65.

Ceia, F.R. \& Ramos, J.A. (2015). Individual specialization in the foraging and feeding strategies of seabirds: a review. Mar. Biol., 162, 1923-1938.

Courbin, N., Fortin, D., Dussault, C., Fargeot, V. \& Courtois, R. (2013). Multi-trophic resource selection function enlightens the behavioural game between wolves and their prey. $J$. Anim. Ecol., 82, 1062-1071.

Cury, P.M. et al. (2011). Global seabird response to forage fish depletion - One-third for the 
birds. Science, 334, 1703-1706.

Dall, S.R.X., Houston, A.I. \& McNamara, M. (2004). The behavioural ecology of personality: consistent individual differences from an adaptive perspective. Ecol. Lett., 7, 734-739.

Dell'Ariccia, G., Célérier, A., Gabirot, M., Palmas, P., Massa, B. \& Bonadonna, F. (2014).

Olfactory foraging in temperate waters: sensitivity to dimethylsulphide of shearwaters in the Atlantic Ocean and Mediterranean Sea. J. Exp. Biol., 217, 1701-1709.

Dormann, C.F. et al. (2013). Collinearity: a review of methods to deal with it and a simulation study evaluating their performance. Ecography, 36, 27-46.

Duchesne, T., Fortin, D. \& Courbin, N. (2010). Mixed conditional logistic regressions for habitat selection studies. J. Anim. Ecol., 79, 548-555.

Fernandez, M., Yesson, C., Gannier, A., Miller, P.I. \& Azevedo, J.M.N. (2017). The importance of temporal resolution for niche modelling in dynamic environments. $J$. Biogeogr., 00, 1-12. https://doi.org/10.1111/jbi.13080.

Fieberg, J. \& Kochanny, C.O. (2005). Quantifying homerange overlap: the importance of the utilization distribution. J. Wildlife Manage., 69, 1346-1359.

Fortin, D., Morris, D.W. \& McLoughlin, P.D. (2008). Habitat selection and the evolution of specialists in heterogeneous environments. Israel J. Ecol. Evol., 54, 311-328.

Garthe, S., Montevecchi, W.A. \& Davoren, G.K. (2011). Inter-annual changes in prey fields trigger different foraging tactics in a large marine predator. Limnol. Oceanogr., 56, 802-812. Gillies, C. et al. (2006) Application of random effects to the study of resource selection by animals. J. Anim. Ecol., 75, 887-898.

Grémillet, D., Wilson, R.P., Storch, S. \& Gary, Y. (1999). Three-dimensional space utilization by a marine predator. Mar. Ecol. Prog. Ser., 183, 263-273.

Grémillet, D. et al. (2004). Linking the foraging performance of a marine predator to local prey abundance. Funct. Ecol., 18, 793-801. 
595

596

597

598

599

600

601

602

603

604

605

606

607

608

609

610

Grémillet, D. \& Charmantier, A. (2010). Shifts in phenotypic plasticity constrain the value of seabirds as ecological indicators of marine ecosystems. Ecol. Appl., 20, 1498-1503.

Harel, R., Horvitz, N. \& Nathan, R. (2016). Adult vultures outperform juveniles in challenging thermal soaring conditions. Sci. Rep., 6:27865.

Harel, R., Spiegel, O., Getz, W.M. \& Nathan, R. (2017). Social foraging and individual consistency in following behaviour: testing the information centre hypothesis in free-ranging vultures. Proc. R. Soc. B, 284, 20162654.

Harmelin-Vivien, M., Mahé, K., Bodiguel, X. \& Mellon-Duval, C. (2012). Possible link between prey quality, condition and growth of juvenile hake (Merluccius merluccius) in the Gulf of Lions (NW Mediterranean). Cybium, 36, 323-328.

Hebblewhite, M. \& Merrill, E. (2008). Modelling wildlife-human relationships for social species with mixed-effects resource selection models. J. Appl. Ecol., 45, 834-844.

Hendry, A.P. (2016). Key questions on the role of phenotypic plasticity in eco-evolutionary dynamics. J. Hered., 107, 25-41.

Hunsicker, M.E. et al. (2011). Functional responses and scaling in predator-prey interactions of marine fishes: contemporary issues and emerging concepts. Ecol. Lett., 14, 1288-1299. Johnson, P.C.D. (2014) Extension of Nakagawa \& Schielzeth's R $_{\text {GLMM }}$ to random slopes models. Methods Ecol. Evol., 5, 944-946.

Leclerc, M., Vander Wal, E., Zedrosser, A., Swenson, J.E., Kindberg, J. \& Pelletier, F. (2016). Quantifying consistent individual differences in habitat selection. Oecologia, 180, 697-705.

Manly, B.F.J., McDonald, L.L., Thomas, D.L., McDonald, T.L. \& Erickson, W.P. (2002). Resource selection by animals: statistical analysis and design for field studies. Second edition. Kluwer Academic Publishers, Dordretch, pp. 1-221.

Meier, R.E. et al. (2017). Tracking, feather moult and stable isotopes reveal foraging 
620

621

622

623

624

625

626

627

628

629

630

631

632

633

634

635

636

637

638

639

640

641

642

behaviour of a critically endangered seabird during the non-breeding season. Divers. Distrib., 23, 130-145.

Merrick, M.J. \& Koprowski, J.L. (2017). Should we consider individual behavior differences in applied wildlife conservation studies. Biol. Conserv., 209, 34-44.

Monsarrat, S., Benhamou, S., Sarrazin, F., Bessa-Gomes, C., Bouten, W. \& Duriez, O. (2013). How predictability of feeding patches affects home range and foraging habitat selection in avian social scavengers? PLoS ONE, 8, e53077.

Nakagawa, S., Johnson, P.C.D. \& Schielzeth, H. (2017). The coefficient of determination R2 and intra-class correlation coefficient from generalized linear mixed-effects models revisited and expanded. J. R. Soc. Interface, 14, 20170213.

Navarro, J., Grémillet, D., Ramirez, F.J., Afán, I., Bouten, W. \& Forero, M.G. (2017).

Shifting individual habitat specialization of a successful predator living in anthropogenic landscapes. Mar. Ecol. Prog. Ser., 578, 243-251.

Patrick, S.C. et al. (2014). Individual foraging specialisation and differences in searching behaviour of a wide-ranging marine predator. Oikos, 123, 33-40.

Pettex, E., Bonadonna, F., Enstipp, M.R., Siorat, F. \& Grémillet, D. (2010). Northern gannets anticipate the spatio-temporal occurrence of their prey. J. Exp. Biol., 213, 2365-2371.

Phillips, R.A., Lewis, S., González-Solís, J. \& Daunt, F. (2017). Causes and consequences of individual variability and specialization in foraging and migration strategies of seabirds. Mar. Ecol. Prog. Ser., 578, 117-150.

Plounevez, S. \& Champalbert, G. (2000). Diet, feeding behaviour and trophic activity of the anchovy (Engraulis encrasicolus L.) in the Gulf of Lions (Mediterranean Sea). Oceanologica Acta, 23:175-192. 
Potier, S., Carpentier, A., Grémillet, D., Leroy, B. \& Lescroël, A. (2015). Individual repeatability of foraging behaviour in a marine predator, the great cormorant, Phalacrocorax carbo. Anim. Behav., 103, 83-90.

R Development Core Team (2016). R: A Language and Environment for Statistical Computing. R Foundation for Statistical Computing, Vienna.

Ramos, R., González-Solís, J. \& Ruiz, X. (2009). Linking isotopic and migratory patterns in a pelagic seabird. Oecologia, 160, 97-105.

Raymond, B. et al. (2015). Important marine habitat shift off east Antarctica revealed by two decades of multi-species predator tracking. Ecography, 38, 121-129. Sara, M. (1993) Feeding habits of Cory's shearwater (Calonectris diomedea) in the central Mediterranean Sea. In: Estatus y conservacion de aves marinas \{eds. Aguilar, J.S., Monbailliu, X.Y. \& Paterson, A.M.\}. Sociedad Espanola de Ornitologia, Madrid, pp. 213222.

Saraux, C. et al. (2014) Spatial Structure and Distribution of Small Pelagic Fish in the Northwestern Mediterranean Sea. PLoS ONE, 9, e111211.

Savoca, M.S \& Nevitt, G.A. (2014). Evidence that dimethyl sulfide facilitates a tritrophic mutualism between marine primary producers and top predators. Proc. Natl. Acad. Sci. U.S.A., 111, 4157-4161.

Sih, A. Bell, A. \& Johnson, J.C. (2004). Behavioral syndromes: an ecological and evolutionary overview. Trends Ecol. Evol., 19, 372-378.

Spiegel, O. \& Crofoot, M.C. (2016). The feedback between where we go and what we know information shapes movement, but movement also impacts information acquisition. Cur. Opin. Behav. Sci., 12, 90-96.

Spiegel, O., Leu, S.T., Bull, C.M. \& Sih, A. (2017). What's your move? Movement as a link between personality and spatial dynamics in animal populations. Ecol. Lett., 20, 3-18. 
668

669

670

671

672

673

674

675

676

677

678

679

680

681

682

683

684

685

686

687

688

689

690

691

Stoffel, M.A., Nakagawa, S. \& Schielzeth, H. (2017). rptR: Repeatability estimation and variance decomposition by generalized linear mixed-effects models. Methods Ecol. Evol., 8, 1639-1644.

Subalusky, A.L., Dutton, C.L., Rosi, E.J. \& Post, D.M. (2017). Annual mass drownings of the Serengeti wildebeest migration influence nutrient cycling and storage in the Mara River. Proc. Natl. Acad. Sci. U.S.A., 114, 7647-7652.

Sutherland, W.J. (1987). Why do animals specialize? Nature, 32, 483-484.

Svanbäck, R. \& Bolnick, D.I. (2005). Intraspecific competition affects the strength of individual specialization: an optimal diet theory method. Evol. Ecol. Res., 7, 993-1012.

Svanbäck, R. \& Bolnick, D.I. (2007). Intraspecific competition drives increased resource use diversity within a natural population. Proc. $R$. Soc. B, 274, 839-844.

Switzer, P.V. (1993). Site fidelity in predictable and unpredictable habitats. Evol. Ecol., 7, 533-555.

Tew Kai, E. et al. (2013). Are Cape gannets dependent upon fishery waste? A multi-scale analysis using seabird GPS-tracking, hydro-acoustic surveys of pelagic fish and vessel monitoring systems. J. Appl. Ecol., 50, 659-670.

Tinker, M.T. et al. (2012). Structure and mechanism of diet specialisation: testing models of individual variation in resource use with sea otters. Ecol. Lett., 15, 475-483.

Torres, L.G., Read, A.J. \& Halpin, P. (2008) Fine-Scale Habitat Modeling of a Top Marine Predator: Do Prey Data Improve Predictive Capacity. Ecol. Appl., 18, 1702-1717.

Torres, L.G., Orben, R.A., Tolkova, I. \& Thompson, D.R. (2017) Classification of Animal Movement Behavior through Residence in Space and Time. PLoS ONE, 12, e0168513.

Violle, C. et al. (2012). The return of the variance: intraspecific variability in community ecology. Trends Ecol. Evol., 27, 244-252. 
692

693

694

695

696

697

698

699

700

701

702

703

704

705

706

707

708

709

710

711

712

Wakefield, E.D., Phillips, R.A. \& Matthiopoulos, J. (2009). Quantifying habitat use and preferences of pelagic seabirds using individual movement data: a review. Mar. Ecol. Prog. Ser., 391, 165-182.

Wakefield, E.D. et al. (2011). Habitat preference, accessibility, and competition limit the global distribution of breeding black-browed albatrosses. Ecol. Monogr., 81, 141-167

Wakefield, E.D. et al. (2013). Space partitioning without territoriality in gannets. Science, 341, 68-70.

Wakefield, E.D. et al. (2015). Long-term individual foraging site fidelity - why some gannets don't change their spots. Ecology, 96, 3058-3074.

Weimerskirch, H. (2007). Are seabirds foraging for unpredictable resources? Deep Sea Res. Part 2 Top. Stud. Oceanogr., 54, 211-223.

Weimerskirch, H., Bertrand, S., Silva, J., Marques, C. \& Goya, E. (2010). Use of social information in seabirds: compass raft indicate the heading of food patches. PLoS ONE, 5, e9928.

Wells, M.R., Angel, L.P. \& Arnould, J.P.Y. (2016). Habitat-specific foraging strategies in Australasian gannets. Biol. Open, 15, 921-927.

Wolf, M. \& Weissing, F.J. (2012). Animal personalities: consequences for ecology and evolution. Trends Ecol. Evol., 27, 452-461.

Woo, K.J., Elliott, K.H., Davidson, M., Gaston, A.J. \& Davoren, G.K. (2008). Individual specialization in diet by a generalist marine predator reflects specialization in foraging behaviour. J. Anim. Ecol., 77, 1082-1091. 


\section{Figure legends}

Figure 1. Theoretical outcomes for resource selection patterns (i.e. disproportionate use relative to the availability of resources, from no selection [generalism] to positive selection) in predators depending on individual foraging site fidelity (from low to high) and spatiotemporal variability of prey distribution among days (from low to high). The intersection of the three axes represents the lowest value along each axis.

Figure 2. Spatial distribution of foraging locations (black point) for Scopoli's shearwaters breeding off Marseille (red triangle), Western Mediterranean during the chick-rearing period in August 2011, 2012, 2014 and 2015. Foraging locations were determined using an automatic process discriminating between different behavioural modes (travelling, resting and foraging) along foraging trips (Torres et al. 2017).

Figure 3. RSF coefficients of Scopoli's shearwaters at the individual (A) and trip (B) levels (solid circle), in the Gulf of Lions (Western Mediterranean) during the chick-rearing period between 2011 and 2015, estimated from three-level mixed-effects logistic regression models (i.e. 75 individuals, 182 trips, 56945 GPS locations). Grey square represent the populationlevel inference. Values are jittered and * mean values are divided by 10 to ease visualization.

Figure 4. (A) Individual specialization in resource selection of Scopoli's shearwaters $(n=47)$ assessed with an index of repeatability $R$, varying between 0 and 1 (i.e. low to high selection consistency). (B) Individual foraging site fidelity of Scopoli's shearwaters $(n=47)$ among their consecutive trips $(B A)$, among trips of individuals foraging on the same day $\left(B A_{\text {between }}\right)$ and expected under a random space use without selection $\left(B A_{\text {random }}\right)$, using a Bhattacharyya's 
index ranging between 0 (no spatial overlap of UDs) and 1 (perfect spatial overlap of UDs).

Boxplot shows the median, $25^{\text {th }}$ and $75^{\text {th }}$ percentiles and solid circle represents the data.

Figure 5. RSF coefficients for (A) zooplankton-fish specialist trips and (B) zooplankton-only specialist trips ( $\mathrm{n}=83$ and 99 trips, respectively) used by Scopoli's shearwaters in the Gulf of Lions (Western Mediterranean) during the chick-rearing period between 2011 and 2015. Means (solid circle) are shown with their $95 \%$ confidence intervals. $*$ mean values are divided by 10 to ease visualization.

Figure 6. Stable isotope ratios representing the diet of Scopoli's shearwaters in the Gulf of Lions (Western Mediterranean) during the chick-rearing period between 2010 and 2015. Due to the molting pattern of shearwaters, isotopic signature of birds sampled at year $n$ are matched with isotopic signature of their prey at year $n$-1. Black points represent the stable isotope ratios of each shearwater. We show the mean expected range (solid lines) and its standard deviation (dotted lines) in prey isotopic values for shearwaters, based on shearwater tissue. We used a diet-tissue discrimination factor of $\delta^{15} N: 3.7+/-1 \%$ [mean +/- SD] as recommended by Meier et al. (2017) for shearwaters. The mean stable isotope ratios with their standard deviations assessed independently for prey are also shown: zooplankton, copepods, euphausiids (empty squares), small pelagic fish (empty triangles) and squids (empty circles). Isotopic signatures of small pelagic fish are year-specific, while considered constant across years for the other prey (no data available). Inferences on diet of shearwaters from $\delta^{15} \mathrm{~N}$ values were valuable because average $\delta^{15} \mathrm{~N}$ isotopic signatures in zooplankton/copepods and fish species differed significantly and $\delta^{15} \mathrm{~N}$ remained stable over space and time within the Gulf of Lions during our study (see details in Appendix S4). 


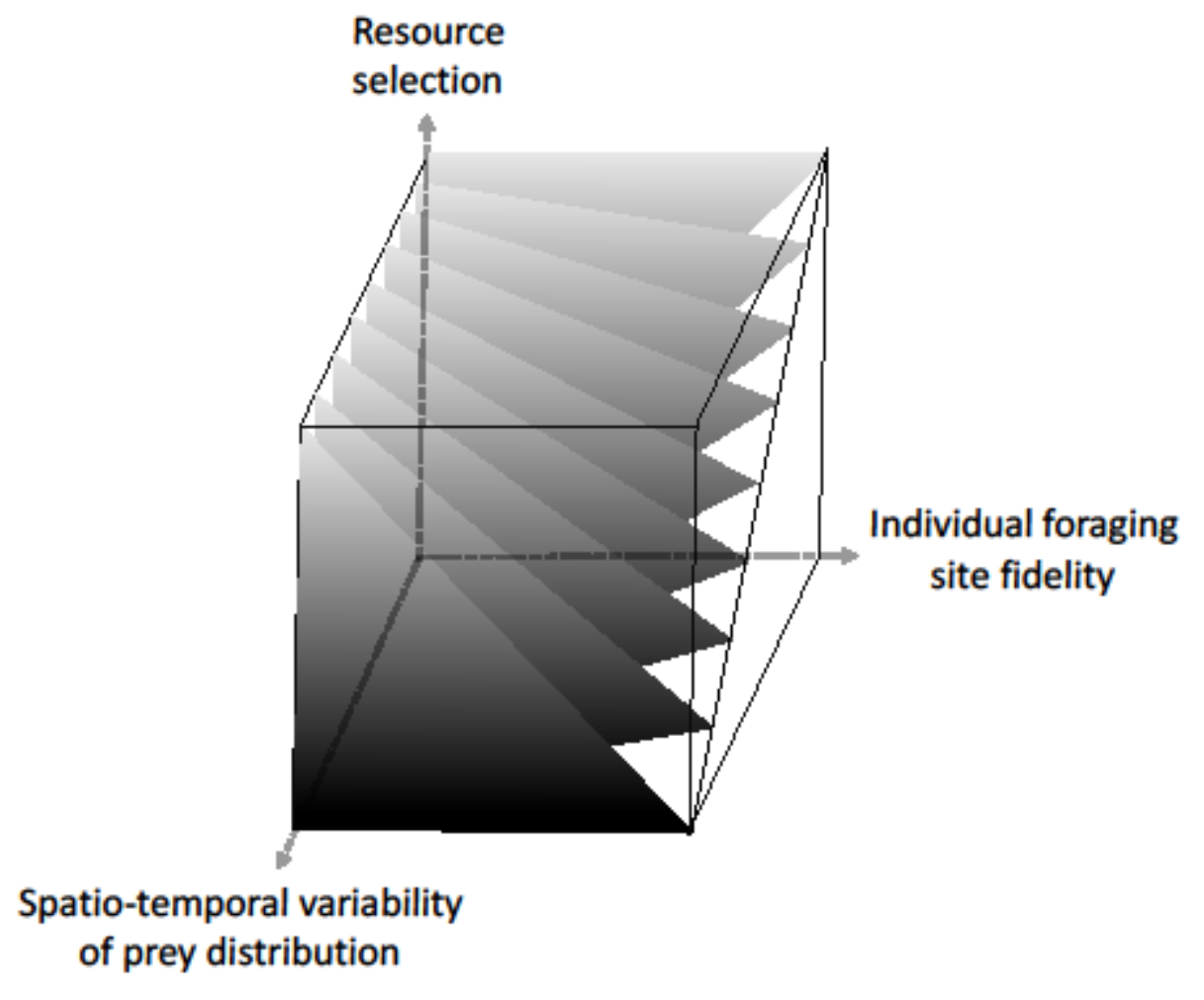

763 Figure 1. 

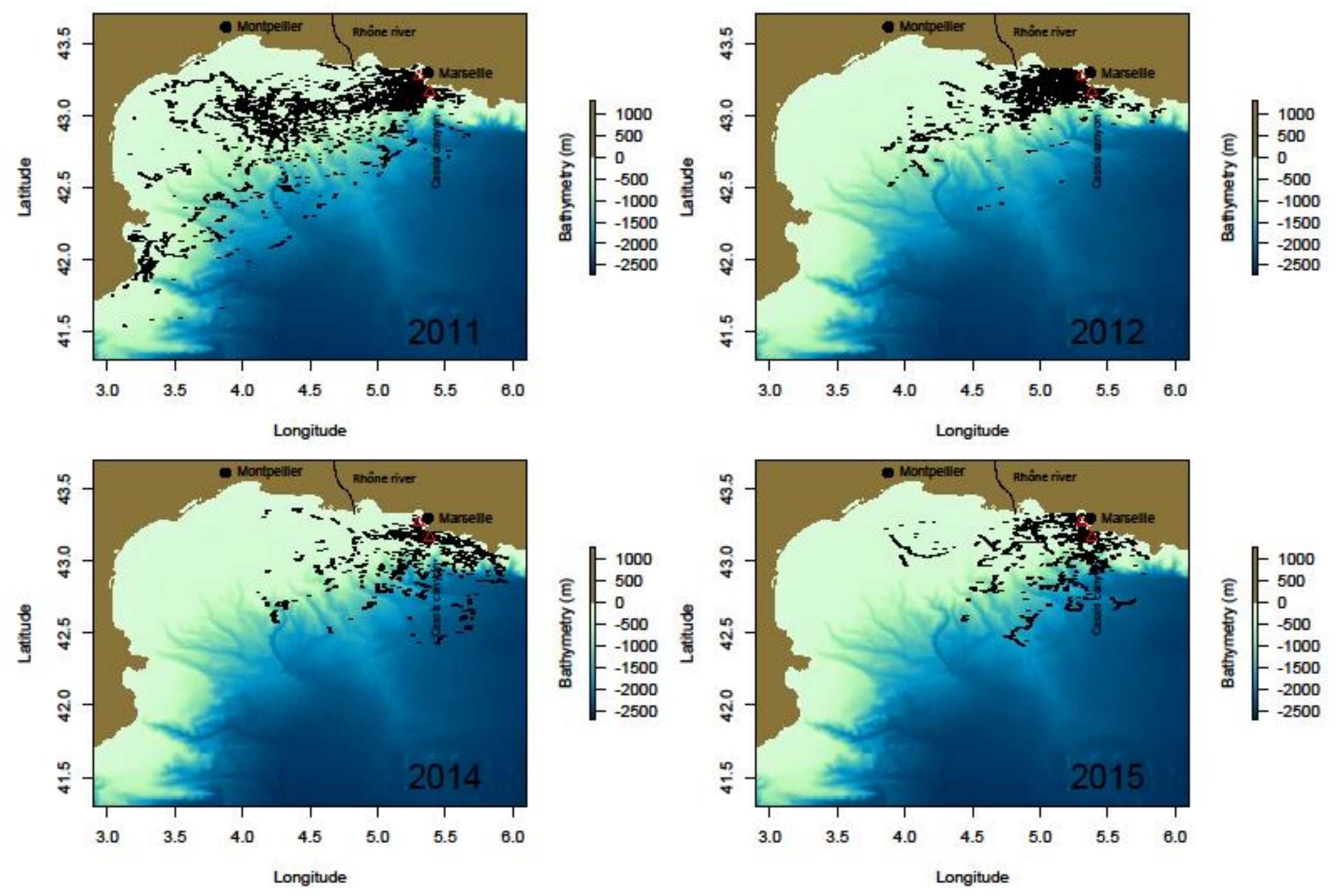

Figure 2. 

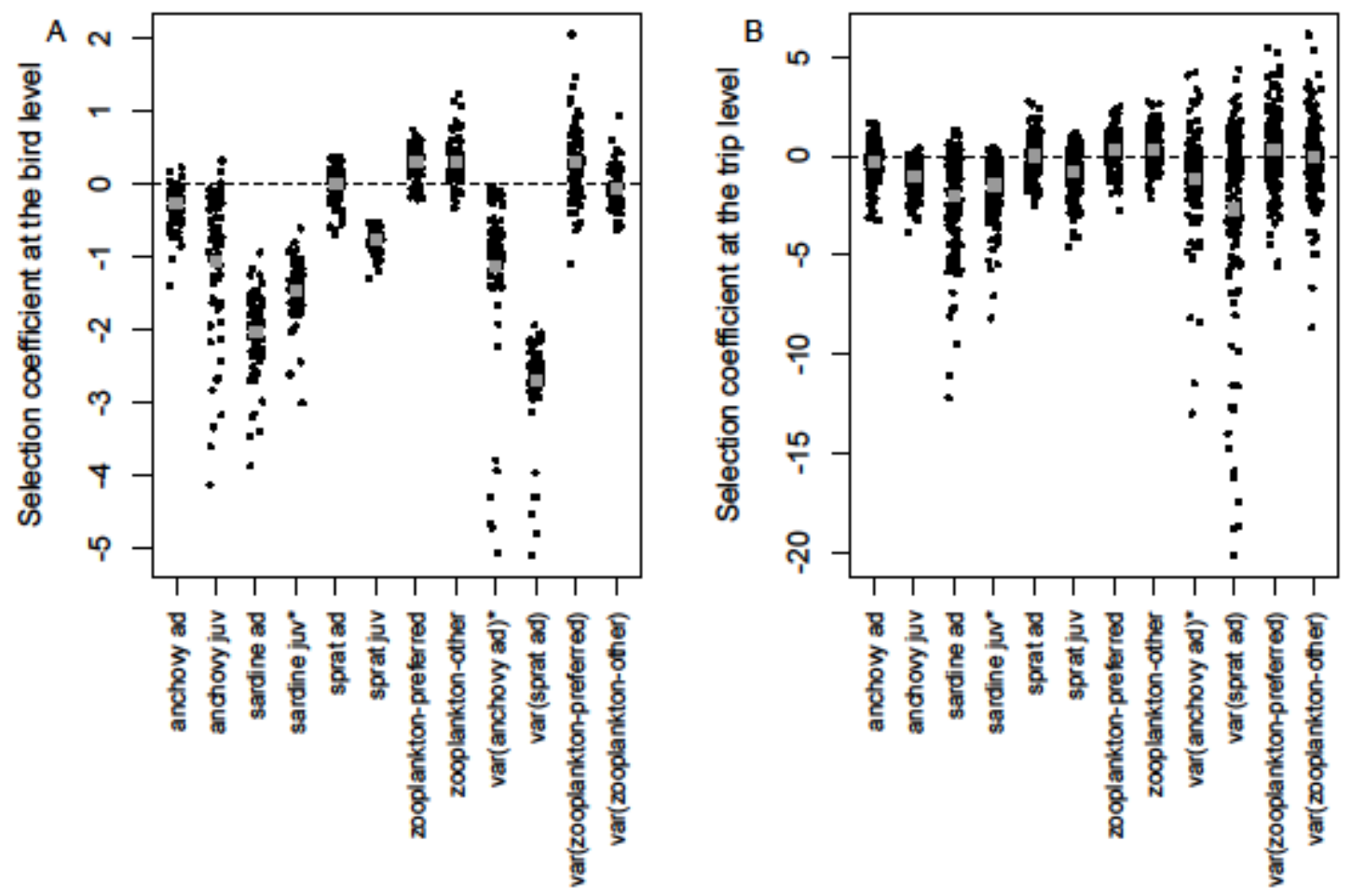

767 Figure3. 

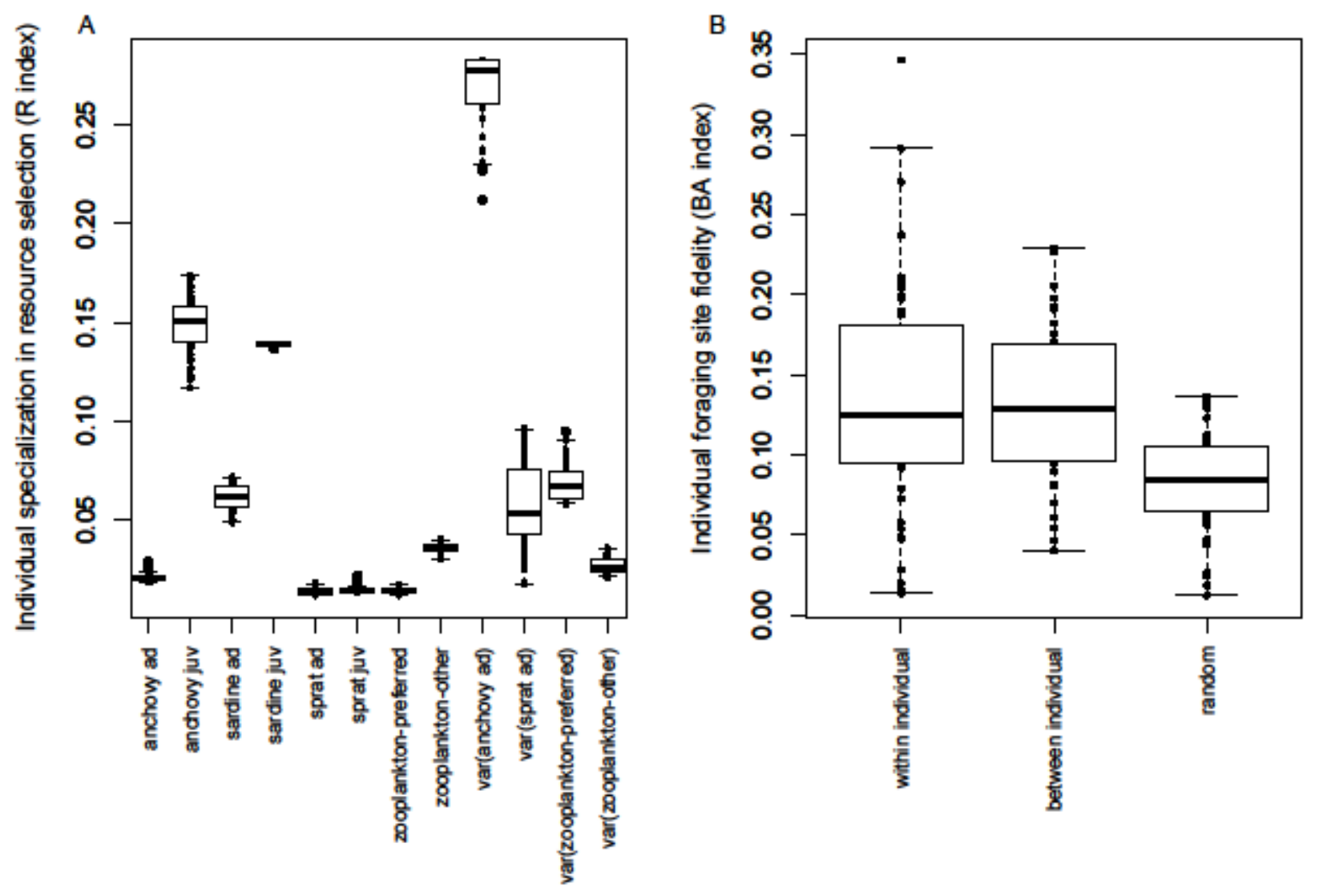

Figure 4. 

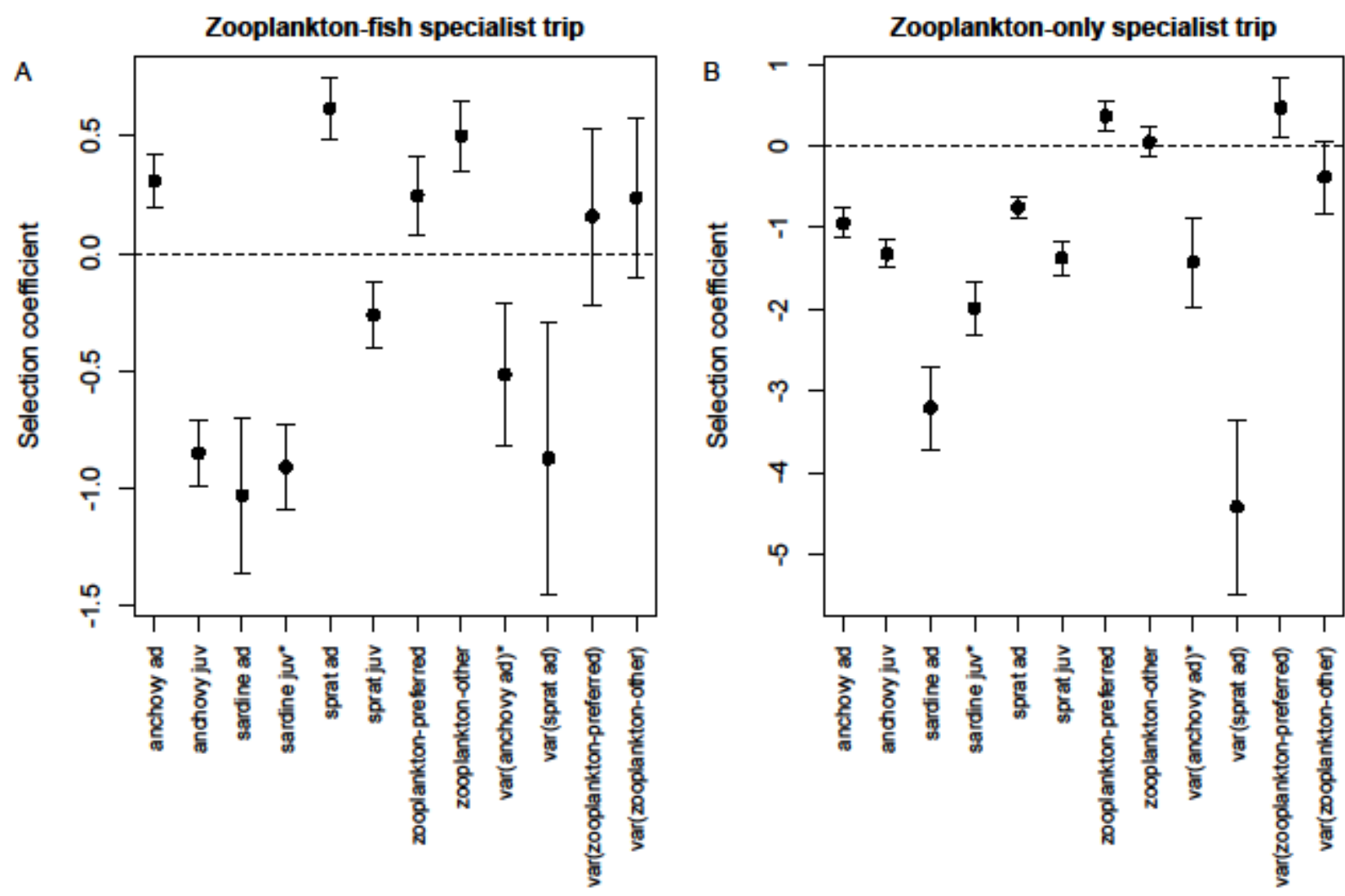

Figure 5. 

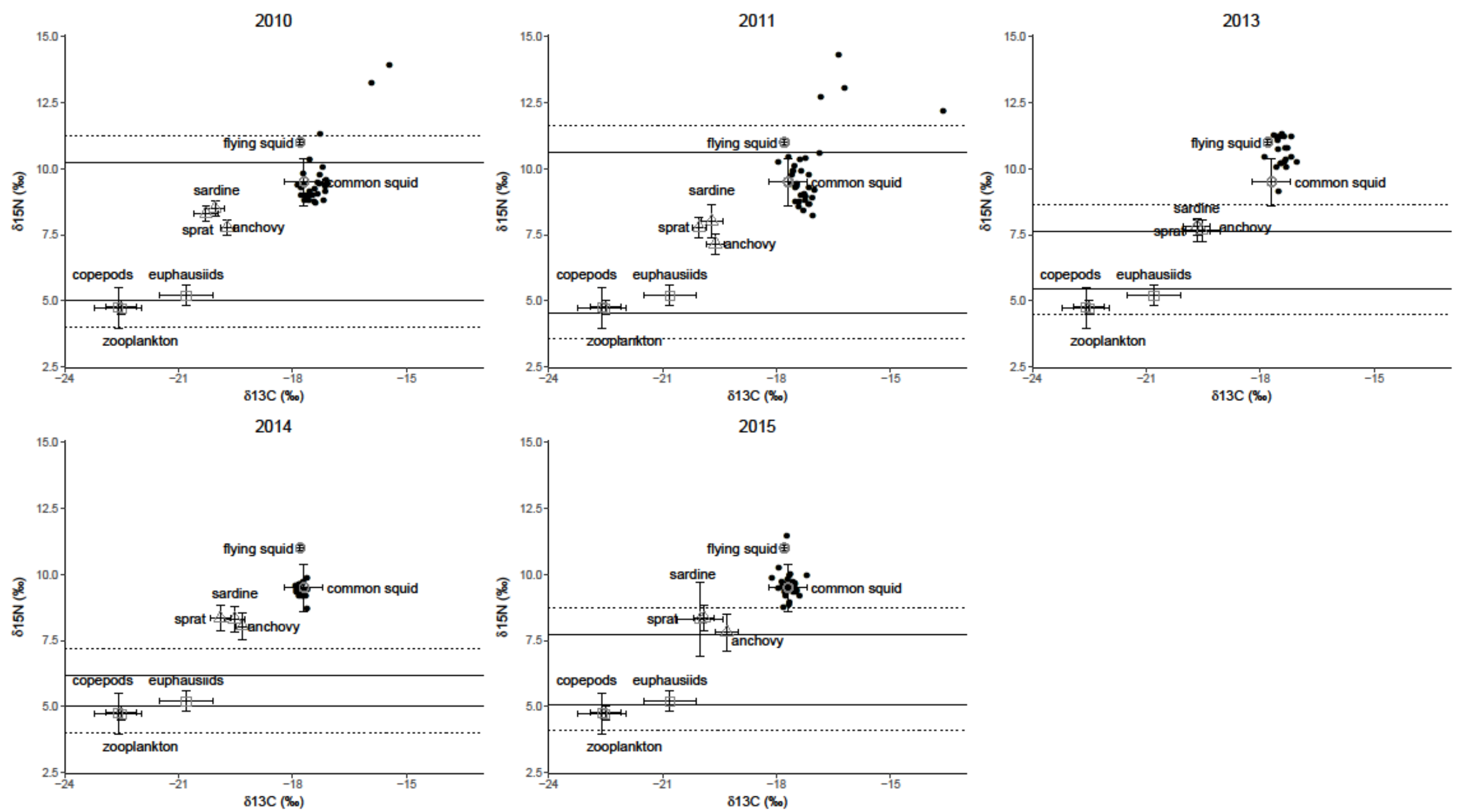

Figure 6. 
Short-term prey field lability constrains individual resource specialization and foraging site fidelity in a marine predator

5

6 Nicolas Courbin ${ }^{1}$, Aurélien Besnard ${ }^{1}$, Clara Péron ${ }^{2}$, Claire Saraux ${ }^{3}$, Jérôme Fort ${ }^{4}$, Samuel 7 Perret $^{1}$, Jérémy Tornos ${ }^{1}$, David Grémillet ${ }^{1,5}$

${ }^{1}$ Centre d'Ecologie Fonctionnelle et Evolutive (CEFE), UMR 5175, Centre National de la Recherche Scientifique (CNRS), Université de Montpellier, Université Paul Valéry Montpellier, Ecole Pratiques des Hautes Etudes (EPHE), 1919 Route de Mende, 34293 Montpellier Cedex 5, France

${ }^{2}$ Marine Biodiversity Exploitation and Conservation (MARBEC), UMR 248, Institut de Recherche pour le Développement (IRD), Université de Montpellier, Place Eugène Bataillon - bât 24 - CC093, 34095 Montpellier Cedex 5, France

${ }^{3}$ Institut Français de Recherche pour l'Exploitation de la Mer (IFREMER), UMR 248 MARBEC, Avenue Jean Monnet CS 3017, 34203 Sète, France

${ }^{4}$ Littoral, Environnement et Sociétés (LIENSs), UMR 7266, Centre National de la Recherche Scientifique (CNRS), Université La Rochelle, 2 rue Olympe de Gouges, $17000 \mathrm{La}$ Rochelle, France

${ }^{5}$ FitzPatrick Institute, DST/NRF Excellence Centre at the University of Cape Town, Rondebosch 7701, South Africa 


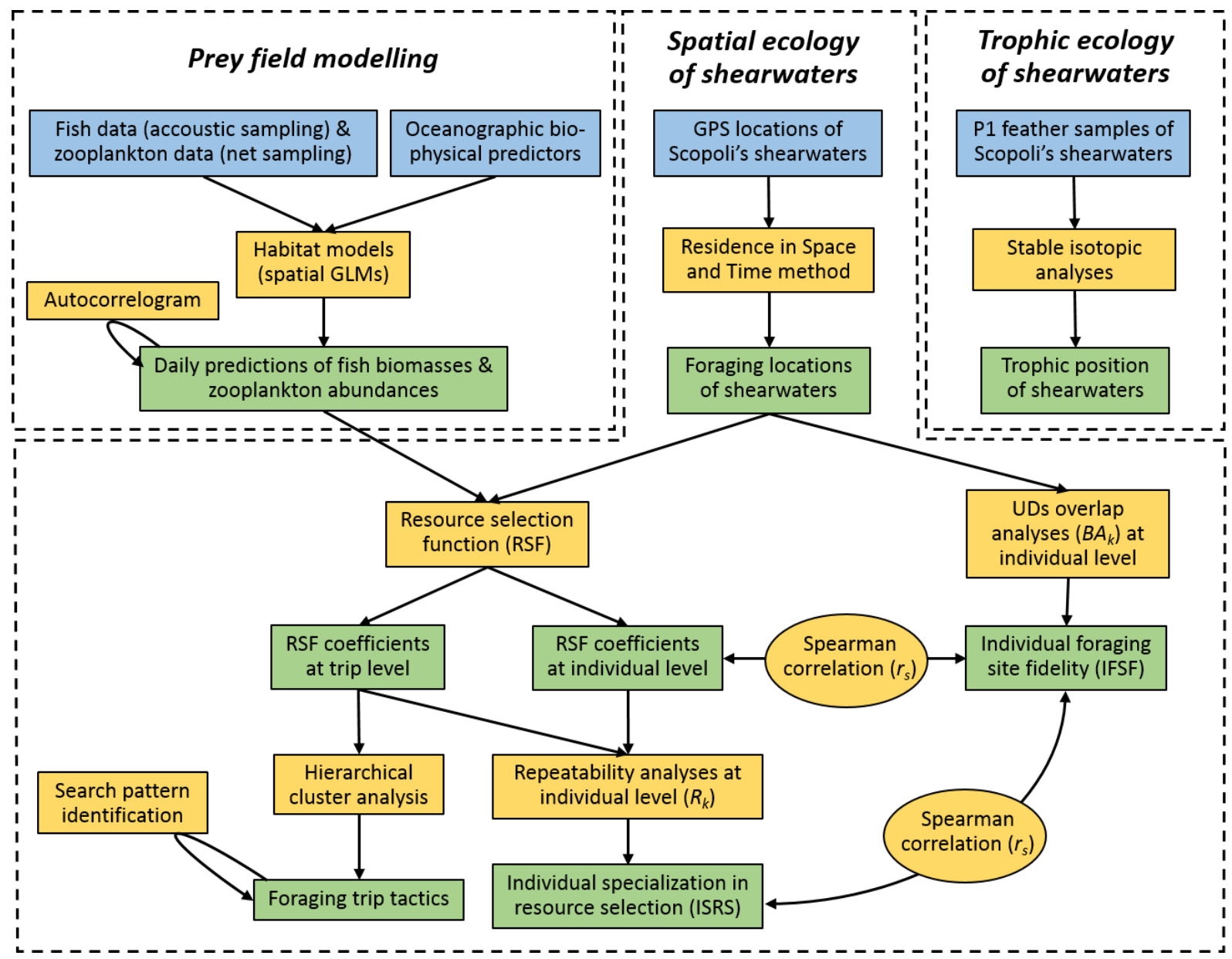

Figure S1.1. Analytical framework to study the foraging behavior of breeding Scopoli's

27 shearwaters in the Gulf of Lions (Western Mediterranean) showing input empirical datasets

(blue boxes), the statistical models and analyses (orange boxes) and outcomes (green boxes). 


\section{Supporting Information S2. Modelling of daily spatial distribution of biomass and}

abundance of prey of shearwaters

In order to determine the resource selection of shearwaters at foraging locations, we built dynamic habitat models predicting the daily spatial distribution of biomass of European anchovies (Engraulis encrasicolus), sardines (Sardina pilchardus) and sprats (Sprattus sprattus) in our study area. We distinguished between juvenile and adult fish based on their length-at-maturity $(9 \mathrm{~cm}, 11 \mathrm{~cm}$, and $9 \mathrm{~cm}$ for anchovies, sardines and sprats, respectively, Authier et al. 2017) because juveniles and adults are spatially segregated during the summer (see Fig. S2.3). We used biomass data per species and per stage, estimated from yearly standardized hydro-acoustic and trawl surveys of small pelagic fish carried out every July between 2010 and 2015 in the Gulf of Lions by IFREMER during the PELagic MEDiterranean (PELMED) at-sea campaigns (doi: http://dx.doi.org/10.18142/19). Biomass data were systematically collected each nautical mile along 9 parallel hydro-acoustic transects perpendicular to the coastline, 12 nautical miles apart, covering the continental shelf of the Gulf of Lions (see more details on sampling design and biomass data estimation in Authier et al. 2017).

We modelled fish biomass (tonnes) using zero-inflated spatial generalized linear mixed models with a Horseshoe prior in a Bayesian framework (except we used a non-spatial model for juvenile anchovies due to convergence issue). Such models have already demonstrated their robustness to predict fish biomass in the Gulf of Lions and allow accurate predictions, including extrapolations (Authier et al. 2017). Random spatial effects were modelled with a stationary Gaussian process of mean 0 , an isotropic Matèrn covariance function of order $3 / 2$ and a year-specific sill parameter. The Horseshoe prior favours a parsimonious variable selection by shrinking toward 0 small regression coefficient effects, yet 
leaving larger regression coefficient effects unshrunk, while avoiding overfitting (see statistical details in Authier et al. 2017). We used a set of dynamic predictors on a daily basis and 1.2 km-resolution: sea surface salinity (g.kg-1 , PREVIMER-MARS3D model), sea surface temperature $\left({ }^{\circ} \mathrm{C}\right.$, MODIS satellite data) and its variance describing the spatio-temporal dynamic of water mass features, and chlorophyll a concentration (mg.m ${ }^{-3}$, MODIS satellite data) and its variance used as proxies of primary productivity dynamics. Variance was calculated from the previous 15 days. We considered sea level anomaly (m) and Eddy kinetic energy $\left(\mathrm{cm}^{2} \cdot \mathrm{s}^{-2}\right)$ on a daily basis and $14 \mathrm{~km}$-resolution (AVISO satellite data) reflecting hydrodynamic movements and turbulences occurring at the meso-scale within the Gulf of Lions. Bathymetry with a 180 m-resolution (m, Marine Geoscience Data System), its gradient and seabed substrate (four levels: sands, muddy sands, sandy muds and muds; EUSeaMap) were used as static predictors in the models. Year was finally considered as a random effect to control for the inter-annual variation in fish biomasses. Models were fitted by initializing four chains with random starting values and running at least 3000 iterations to get the posterior sample distributions. Convergence was assessed based on the Gelman-Rubin potential scale reduction factor $\hat{r}$. We used the RStan package (Stan Development Team 2016) of R software (R Development Core Team 2016).

Similarly, we modelled mesozooplankton (thereafter 'zooplankton') abundance (ind. $\mathrm{m}^{-3}$ ) using data collected with vertical WP2 plankton-net $(200 \mu \mathrm{m}$ mesh size) during the PELMED survey conducted in July 2015 (data were not available for previous years) at 37 stations (Fig. S2.2). Zooplankton samples $(n=37)$ were identified and classified in two groups based on shearwater diet. The first group, 'zooplankton-preferred', included copepods, euphausiids, fish eggs and fish larvae already found in stomach contents or regurgitates of shearwaters (Beaubrun et al. 2013), and the rest of zooplankton formed the 'zooplanktonother' group. We fitted a spatial GLM with a Horseshoe prior, and considered a bivariate 
normal distribution for the dependent variable (both zooplankton groups) and the same set of environmental predictors as for fish biomass models. Model was fitted by initializing four chains with random starting values and running at least 3000 iterations to get the posterior sample distributions. Convergence was assessed based on the Gelman-Rubin potential scale reduction factor $\hat{r}$. We used the RStan package (Stan Development Team 2016) of R software (R Development Core Team 2016). We finally assessed the robustness and predictive power of the zooplankton model using leave-one-out cross-validation and compared the predicted abundance to the observed abundance within the range of abundance used by shearwaters. All parameters converged (Gelman-Rubin potential scale reduction factor $\hat{r}<1.2)$ for fish and zooplankton models. The zooplankton model significantly predicted observed abundances of zooplankton-preferred group within the range of abundance used by shearwaters $\left[0-800\right.$ ind. $\left.\mathrm{m}^{-3}\right]\left(\mathrm{r}^{2}=0.24, \mathrm{P}<0.005\right)$ (Fig. S2.4). The zooplankton model performed poorly to predict observed abundances of zooplankton-other group within the range of abundance used by shearwaters $\left[0-600\right.$ ind. $\left.\mathrm{m}^{-3}\right]\left(\mathrm{r}^{2}=0.02, \mathrm{P}=0.44\right)$ (Fig. S2.4). Sardines and juvenile sprats were coastal and their biomasses mainly decreased with bathymetry (Table S2.3, S2.4 and S2.6, Fig. S2.3). Juvenile anchovies were more widely distributed across the Gulf of Lions and were related to the plume of the Rhône river (Table S2.2, Fig. S2.3). Biomass of adult sprats was higher at the center of the Gulf than along the coast (Table S2.5, Fig. S2.3). Adult anchovies were the most pelagic prey category and their biomasses increased along the edge of the continental shelf, and also in some coastal areas (Table S2.1, Fig. S2.3). Both biomasses of adult anchovies and adult sprats increased near the Cassis canyon head close to the colony (Fig. S2.3). Abundance of zooplankton-preferred was related to coastal areas, the plume of the Rhône river and canyon areas (Table S2.7, Fig. S2.3). Zooplankton-other abundance was widely distributed across the Gulf of Lions (Table S2.7, Fig. S2.3). 
105 decrease of their temporal autocorrelation after only 1 day (Fig. S2.1). Autocorrelation of 106 biomasses of adult anchovies and sprats strongly declined after 2-3 days, particularly in the

107 eastern part of the Gulf of Lions where most foraging locations occurred (Fig. S2.1B).

108 Autocorrelation of other fish biomasses vanished in less than 5 days.

\section{References}

111 Authier, M., Saraux, C. \& Péron, C. (2017). Variable selection and accurate predictions in 112 habitat modelling: a shrinkage approach. Ecography, 40, 549-560.

113 Beaubrun, P. et al. (2012). Etat de l'art des connaissances sur les distributions spatiales des 114 oiseaux marins et des petits poissons pélagiques dans le golfe du Lion. Rapport final du 115 Contrat DREAL-LR / IFREMER n¹1/3211726/F, 1-580 pp.

116 Stan Development Team (2016). RStan: the R interface to Stan. R package version 2.14.1.

117 http://mc-stan.org/. 
Table S2.1. Zero-inflated spatial generalized linear mixed model with Horseshoe priors

119 predicting the spatial distribution of adult anchovies in the Gulf of Lions (Western

120 Mediterranean) between 2010 and 2015. Model parameters ( $\beta$ ) are shown with their standard

121 deviation (SD) and 95\% confidence intervals (CI) for both the absence (zero-inflated part

122 modelling the probability of being absent) and biomass models of fish.

123

\begin{tabular}{|c|c|c|c|c|c|c|}
\hline \multirow[t]{2}{*}{ Variable } & \multicolumn{3}{|c|}{ Absence (zero-inflated part) } & \multicolumn{3}{|c|}{ Biomass } \\
\hline & $\beta$ & $\mathrm{SD}$ & $95 \% \mathrm{CI}$ & $\beta$ & $\mathrm{SD}$ & $95 \% \mathrm{CI}$ \\
\hline \multicolumn{7}{|l|}{ Fixed effects } \\
\hline Intercept & -6.07 & 2.28 & $-11.87 ;-3.37$ & 1.31 & 0.20 & $0.90 ; 1.71$ \\
\hline Bathymetry (m) & 0.10 & 0.48 & $-0.54 ; 1.35$ & -0.01 & 0.04 & $-0.10 ; 0.07$ \\
\hline G(bathymetry) & -0.18 & 0.61 & $-1.87 ; 0.31$ & -0.04 & 0.04 & $-0.12 ; 0.01$ \\
\hline Sea surface salinity $\left(\mathrm{g} \cdot \mathrm{kg}^{1}\right)$ & 0.15 & 0.54 & $-0.42 ; 1.63$ & -0.04 & 0.05 & $-0.16 ; 0.03$ \\
\hline Sea surface temperature $\left({ }^{\circ} \mathrm{C}\right)$ & -0.002 & 0.33 & $-0.77 ; 0.75$ & -0.01 & 0.04 & $-0.10 ; 0.07$ \\
\hline Var(sea surface temperature) & -0.05 & 0.42 & $-1.22 ; 0.63$ & -0.01 & 0.03 & $-0.09 ; 0.05$ \\
\hline Chlorophyll a $\left(\mathrm{mg} \cdot \mathrm{m}^{-3}\right)$ & -0.13 & 0.39 & $-1.26 ; 0.27$ & -0.02 & 0.03 & $-0.09 ; 0.05$ \\
\hline Var(chlorophyll a) & -0.20 & 0.62 & $-2.02 ; 0.22$ & -0.01 & 0.02 & $-0.06 ; 0.04$ \\
\hline Eddy kinetic energy $\left(\mathrm{cm}^{2} \cdot \mathrm{s}^{-2}\right)$ & -0.06 & 0.43 & $-1.20 ; 0.62$ & -0.02 & 0.04 & $-0.12 ; 0.05$ \\
\hline Sea level anomalies (m) & -0.03 & 0.41 & $-0.96 ; 0.73$ & 0.01 & 0.04 & $-0.06 ; 0.12$ \\
\hline \multicolumn{7}{|l|}{ Seabed substrate } \\
\hline Muds & -0.08 & 0.78 & $-1.87 ; 1.02$ & -0.02 & 0.10 & $-0.28 ; 0.15$ \\
\hline Muddy sands & -0.09 & 0.88 & $-2.42 ; 1.33$ & -0.17 & 0.18 & $-0.59 ; 0.05$ \\
\hline Sandy muds & -0.20 & 0.85 & $-2.51 ; 0.75$ & 0.05 & 0.12 & $-0.13 ; 0.38$ \\
\hline Sands & -0.16 & 0.79 & $-2.37 ; 0.91$ & 0.44 & 0.15 & $0.16 ; 0.79$ \\
\hline
\end{tabular}

\section{Random effect}




$\begin{array}{lllllll}2010 & -6.14 & 2.37 & -12.33 ;-3.27 & 1.28 & 0.17 & 0.92 ; 1.60 \\ 2011 & -6.17 & 2.38 & -12.13 ;-3.33 & 1.27 & 0.18 & 0.91 ; 1.62 \\ 2012 & -6.11 & 2.42 & -12.33 ;-3.22 & 1.41 & 0.18 & 1.05 ; 1.76 \\ 2013 & -6.14 & 2.41 & -12.15 ;-3.14 & 1.01 & 0.23 & 0.58 ; 1.42 \\ 2014 & -6.13 & 2.36 & -12.10 ;-3.29 & 1.38 & 0.18 & 0.99 ; 1.72 \\ 2015 & -6.17 & 2.49 & -12.71 ;-3.15 & 1.56 & 0.20 & 1.16 ; 1.96\end{array}$

Spatial effect

Rho

$6.73 \quad 0.87 \quad 5.24 ; 8.61$

Sill in 2010

$0.78 \quad 0.10 \quad 0.61 ; 0.98$

Sill in 2011

$0.79 \quad 0.10 \quad 0.63 ; 0.99$

Sill in 2012

$0.89 \quad 0.10 \quad 0.73 ; 1.08$

Sill in 2013

$0.95 \quad 0.11 \quad 0.76 ; 1.18$

Sill in 2014

$0.90 \quad 0.12 \quad 0.69 ; 1.14$

Sill in 2015

$0.95 \quad 0.12 \quad 0.73 ; 1.19$

Horseshoe (global)

$0.26 \quad 0.26 \quad 0.03 ; 0.96$

$\begin{array}{lll}0.07 & 0.07 \quad 0.01 ; 0.27\end{array}$ 
Table S2.2. Zero-inflated generalized linear mixed model with Horseshoe priors predicting

126 the spatial distribution of juvenile anchovies in the Gulf of Lions (Western Mediterranean)

127 between 2010 and 2015. Model parameters ( $\beta$ ) are shown with their standard deviation (SD)

128 and $95 \%$ confidence intervals (CI) for both the absence (zero-inflated part modelling the

129 probability of being absent) and biomass models of fish.

\begin{tabular}{|c|c|c|c|c|c|c|}
\hline \multirow[t]{2}{*}{ Variable } & \multicolumn{3}{|c|}{ Absence (zero-inflated part) } & \multicolumn{3}{|c|}{ Biomass } \\
\hline & $\beta$ & SD & $95 \% \mathrm{CI}$ & $\beta$ & SD & $95 \% \mathrm{CI}$ \\
\hline \multicolumn{7}{|l|}{ Fixed effects } \\
\hline Intercept & -3.91 & 0.71 & $-5.55 ;-2.95$ & 0.01 & 0.01 & $-0.002 ; 0.03$ \\
\hline Bathymetry (m) & -0.04 & 0.14 & $-0.35 ; 0.26$ & 0.015 & 0.002 & $0.010 ; 0.018$ \\
\hline G(bathymetry) & -0.21 & 0.38 & $-1.27 ; 0.16$ & 0.007 & 0.002 & $0.003 ; 0.010$ \\
\hline Sea surface salinity $\left(\mathrm{g} \cdot \mathrm{kg}^{1}\right)$ & -0.62 & 0.11 & $-0.85 ;-0.42$ & -0.05 & 0.003 & $-0.06 ;-0.05$ \\
\hline Sea surface temperature $\left({ }^{\circ} \mathrm{C}\right)$ & 0.39 & 0.37 & $-0.05 ; 1.26$ & 0.005 & 0.002 & $0.001 ; 0.009$ \\
\hline Var(sea surface temperature) & 0.17 & 0.19 & $-0.14 ; 0.54$ & -0.008 & 0.002 & $-0.011 ;-0.004$ \\
\hline Chlorophyll a $\left(\mathrm{mg} \cdot \mathrm{m}^{-3}\right)$ & -0.06 & 0.09 & $-0.28 ; 0.06$ & -0.007 & 0.002 & $-0.011 ;-0.002$ \\
\hline Var(chlorophyll a) & -0.07 & 0.19 & $-0.60 ; 0.18$ & -0.001 & 0.001 & $-0.003 ; 0.002$ \\
\hline Eddy kinetic energy $\left(\mathrm{cm}^{2} \cdot \mathrm{s}^{-2}\right)$ & -0.76 & 0.47 & $-1.77 ;-0.003$ & 0.002 & 0.002 & $-0.001 ; 0.006$ \\
\hline Sea level anomalies (m) & -0.06 & 0.24 & $-0.68 ; 036$ & -0.001 & 0.002 & $-0.005 ; 0.002$ \\
\hline \multicolumn{7}{|l|}{ Seabed substrate } \\
\hline Muds & 0.07 & 0.37 & $-0.47 ; 1.01$ & -0.001 & 0.004 & $-0.009 ; 0.009$ \\
\hline Muddy sands & -0.38 & 1.50 & $-4.37 ; 0.61$ & -0.01 & 0.01 & $-0.03 ; 0.002$ \\
\hline Sandy muds & -0.01 & 0.37 & $-0.63 ; 0.83$ & 0.002 & 0.004 & $-0.006 ; 0.011$ \\
\hline Sands & -0.94 & 3.21 & $-15.01 ; 0.70$ & 0.003 & 0.007 & $-0.007 ; 0.021$ \\
\hline
\end{tabular}

\section{Random effect}


2010

2011

2012

2013

2014

2015

Horseshoe (global) $\begin{array}{llllll}-4.12 & 0.84 & -6.10 ;-2.97 & 0.01 & 0.005 & -0.002 ; 0.02\end{array}$

$\begin{array}{llllll}-3.99 & 0.81 & -5.84 ;-2.87 & 0.01 & 0.005 & -0.002 ; 0.02\end{array}$

$\begin{array}{llllll}-4.03 & 0.82 & -5.90 ;-2.91 & 0.01 & 0.005 & 0.001 ; 0.02\end{array}$

$\begin{array}{llllll}-3.71 & 0.71 & -5.40 ;-2.59 & 0.02 & 0.005 & 0.01 ; 0.03\end{array}$

$\begin{array}{llllll}-3.91 & 0.68 & -5.49 ;-2.90 & 0.03 & 0.005 & 0.02 ; 0.04\end{array}$

$\begin{array}{llllll}-3.87 & 0.74 & -5.57 ;-2.79 & 0.01 & 0.005 & -0.002 ; 0.02\end{array}$

$\begin{array}{llllll}0.32 & 0.22 & 0.08 ; 0.87 & 0.009 & 0.005 & 0.003 ; 0.240\end{array}$ 
Table S2.3. Zero-inflated spatial generalized linear mixed model with Horseshoe priors

132 predicting the spatial distribution of adult sardines in the Gulf of Lions (Western

133 Mediterranean) between 2010 and 2015. Model parameters ( $\beta$ ) are shown with their standard 134 deviation (SD) and 95\% confidence intervals (CI) for both the absence (zero-inflated part 135 modelling the probability of being absent) and biomass models of fish.

\begin{tabular}{|c|c|c|c|c|c|c|}
\hline \multirow[t]{2}{*}{ Variable } & \multicolumn{3}{|c|}{ Absence (zero-inflated part) } & \multicolumn{3}{|c|}{ Biomass } \\
\hline & $\beta$ & SD & $95 \% \mathrm{CI}$ & $\beta$ & SD & $95 \% \mathrm{CI}$ \\
\hline \multicolumn{7}{|l|}{ Fixed effects } \\
\hline Intercept & -5.61 & 1.99 & $-9.73 ;-1.41$ & 1.32 & 0.22 & $0.89 ; 1.78$ \\
\hline Bathymetry (m) & 2.09 & 0.78 & $0.96 ; 3.91$ & 0.63 & 0.07 & $0.50 ; 0.76$ \\
\hline G(bathymetry) & -0.07 & 0.74 & $-1.90 ; 1.10$ & 0.16 & 0.05 & $0.07 ; 0.26$ \\
\hline Sea surface salinity $\left(\mathrm{g} \cdot \mathrm{kg}^{1}\right)$ & 0.22 & 0.71 & $-0.27 ; 1.81$ & -0.01 & 0.04 & $-0.09 ; 0.07$ \\
\hline Sea surface temperature $\left({ }^{\circ} \mathrm{C}\right)$ & 0.16 & 0.26 & $-0.18 ; 0.80$ & -0.04 & 0.05 & $-0.17 ; 0.04$ \\
\hline Var(sea surface temperature) & -0.03 & 0.19 & $-0.44 ; 0.34$ & 0.02 & 0.04 & $-0.06 ; 0.13$ \\
\hline Chlorophyll a $\left(\mathrm{mg} \cdot \mathrm{m}^{-3}\right)$ & 0.02 & 0.16 & $-0.37 ; 0.32$ & -0.05 & 0.06 & $-0.18 ; 0.03$ \\
\hline Var(chlorophyll a) & 0.05 & 0.08 & $-0.07 ; 0.22$ & -0.06 & 0.06 & $-0.19 ; 0.04$ \\
\hline Eddy kinetic energy $\left(\mathrm{cm}^{2} \cdot \mathrm{s}^{-2}\right)$ & 0.04 & 0.26 & $-0.52 ; 0.61$ & 0.01 & 0.04 & $-0.06 ; 0.11$ \\
\hline Sea level anomalies (m) & 0.01 & 0.18 & $-0.38 ; 0.40$ & -0.01 & 0.05 & $-0.12 ; 0.07$ \\
\hline \multicolumn{7}{|l|}{ Seabed substrate } \\
\hline Muds & -0.49 & 1.51 & $-4.59 ; 0.60$ & -0.02 & 0.10 & $-0.29 ; 0.18$ \\
\hline Muddy sands & -0.03 & 0.36 & $-0.83 ; 0.89$ & -0.01 & 0.10 & $-0.27 ; 0.19$ \\
\hline Sandy muds & 0.31 & 0.47 & $-0.27 ; 1.60$ & -0.03 & 0.07 & $-0.20 ; 0.10$ \\
\hline Sands & -1.22 & 3.63 & $-8.00 ; 0.28$ & 0.07 & 0.09 & $-0.06 ; 0.28$ \\
\hline
\end{tabular}

\section{Random effect}


2010

2011

2012

2013

2014

2015

Spatial effect

Rho

Sill in 2010

Sill in 2011

Sill in 2012

Sill in 2013

Sill in 2014

Sill in 2015

Horseshoe (global) $\begin{array}{llllll}-4.56 & 2.06 & -8.54 ;-2.37 & 1.10 & 0.14 & 0.81 ; 1.38\end{array}$

$\begin{array}{llllll}-8.49 & 5.69 & -19.18 ;-4.23 & 1.03 & 0.14 & 0.75 ; 1.30\end{array}$

$\begin{array}{llllll}-8.27 & 5.43 & -19.44 ;-4.10 & 1.26 & 0.15 & 0.95 ; 1.55\end{array}$

$\begin{array}{llllll}-4.51 & 1.44 & -7.97 ;-2.41 & 1.71 & 0.20 & 1.31 ; 2.10\end{array}$

$\begin{array}{llllll}-8.04 & 3.82 & -18.76 ;-4.20 & 1.47 & 0.16 & 1.17 ; 1.78\end{array}$

$\begin{array}{llllll}-8.16 & 5.01 & -18.55 ;-4.05 & 1.35 & 0.16 & 1.02 ; 1.68\end{array}$

$4.92 \quad 0.73 \quad 3.71 ; 6.53$

$0.71 \quad 0.10 \quad 0.52 ; 0.91$

$0.70 \quad 0.11 \quad 0.49 ; 0.92$

$0.79 \quad 0.10 \quad 0.61 ; 1.00$

$\begin{array}{lll}1.00 & 0.13 \quad 0.78 ; 1.27\end{array}$

$0.89 \quad 0.11 \quad 0.69 ; 1.11$

$0.92 \quad 0.11 \quad 0.71 ; 1.16$

$\begin{array}{llllll}0.33 & 0.25 & 0.06 ; 0.97 & 0.09 & 0.07 & 0.02 ; 0.26\end{array}$ 
Table S2.4. Zero-inflated spatial generalized linear mixed model with Horseshoe priors

139 predicting the spatial distribution of juvenile sardines in the Gulf of Lions (Western

140 Mediterranean) between 2010 and 2015. Model parameters ( $\beta$ ) are shown with their standard

141 deviation (SD) and 95\% confidence intervals (CI) for both the absence (zero-inflated part

142 modelling the probability of being absent) and biomass models of fish.

\begin{tabular}{|c|c|c|c|c|c|c|}
\hline \multirow[t]{2}{*}{ Variable } & \multicolumn{3}{|c|}{ Absence (zero-inflated part) } & \multicolumn{3}{|l|}{ Biomass } \\
\hline & $\beta$ & SD & $95 \% \mathrm{CI}$ & $\beta$ & SD & $95 \% \mathrm{CI}$ \\
\hline \multicolumn{7}{|l|}{ Fixed effects } \\
\hline Intercept & -0.76 & 0.62 & $-2.08 ; 0.44$ & 0.81 & 0.17 & $0.47 ; 1.16$ \\
\hline Bathymetry (m) & -1.80 & 0.18 & $-2.16 ;-1.47$ & 0.92 & 0.08 & $0.77 ; 1.06$ \\
\hline G(bathymetry) & -0.62 & 0.18 & $-1.04 ;-0.32$ & 0.19 & 0.08 & $0.03 ; 0.33$ \\
\hline Sea surface salinity $\left(\mathrm{g} \cdot \mathrm{kg}^{1}\right)$ & 0.11 & 0.11 & $-0.08 ; 0.34$ & -0.005 & 0.03 & $-0.07 ; 0.06$ \\
\hline Sea surface temperature $\left({ }^{\circ} \mathrm{C}\right)$ & 0.01 & 0.07 & $-0.14 ; 0.16$ & -0.03 & 0.05 & $-0.17 ; 0.05$ \\
\hline Var(sea surface temperature) & -0.002 & 0.08 & $-0.19 ; 0.15$ & 0.01 & 0.04 & $-0.06 ; 0.11$ \\
\hline Chlorophyll a (mg.m ${ }^{-3}$ ) & -0.08 & 0.13 & $-0.40 ; 0.13$ & 0.002 & 0.03 & $-0.06 ; 0.07$ \\
\hline Var(chlorophyll a) & 0.21 & 0.10 & $-0.001 ; 0.40$ & 0.01 & 0.03 & $-0.04 ; 0.07$ \\
\hline Eddy kinetic energy $\left(\mathrm{cm}^{2} \cdot \mathrm{s}^{-2}\right)$ & 0.03 & 0.07 & $-0.10 ; 0.18$ & -0.0001 & 0.04 & $-0.08 ; 0.09$ \\
\hline Sea level anomalies (m) & -0.03 & 0.09 & $-0.23 ; 0.13$ & -0.03 & 0.06 & $-0.20 ; 0.05$ \\
\hline \multicolumn{7}{|l|}{ Seabed substrate } \\
\hline Muds & 0.10 & 0.24 & $-0.28 ; 0.79$ & -0.004 & 0.10 & $-0.24 ; 0.22$ \\
\hline Muddy sands & -0.14 & 1.29 & $-1.12 ; 0.78$ & -0.002 & 0.08 & $-0.19 ; 0.17$ \\
\hline Sandy muds & 0.05 & 0.17 & $-0.30 ; 0.42$ & 0.003 & 0.06 & $-0.13 ; 0.14$ \\
\hline Sands & -0.19 & 0.21 & $-0.67 ; 0.09$ & -0.005 & 0.06 & $-0.15 ; 0.12$ \\
\hline
\end{tabular}

\section{Random effect}




$\begin{array}{lllllll}2010 & -0.66 & 0.24 & -1.13 ;-0.17 & 0.92 & 0.15 & 0.64 ; 1.25 \\ 2011 & 0.63 & 0.24 & 0.19 ; 1.14 & 0.61 & 0.23 & 0.16 ; 1.07 \\ 2012 & -2.12 & 0.35 & -2.87 ;-1.44 & 1.12 & 0.17 & 0.81 ; 1.42 \\ 2013 & -2.67 & 1.27 & -6.54 ;-1.35 & 0.78 & 0.15 & 0.49 ; 1.05 \\ 2014 & 0.26 & 0.24 & -0.18 ; 0.76 & 0.63 & 0.14 & 0.36 ; 0.92 \\ 2015 & -0.81 & 0.27 & -1.33 ;-0.28 & 0.87 & 0.15 & 0.56 ; 1.17\end{array}$

Spatial effect

Rho

$\begin{array}{lll}4.02 & 0.83 & 2.69 ; 5.93\end{array}$

Sill in 2010

$0.97 \quad 0.13 \quad 0.71 ; 1.23$

Sill in 2011

$1.28 \quad 0.17 \quad 0.99 ; 1.64$

Sill in 2012

$0.96 \quad 0.11 \quad 0.77 ; 1.18$

Sill in 2013

$\begin{array}{lll}0.74 & 0.09 & 0.57 ; 0.93\end{array}$

Sill in 2014

$\begin{array}{lll}0.56 & 0.14 & 0.31 ; 0.84\end{array}$

Sill in 2015

$0.74 \quad 0.12 \quad 0.52 ; 0.98$

Horseshoe (global)

$0.24 \quad 0.15 \quad 0.07 ; 0.62$

$0.07 \quad 0.05 \quad 0.01 ; 0.21$ 
Table S2.5. Zero-inflated spatial generalized linear mixed model with Horseshoe priors

146 predicting the spatial distribution of adult sprats in the Gulf of Lions (Western Mediterranean)

147 between 2010 and 2015. Model parameters $(\beta)$ are shown with their standard deviation (SD)

148 and $95 \%$ confidence intervals (CI) for both the absence (zero-inflated part modelling the

149 probability of being absent) and biomass models of fish.

150

\begin{tabular}{|c|c|c|c|c|c|c|}
\hline \multirow[t]{2}{*}{ Variable } & \multicolumn{3}{|c|}{ Absence (zero-inflated part) } & \multicolumn{3}{|c|}{ Biomass } \\
\hline & $\beta$ & SD & $95 \% \mathrm{CI}$ & $\beta$ & $\mathrm{SD}$ & $95 \% \mathrm{CI}$ \\
\hline \multicolumn{7}{|l|}{ Fixed effects } \\
\hline Intercept & -4.41 & 1.82 & $-7.92 ;-0.30$ & 1.17 & 0.28 & $0.60 ; 1.78$ \\
\hline Bathymetry (m) & 2.39 & 0.41 & $1.76 ; 3.31$ & 0.11 & 0.06 & $-0.01 ; 0.23$ \\
\hline G(bathymetry) & 0.45 & 0.72 & $-0.83 ; 1.65$ & -0.03 & 0.04 & $-0.11 ; 0.03$ \\
\hline Sea surface salinity $\left(\mathrm{g} \cdot \mathrm{kg}^{1}\right)$ & 0.08 & 0.12 & $-0.11 ; 0.38$ & 0.02 & 0.04 & $-0.04 ; 0.11$ \\
\hline Sea surface temperature $\left({ }^{\circ} \mathrm{C}\right)$ & 0.29 & 0.25 & $-0.04 ; 0.84$ & -0.02 & 0.04 & $-0.14 ; 0.05$ \\
\hline Var(sea surface temperature) & -0.03 & 0.13 & $-0.33 ; 0.19$ & -0.03 & 0.04 & $-0.14 ; 0.05$ \\
\hline Chlorophyll a (mg. $\left.\mathrm{m}^{-3}\right)$ & 0.03 & 0.10 & $-0.16 ; 0.26$ & -0.001 & 0.04 & $-0.09 ; 0.09$ \\
\hline Var(chlorophyll a) & 0.03 & 0.08 & $-0.12 ; 0.19$ & 0.04 & 0.06 & $-0.06 ; 0.18$ \\
\hline Eddy kinetic energy $\left(\mathrm{cm}^{2} \cdot \mathrm{s}^{-2}\right)$ & 0.14 & 0.17 & $-0.13 ; 0.50$ & -0.002 & 0.03 & $-0.08 ; 0.07$ \\
\hline Sea level anomalies (m) & 0.05 & 0.16 & $-0.27 ; 0.40$ & -0.05 & 0.06 & $-0.21 ; 0.04$ \\
\hline \multicolumn{7}{|l|}{ Seabed substrate } \\
\hline Muds & -0.04 & 0.38 & $-0.87 ; 0.66$ & 0.02 & 0.08 & $-0.14 ; 0.23$ \\
\hline Muddy sands & -0.04 & 0.28 & $-0.69 ; 0.49$ & -0.12 & 0.18 & $-0.61 ; 0.07$ \\
\hline Sandy muds & -0.08 & 0.22 & $-0.68 ; 0.26$ & -0.03 & 0.10 & $-0.26 ; 0.15$ \\
\hline Sands & 0.07 & 0.21 & $-0.28 ; 0.65$ & 0.22 & 0.14 & $-0.01 ; 0.49$ \\
\hline
\end{tabular}

\section{Random effect}




$\begin{array}{lllllll}2010 & -3.48 & 0.65 & -5.02 ;-2.42 & 0.72 & 0.17 & 0.40 ; 1.08 \\ 2011 & -8.40 & 3.66 & -19.01 ;-4.91 & 1.11 & 0.21 & 0.72 ; 1.55 \\ 2012 & -6.84 & 2.70 & -14.71 ;-4.01 & 1.34 & 0.21 & 0.92 ; 1.76 \\ 2013 & -1.36 & 0.44 & -2.33 ;-0.67 & 1.78 & 0.31 & 1.15 ; 2.33 \\ 2014 & -8.47 & 3.07 & -16.93 ;-5.27 & 1.06 & 0.19 & 0.69 ; 1.44 \\ 2015 & -7.65 & 3.72 & -18.21 ;-4.16 & 0.81 & 0.15 & 0.50 ; 1.13\end{array}$

Spatial effect

Rho

$6.92 \quad 1.31 \quad 4.63 ; 9.66$

Sill in 2010

$0.65 \quad 0.08 \quad 0.50 ; 0.81$

Sill in 2011

$1.05 \quad 0.11 \quad 0.85 ; 1.28$

Sill in 2012

$1.00 \quad 0.10 \quad 0.81 ; 1.20$

Sill in 2013

$1.16 \quad 0.15 \quad 0.90 ; 1.48$

Sill in 2014

$1.00 \quad 0.14 \quad 0.76 ; 1.31$

Sill in 2015

$0.57 \quad 0.07 \quad 0.43 ; 0.72$

Horseshoe (global)

0.26

$0.18 \quad 0.05 ; 0.72$

0.07

$0.05 \quad 0.01 ; 0.21$ 
Table S2.6. Zero-inflated spatial generalized linear mixed model with Horseshoe priors predicting the spatial distribution of juvenile sprats in the Gulf of Lions (Western

Mediterranean) between 2010 and 2015. Model parameters ( $\beta$ ) are shown with their standard deviation (SD) and 95\% confidence intervals (CI) for both the absence (zero-inflated part modelling the probability of being absent) and biomass models of fish.

\begin{tabular}{|c|c|c|c|c|c|c|}
\hline \multirow[t]{2}{*}{ Variable } & \multicolumn{3}{|c|}{ Absence (zero-inflated part) } & \multicolumn{3}{|c|}{ Biomass } \\
\hline & $\beta$ & $\mathrm{SD}$ & $95 \% \mathrm{CI}$ & $\beta$ & SD & $95 \% \mathrm{CI}$ \\
\hline \multicolumn{7}{|l|}{ Fixed effects } \\
\hline Intercept & -2.43 & 1.98 & $-6.11 ; 2.68$ & 0.73 & 0.25 & $0.31 ; 1.25$ \\
\hline Bathymetry (m) & -1.31 & 0.13 & $-1.62 ;-1.07$ & 0.19 & 0.08 & $0.03 ; 0.34$ \\
\hline G(bathymetry) & -0.18 & 0.17 & $-0.58 ; 0.07$ & 0.03 & 0.04 & $-0.02 ; 0.12$ \\
\hline Sea surface salinity $\left(\mathrm{g} \cdot \mathrm{kg}^{1}\right)$ & 0.08 & 0.18 & $-0.16 ; 0.61$ & 0.02 & 0.03 & $-0.02 ; 0.08$ \\
\hline Sea surface temperature $\left({ }^{\circ} \mathrm{C}\right)$ & 0.15 & 0.20 & $-0.09 ; 0.65$ & -0.04 & 0.05 & $-0.15 ; 0.03$ \\
\hline Var(sea surface temperature) & -0.17 & 0.14 & $-0.50 ; 0.02$ & -0.003 & 0.05 & $-0.13 ; 0.08$ \\
\hline Chlorophyll a (mg.m $\left.{ }^{-3}\right)$ & 0.02 & 0.10 & $-0.17 ; 0.24$ & -0.02 & 0.03 & $-0.09 ; 0.02$ \\
\hline Var(chlorophyll a) & -0.02 & 0.06 & $-0.18 ; 0.08$ & -0.01 & 0.02 & $-0.06 ; 0.04$ \\
\hline Eddy kinetic energy $\left(\mathrm{cm}^{2} \cdot \mathrm{s}^{-2}\right)$ & -0.02 & 0.06 & $-0.17 ; 0.10$ & -0.03 & 0.04 & $-0.12 ; 0.04$ \\
\hline Sea level anomalies (m) & 0.01 & 0.08 & $-0.16 ; 0.24$ & -0.04 & 0.06 & $-0.18 ; 0.04$ \\
\hline \multicolumn{7}{|l|}{ Seabed substrate } \\
\hline Muds & 0.07 & 0.45 & $-0.87 ; 1.04$ & -0.02 & 0.08 & $-0.26 ; 0.11$ \\
\hline Muddy sands & 1.33 & 0.58 & $0.01 ; 2.24$ & -0.10 & 0.13 & $-0.42 ; 0.05$ \\
\hline Sandy muds & -0.01 & 0.16 & $-0.39 ; 0.32$ & 0.02 & 0.07 & $-0.10 ; 0.18$ \\
\hline Sands & -0.11 & 0.21 & $-0.70 ; 0.15$ & 0.14 & 0.10 & $-0.01 ; 0.35$ \\
\hline
\end{tabular}

\section{Random effect}




$\begin{array}{llllllll}2010 & -7.84 & 3.37 & -18.38 ;-4.24 & 0.48 & 0.18 & 0.13 ; 0.86 \\ 2011 & -0.01 & 0.25 & -0.46 ; 0.52 & 0.65 & 0.26 & 0.17 ; 1.15 \\ 2012 & -6.41 & 3.33 & -13.18 ;-2.96 & 0.77 & 0.28 & 0.15 ; 1.26 \\ 2013 & 0.82 & 0.24 & 0.43 ; 1.42 & 1.11 & 0.42 & 0.40 ; 1.96 \\ 2014 & -5.74 & 3.06 & -13.20 ;-2.21 & 0.38 & 0.15 & 0.09 ; 0.66 \\ 2015 & -5.06 & 2.18 & -11.13 ;-2.78 & 0.67 & 0.20 & 0.31 ; 1.07\end{array}$

Spatial effect

Rho

$11.97 \quad 1.49 \quad 9.45 ; 15.62$

Sill in 2010

$0.72 \quad 0.10 \quad 0.53 ; 0.93$

Sill in 2011

$0.96 \quad 0.16 \quad 0.68 ; 1.33$

Sill in 2012

$1.13 \quad 0.13 \quad 0.90 ; 1.46$

Sill in 2013

$\begin{array}{lll}1.51 & 0.27 \quad 1.04 ; 2.09\end{array}$

Sill in 2014

$0.49 \quad 0.07 \quad 0.36 ; 0.65$

Sill in 2015

$0.81 \quad 0.11 \quad 0.61 ; 1.04$

Horseshoe (global)

$0.25 \quad 0.21 \quad 0.04 ; 0.81$

0.07

$0.06 \quad 0.01 ; 0.19$ 
159

160

161

162

163

Table S2.7. Spatial generalized linear mixed model with Horseshoe priors predicting the

spatial distribution of zooplankton abundance in the Gulf of Lions (Western Mediterranean)

in 2015. Model parameters ( $\beta$ ) are shown with their standard deviation (SD) and 95\%

confidence intervals $(\mathrm{CI})$.

\begin{tabular}{|c|c|c|c|c|c|c|}
\hline \multirow[t]{2}{*}{ Variable } & \multicolumn{3}{|c|}{ Zooplankton-preferred } & \multicolumn{3}{|c|}{ Zooplankton-other } \\
\hline & $\beta$ & SD & $95 \% \mathrm{CI}$ & $\beta$ & SD & $95 \% \mathrm{CI}$ \\
\hline \multicolumn{7}{|l|}{ Fixed effects } \\
\hline Intercept & 5.46 & 0.80 & $3.32 ; 6.57$ & 5.53 & 0.62 & $3.98 ; 6.54$ \\
\hline Bathymetry (m) & 0.001 & 0.06 & $-0.14 ; 0.15$ & 0.03 & 0.09 & $-0.12 ; 0.26$ \\
\hline G(bathymetry) & 0.02 & 0.07 & $-0.08 ; 0.21$ & -0.07 & 0.11 & $-0.35 ; 0.08$ \\
\hline Sea surface salinity $\left(\mathrm{g} \cdot \mathrm{kg}^{1}\right)$ & -0.01 & 0.06 & $-0.17 ; 0.11$ & 0.16 & 0.15 & $-0.03 ; 0.48$ \\
\hline Sea surface temperature $\left({ }^{\circ} \mathrm{C}\right)$ & 0.005 & 0.06 & $-0.11 ; 0.15$ & -0.01 & 0.08 & $-0.19 ; 0.17$ \\
\hline Var(sea surface temperature) & -0.04 & 0.09 & $-0.28 ; 0.08$ & -0.02 & 0.08 & $-0.23 ; 0.12$ \\
\hline Chlorophyll a (mg.m $\left.{ }^{-3}\right)$ & 0.03 & 0.07 & $-0.07 ; 0.21$ & -0.003 & 0.07 & $-0.16 ; 0.14$ \\
\hline Var(chlorophyll a) & -0.08 & 0.11 & $-0.36 ; 0.04$ & -0.04 & 0.10 & $-0.30 ; 0.09$ \\
\hline Eddy kinetic energy $\left(\mathrm{cm}^{2} \cdot \mathrm{s}^{-2}\right)$ & -0.01 & 0.06 & $-0.18 ; 0.10$ & -0.01 & 0.08 & $-0.20 ; 0.14$ \\
\hline Sea level anomalies (m) & -0.01 & 0.06 & $-0.18 ; 0.10$ & 0.05 & 0.10 & $-0.10 ; 0.31$ \\
\hline \multicolumn{7}{|l|}{ Seabed substrate } \\
\hline Muds & 0.03 & 0.11 & $-0.12 ; 0.35$ & -0.09 & 0.18 & $-0.61 ; 0.12$ \\
\hline Muddy sands & -0.01 & 0.09 & $-0.25 ; 0.16$ & 0.11 & 0.20 & $-0.12 ; 0.68$ \\
\hline Sandy muds & -0.02 & 0.14 & $-0.39 ; 0.19$ & 0.02 & 0.18 & $-0.31 ; 0.48$ \\
\hline Sands & -0.03 & 0.18 & $-0.55 ; 0.22$ & -0.001 & 0.22 & $-0.44 ; 0.44$ \\
\hline Spatial effect (Rho) & 112.71 & 57.42 & $3.87 ; 197.20$ & 89.73 & 59.84 & $4.35 ; 194.25$ \\
\hline Horseshoe (global) & 0.06 & 0.05 & $0.003 ; 0.20$ & 0.09 & 0.08 & $0.01 ; 0.30$ \\
\hline
\end{tabular}



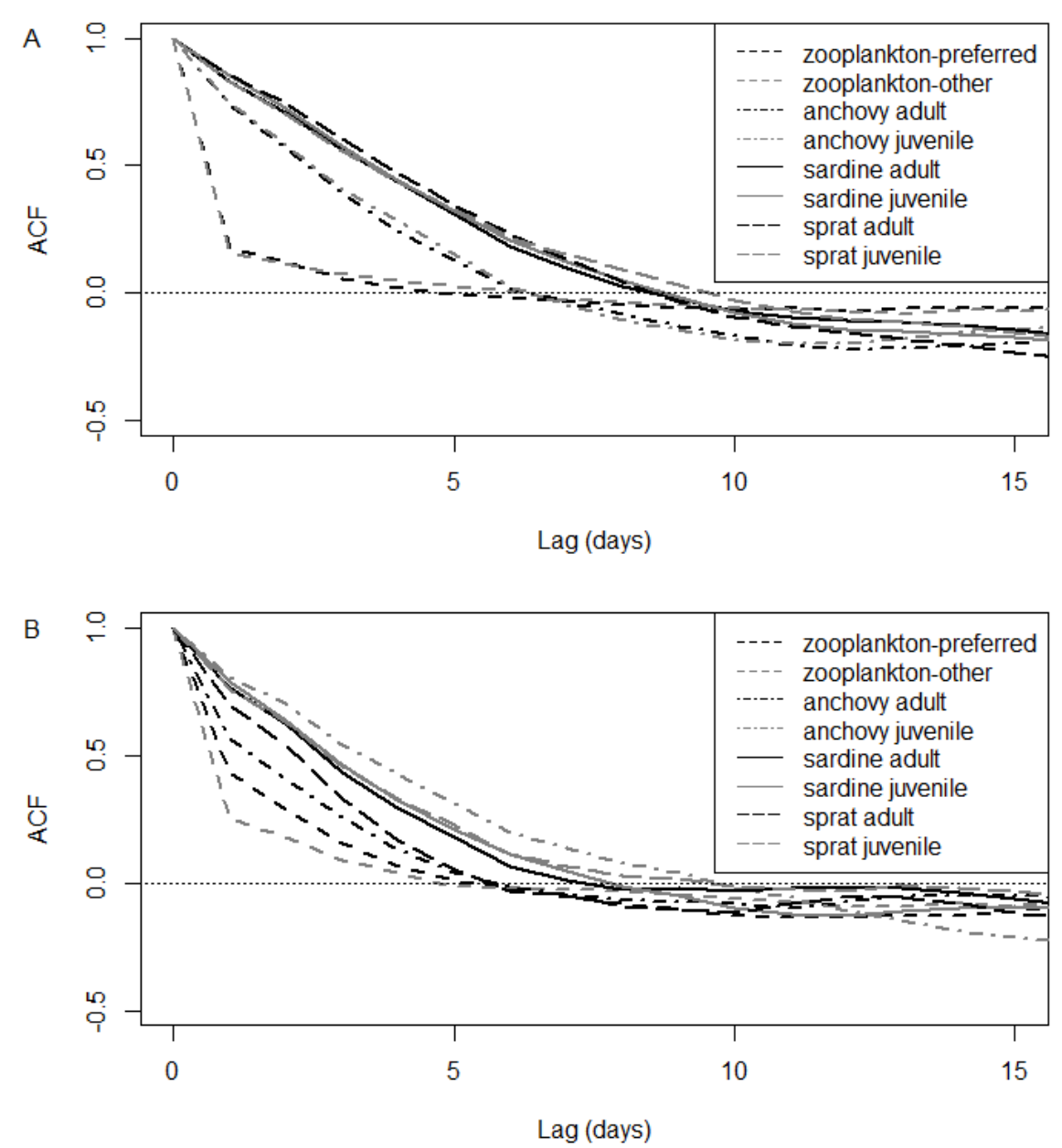

Figure S2.1. Temporal autocorrelation in the zooplankton abundances (ind. $\mathrm{m}^{-3}$ ) and small pelagic fish biomasses (tonnes) (A) in the entire the Gulf of Lions (Western Mediterranean) and (B) in its eastern part where most foraging locations occurred (longitude $>4.5^{\circ}$ ), during the chick-rearing period of Scopoli's shearwater (August). We considered three fish species (anchovy, sardine and sprat) at two stages (adult or juvenile) and zooplankton in two distinct categories: zooplankton-preferred that includes mesozooplankton already found in the diet of

171 shearwater (copepods, euphausiid, fish eggs and fish larvae) and zooplankton-other that

172 includes the rest of holoplankton and meroplankton. We assessed an autocorrelogram for each

173 prey abundance/biomass daily predicted between the 20 July and 20 August 2015 at 900

174 locations randomly distributed in the Gulf of Lions. For each prey type, values were averaged 175 among the 900 autocorrelograms at each lag and the mean values are presented. Abundances 
176 and biomasses data are predicted based on habitat models estimated from data collected on

177 July 2015 using plankton-net and hydro-acoustic survey (PELagic MEDiterranean campaigns,

178 IFREMER), respectively. 


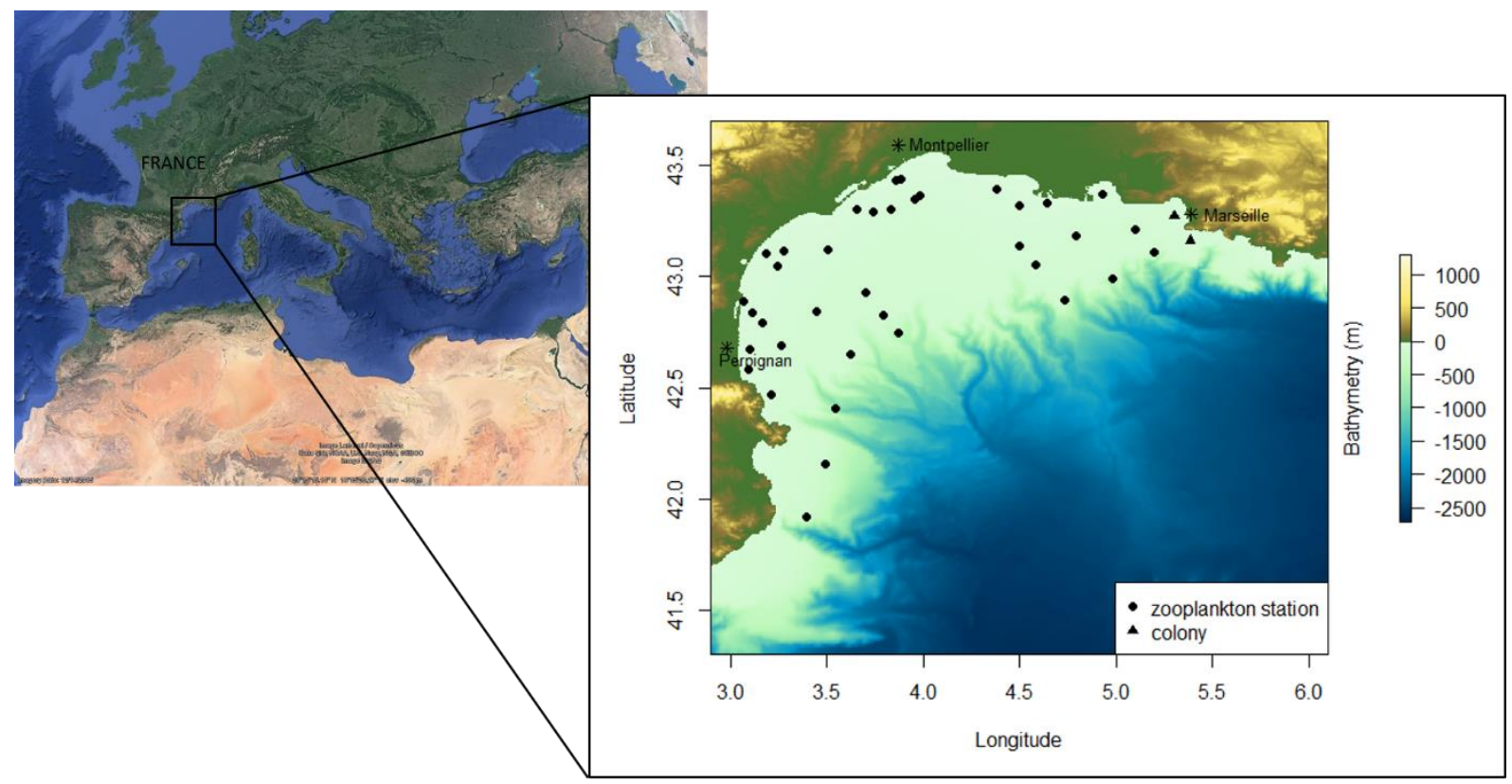

180 Figure S2.2. Spatial distribution of the 37 stations where zooplankton abundance was sampled

181 during the PELMED campaign in July 2015, within the Gulf of Lions (Western

182 Mediterranean). 

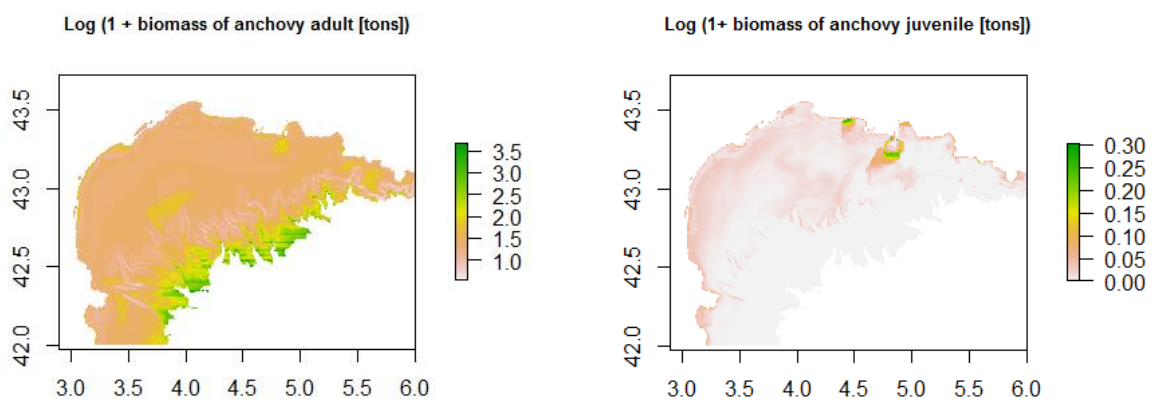

183
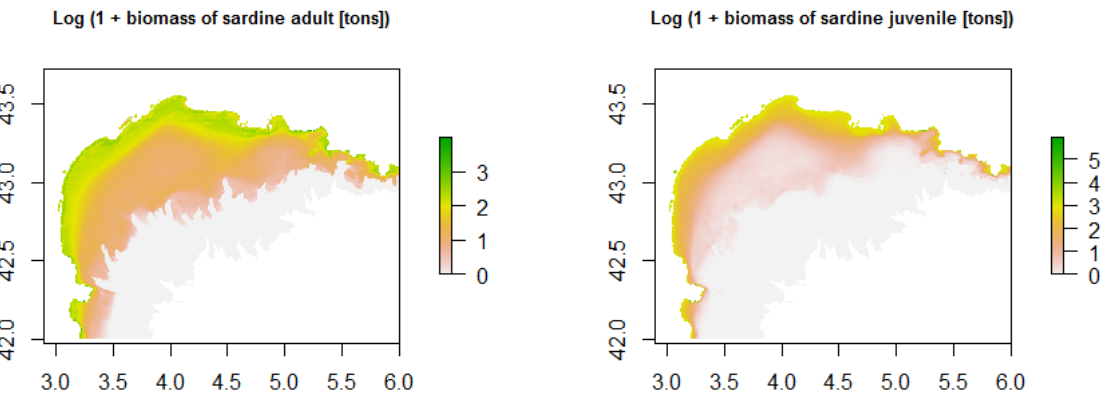

184
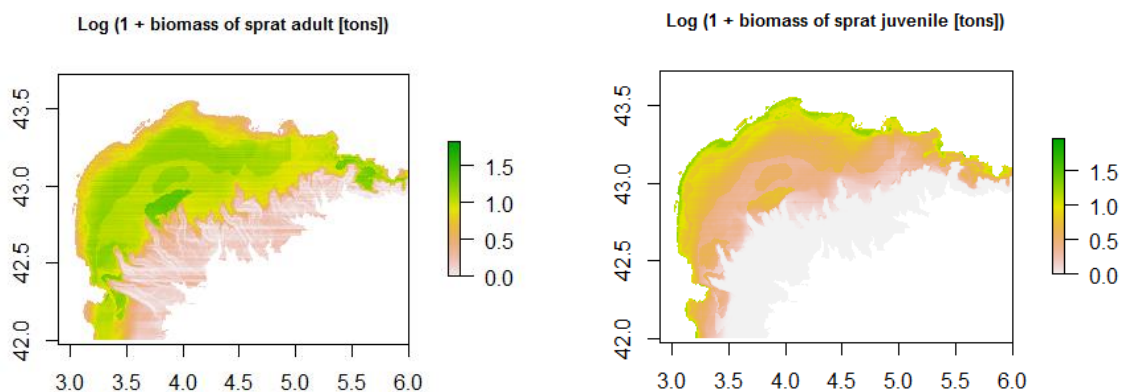

185

$\log (1+$ abundance of zooplankton [preferred] [ind.m^^-3])

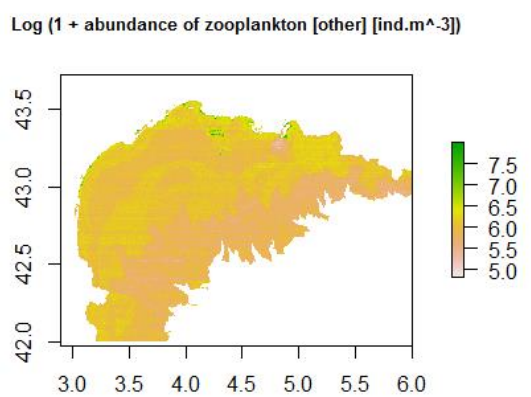

187 Figure S2.3. Example of predictions of fish biomasses and zooplankton abundances in our study area (Gulf of Lions, Western Mediterranean) for the August 17 2014 . 


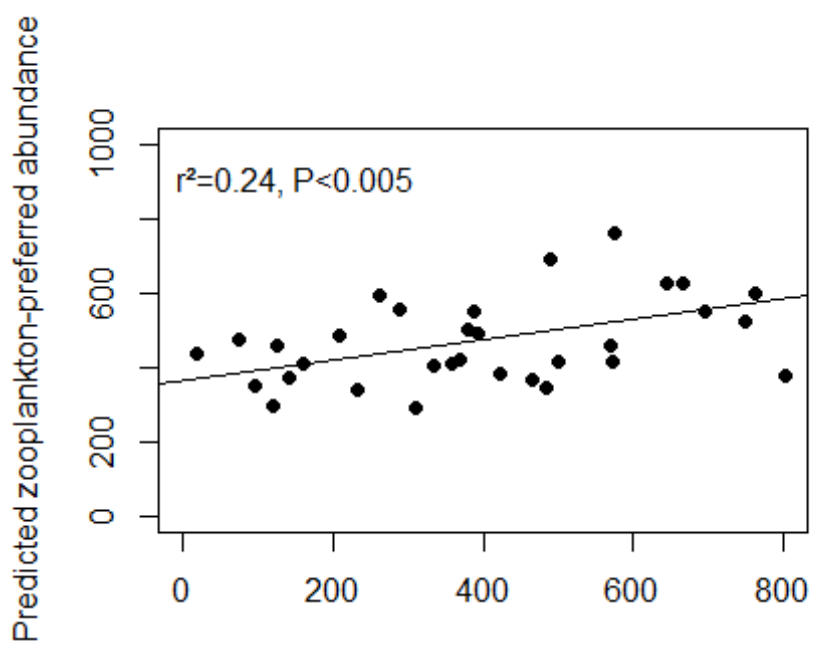

Observed zooplankton-preferred abundance

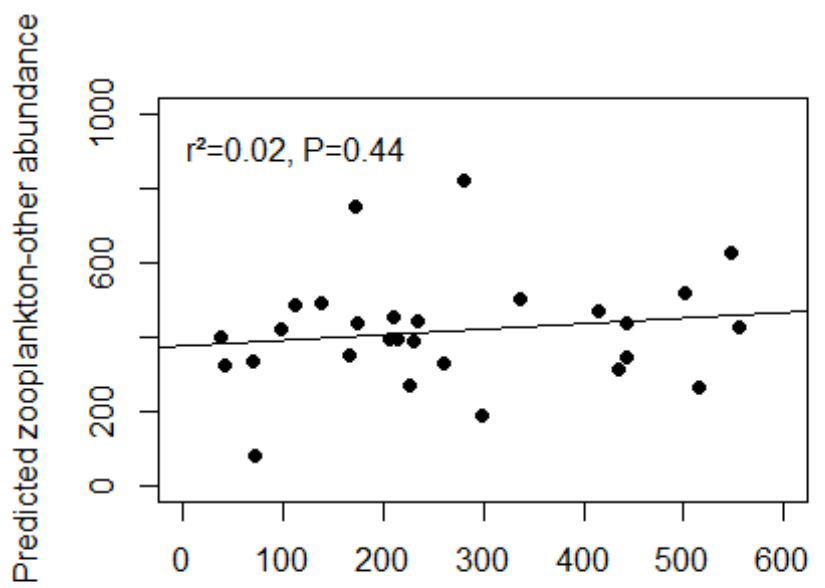

Observed zooplankton-other abundance

190 Figure S2.4. Relationship between observed and predicted zooplankton-preferred and

191 zooplankton-other abundances within the range of abundances used by shearwaters, between

1920 and 800 ind. $\mathrm{m}^{-3}$ for zooplankton-preferred group and between 0 and 600 ind. $\mathrm{m}^{-3}$ for

193 zooplankton-other group. A significant positive correlated relationship represents the ability

194 of the model to correctly predict zooplankton abundance. Predicted abundances were

195 estimated using a leave-one-out cross-validation. Note that an exceptional low salinity or deep

196 bathymetry or type of seabed substrate found at three samples stations produced unrealistic

197 predictions (>3000 ind. $\mathrm{m}^{-3}$ ) and we removed these outliers before determining the correlation 198 between observed and predicted abundances. 
199 Supporting Information S3. Summary of the features of foraging trips of the GPS-

200 tracked Scopoli's shearwaters in the Gulf of Lions (Western Mediterranean) during the

201 chick-rearing period between 2011 and 2015.

202

\begin{tabular}{|c|c|c|c|c|c|c|c|}
\hline ID & Island & Year & Trip ID & $\begin{array}{c}\text { Number of foraging } \\
\text { locations }\end{array}$ & Duration (h) & $\begin{array}{l}\text { Total travelled } \\
\text { distance }(\mathrm{km})\end{array}$ & Trip range $(\mathrm{km})$ \\
\hline EA536869 & Riou & 2015 & 1 & 301 & 17.26667 & 130.3072 & 37.24427 \\
\hline EA537115 & Frioul & 2012 & 1 & 169 & 17.83333 & 95.32814 & 33.77627 \\
\hline EA537115 & Frioul & 2012 & 2 & 527 & 23.86667 & 150.7962 & 44.54079 \\
\hline EA537115 & Frioul & 2012 & 3 & 262 & 22.9 & 235.3361 & 81.88775 \\
\hline EA537119 & Frioul & 2012 & 1 & 352 & 17.86667 & 77.92335 & 21.20606 \\
\hline EA537119 & Frioul & 2012 & 2 & 386 & 21.16667 & 161.5663 & 44.26024 \\
\hline EA537119 & Frioul & 2012 & 3 & 402 & 22.66667 & 112.9971 & 41.98626 \\
\hline EA537314 & Riou & 2014 & 1 & 362 & 17.96667 & 197.3995 & 66.18423 \\
\hline EA537342 & Riou & 2015 & 1 & 431 & 21.23333 & 202.8944 & 46.61669 \\
\hline EA574518 & Frioul & 2012 & 1 & 392 & 18.63333 & 81.73911 & 10.45051 \\
\hline EA574518 & Frioul & 2012 & 2 & 406 & 17.03333 & 67.91646 & 12.91926 \\
\hline EA575316 & Frioul & 2012 & 1 & 134 & 17.8 & 158.9419 & 19.47904 \\
\hline EA575316 & Frioul & 2012 & 2 & 309 & 17.6 & 174.6852 & 32.09053 \\
\hline EA575316 & Frioul & 2012 & 3 & 279 & 17.43333 & 129.372 & 21.23269 \\
\hline EA583455 & Riou & 2014 & 1 & 202 & 20.13333 & 272.5217 & 107.4334 \\
\hline EA583462 & Riou & 2011 & 1 & 1077 & 90.2 & 1041.618 & 187.9398 \\
\hline EA583462 & Riou & 2012 & 1 & 400 & 22.36667 & 102.2403 & 26.37054 \\
\hline EA583462 & Riou & 2014 & 1 & 123 & 22.36667 & 195.9221 & 57.64454 \\
\hline EA583471 & Riou & 2011 & 1 & 185 & 17.96667 & 112.6837 & 22.71272 \\
\hline EA583471 & Riou & 2011 & 2 & 163 & 18.6 & 151.9209 & 48.85248 \\
\hline EA583471 & Riou & 2011 & 3 & 267 & 17.66667 & 255.0441 & 81.3694 \\
\hline EA583471 & Riou & 2012 & 1 & 171 & 16.93333 & 56.63242 & 10.74711 \\
\hline EA583471 & Riou & 2012 & 2 & 297 & 16.86667 & 119.7053 & 35.72179 \\
\hline EA583471 & Riou & 2012 & 3 & 399 & 21.9 & 91.69251 & 20.61444 \\
\hline EA583471 & Riou & 2012 & 4 & 288 & 16.66667 & 62.78475 & 15.29072 \\
\hline EA583473 & Riou & 2011 & 1 & 267 & 20.03333 & 217.588 & 59.64424 \\
\hline EA583473 & Riou & 2011 & 2 & 422 & 23.3 & 204.8924 & 23.58706 \\
\hline EA583473 & Riou & 2011 & 3 & 380 & 22.53333 & 247.112 & 101.1507 \\
\hline EA583473 & Riou & 2011 & 4 & 777 & 47.1 & 478.3253 & 117.6529 \\
\hline EA583473 & Riou & 2011 & 5 & 221 & 25.6 & 227.249 & 59.64342 \\
\hline EA583473 & Riou & 2014 & 1 & 510 & 26.1 & 251.4774 & 52.51986 \\
\hline EA583473 & Riou & 2014 & 2 & 330 & 20.2 & 144.4306 & 28.60502 \\
\hline EA583515 & Riou & 2014 & 1 & 224 & 25 & 369.067 & 61.83389 \\
\hline EA583515 & Riou & 2014 & 2 & 299 & 21.03333 & 170.5801 & 38.05091 \\
\hline EA583521 & Riou & 2011 & 1 & 735 & 47.9 & 654.1349 & 166.7566 \\
\hline EA583521 & Riou & 2011 & 2 & 310 & 18.96667 & 177.8097 & 52.61471 \\
\hline EA583521 & Riou & 2011 & 3 & 836 & 52.76667 & 674.7173 & 231.5562 \\
\hline EA584082 & Frioul & 2012 & 1 & 278 & 17.2 & 140.4598 & 52.02414 \\
\hline EA584082 & Frioul & 2012 & 2 & 437 & 22.2 & 153.8898 & 44.59631 \\
\hline EA584082 & Frioul & 2012 & 3 & 283 & 17.13333 & 135.7145 & 47.14116 \\
\hline EA587492 & Riou & 2012 & 1 & 197 & 19.76667 & 163.0775 & 37.56865 \\
\hline EA587492 & Riou & 2012 & 2 & 204 & 22.2 & 116.4792 & 29.6461 \\
\hline EA587494 & Riou & 2015 & 1 & 119 & 18.6 & 302.4084 & 117.0496 \\
\hline EA587495 & Riou & 2012 & 1 & 215 & 21.66667 & 322.8619 & 132.7221 \\
\hline EA587495 & Riou & 2012 & 2 & 420 & 19.4 & 89.86135 & 29.49951 \\
\hline EA588706 & Frioul & 2012 & 1 & 312 & 16.96667 & 109.8093 & 24.28834 \\
\hline EA588706 & Frioul & 2012 & 2 & 328 & 18.06667 & 176.1783 & 34.26667 \\
\hline EA588706 & Frioul & 2012 & 3 & 453 & 23.4 & 240.9952 & 62.65067 \\
\hline EA591287 & Frioul & 2012 & 1 & 225 & 18.1 & 147.6267 & 34.95949 \\
\hline EA591287 & Frioul & 2012 & 2 & 192 & 17.33333 & 211.9506 & 83.03631 \\
\hline EA591287 & Frioul & 2012 & 3 & 318 & 20.3 & 174.3363 & 52.14879 \\
\hline EA591293 & Frioul & 2011 & 1 & 214 & 17.9 & 301.16 & 90.29346 \\
\hline EA591293 & Frioul & 2011 & 2 & 371 & 18.63333 & 341.9844 & 110.5827 \\
\hline EA591293 & Frioul & 2011 & 3 & 140 & 19.93333 & 439.2692 & 201.86 \\
\hline EA591293 & Frioul & 2011 & 4 & 358 & 24.03333 & 344.7705 & 130.0115 \\
\hline EA591293 & Frioul & 2012 & 1 & 220 & 19.76667 & 106.7811 & 22.414 \\
\hline EA591293 & Frioul & 2012 & 2 & 239 & 17.53333 & 146.2526 & 56.44107 \\
\hline
\end{tabular}




\begin{tabular}{|c|c|c|c|c|c|c|c|}
\hline EA591293 & Frioul & 2012 & 3 & 365 & 17.33333 & 68.91761 & 11.27812 \\
\hline EA591317 & Riou & 2011 & 1 & 117 & 17.8 & 274.1575 & 112.9897 \\
\hline EA591317 & Riou & 2011 & 2 & 135 & 19.1 & 257.104 & 85.67987 \\
\hline EA591317 & Riou & 2011 & 3 & 114 & 17.16667 & 213.4884 & 89.32922 \\
\hline EA591396 & Riou & 2011 & 1 & 253 & 19.33333 & 254.674 & 106.3596 \\
\hline EA591396 & Riou & 2011 & 2 & 534 & 41.93333 & 558.7664 & 178.8871 \\
\hline EA591396 & Riou & 2011 & 3 & 443 & 22.1 & 205.4152 & 30.0629 \\
\hline EA591396 & Riou & 2011 & 4 & 238 & 22.6 & 105.0809 & 17.01076 \\
\hline EA591603 & Frioul & 2012 & 1 & 232 & 17.26667 & 85.05565 & 21.20548 \\
\hline EA591603 & Frioul & 2012 & 2 & 242 & 17.1 & 246.9954 & 109.9167 \\
\hline EA591604 & Frioul & 2011 & 1 & 242 & 19.5 & 312.323 & 117.5258 \\
\hline EA591643 & Frioul & 2011 & 1 & 496 & 25.16667 & 170.1195 & 22.71646 \\
\hline EA591643 & Frioul & 2011 & 2 & 564 & 46 & 737.3911 & 216.5993 \\
\hline EA591643 & Frioul & 2012 & 1 & 177 & 21.93333 & 158.3072 & 46.2028 \\
\hline EA591643 & Frioul & 2012 & 2 & 498 & 23.43333 & 134.9211 & 34.51857 \\
\hline EA593790 & Riou & 2014 & 1 & 290 & 22.26667 & 323.6014 & 58.25641 \\
\hline EA593790 & Riou & 2014 & 2 & 224 & 19.7 & 88.61498 & 17.1535 \\
\hline EA593791 & Riou & 2011 & 1 & 960 & 45.6 & 442.3402 & 125.0831 \\
\hline EA593791 & Riou & 2011 & 2 & 311 & 17.8 & 156.4401 & 38.93911 \\
\hline EA593793 & Riou & 2011 & 1 & 281 & 19.73333 & 345.7348 & 144.5087 \\
\hline EA593793 & Riou & 2011 & 2 & 527 & 41.63333 & 595.6626 & 185.988 \\
\hline EA593793 & Riou & 2011 & 3 & 59 & 5.866667 & 34.50492 & 6.127479 \\
\hline EA593793 & Riou & 2011 & 4 & 403 & 22.93333 & 181.4883 & 14.81019 \\
\hline EA593793 & Riou & 2011 & 5 & 41 & 5.3 & 53.00642 & 22.24902 \\
\hline EA593793 & Riou & 2011 & 6 & 311 & 21.63333 & 110.9618 & 17.80161 \\
\hline EA593793 & Riou & 2012 & 1 & 238 & 17.16667 & 125.5197 & 37.19858 \\
\hline EA593793 & Riou & 2012 & 2 & 177 & 17.66667 & 323.8028 & 133.3971 \\
\hline EA593793 & Riou & 2012 & 3 & 270 & 23.23333 & 148.8923 & 39.52289 \\
\hline EA593793 & Riou & 2014 & 1 & 130 & 13.6 & 159.055 & 23.17425 \\
\hline EA593793 & Riou & 2014 & 2 & 33 & 3.533333 & 19.12922 & 5.73451 \\
\hline EA593798 & Riou & 2012 & 1 & 270 & 19.66667 & 79.77859 & 13.90533 \\
\hline EA593798 & Riou & 2012 & 2 & 193 & 17.13333 & 86.4203 & 16.60192 \\
\hline EA593798 & Riou & 2012 & 3 & 420 & 25.83333 & 275.3548 & 48.85784 \\
\hline EA593798 & Riou & 2012 & 4 & 164 & 16.33333 & 135.0189 & 52.13851 \\
\hline EA595979 & Riou & 2015 & 1 & 336 & 17.66667 & 173.7901 & 71.66334 \\
\hline EA621014 & Riou & 2011 & 1 & 770 & 69.26667 & 682.8429 & 146.2361 \\
\hline EA621014 & Riou & 2011 & 2 & 587 & 47.36667 & 755.6292 & 259.5073 \\
\hline EA621029 & Riou & 2014 & 1 & 61 & 19.9 & 185.4475 & 35.27625 \\
\hline EA621030 & Riou & 2014 & 1 & 230 & 16.33333 & 210.5041 & 73.7311 \\
\hline EA621030 & Riou & 2014 & 2 & 455 & 29 & 248.8434 & 44.4035 \\
\hline EA621030 & Riou & 2014 & 3 & 305 & 21.06667 & 212.2364 & 36.69691 \\
\hline EA621030 & Riou & 2014 & 4 & 460 & 22.83333 & 130.2794 & 33.13248 \\
\hline EA621030 & Riou & 2014 & 5 & 322 & 17.16667 & 175.1493 & 35.69736 \\
\hline EA621030 & Riou & 2014 & 6 & 216 & 19.16667 & 191.0858 & 53.17421 \\
\hline EA621053 & Riou & 2011 & 1 & 1252 & 112.7333 & 1290.359 & 131.7114 \\
\hline EA621081 & Riou & 2014 & 1 & 71 & 17.8 & 172.1036 & 47.827 \\
\hline EA621083 & Riou & 2012 & 1 & 246 & 18.33333 & 136.6396 & 32.34254 \\
\hline EA621083 & Riou & 2012 & 2 & 183 & 16.66667 & 273.245 & 108.3758 \\
\hline EA621085 & Riou & 2011 & 1 & 186 & 21.43333 & 222.1787 & 19.29173 \\
\hline EA621085 & Riou & 2011 & 2 & 814 & 48.86667 & 452.8178 & 69.15876 \\
\hline EA621124 & Frioul & 2012 & 1 & 229 & 19.96667 & 278.0153 & 118.5711 \\
\hline EA621124 & Frioul & 2012 & 2 & 186 & 21.13333 & 155.2585 & 33.80452 \\
\hline EA621124 & Frioul & 2012 & 3 & 574 & 26.33333 & 182.9879 & 31.47239 \\
\hline EA621252 & Riou & 2012 & 1 & 381 & 21.2 & 220.8059 & 23.32588 \\
\hline EA621252 & Riou & 2012 & 2 & 246 & 16.66667 & 120.7745 & 32.78243 \\
\hline EA621254 & Riou & 2015 & 1 & 227 & 19.1 & 31.38855 & 9.478269 \\
\hline EA621282 & Frioul & 2012 & 1 & 359 & 19.66667 & 131.3543 & 19.99216 \\
\hline EA621282 & Frioul & 2012 & 2 & 269 & 20.8 & 185.2309 & 42.75986 \\
\hline EA621282 & Frioul & 2012 & 3 & 219 & 17.26667 & 137.758 & 34.19235 \\
\hline EA621347 & Riou & 2011 & 1 & 96 & 16.66667 & 133.4084 & 25.11375 \\
\hline EA621347 & Riou & 2011 & 2 & 258 & 16.73333 & 159.0478 & 18.94242 \\
\hline EA621379 & Riou & 2011 & 1 & 455 & 25.53333 & 282.486 & 48.67823 \\
\hline EA621379 & Riou & 2011 & 2 & 355 & 24.3 & 229.622 & 85.31952 \\
\hline EA621379 & Riou & 2011 & 3 & 267 & 20.6 & 240.5288 & 78.12428 \\
\hline EA621379 & Riou & 2011 & 4 & 368 & 21.03333 & 99.82077 & 27.36082 \\
\hline EA621673 & Frioul & 2012 & 1 & 167 & 17.43333 & 237.5918 & 61.14044 \\
\hline EA621673 & Frioul & 2012 & 2 & 266 & 18.4 & 309.4056 & 112.24 \\
\hline EA621673 & Frioul & 2012 & 3 & 181 & 17.56667 & 251.4703 & 100.8403 \\
\hline EA621673 & Frioul & 2012 & 4 & 304 & 22.76667 & 362.6366 & 141.9427 \\
\hline EA621683 & Frioul & 2012 & 1 & 392 & 17.83333 & 120.8243 & 17.21523 \\
\hline
\end{tabular}




\begin{tabular}{|c|c|c|c|c|c|c|c|}
\hline EA621683 & Frioul & 2012 & 2 & 217 & 19.3 & 143.1574 & 33.86665 \\
\hline EA621683 & Frioul & 2012 & 3 & 437 & 20.8 & 138.6181 & 24.19683 \\
\hline EC100001 & Riou & 2011 & 1 & 185 & 15.36667 & 109.4745 & 25.37992 \\
\hline EC100001 & Riou & 2011 & 2 & 134 & 11.43333 & 172.7164 & 58.56319 \\
\hline EC100002 & Riou & 2012 & 1 & 228 & 17.83333 & 169.9823 & 57.03959 \\
\hline EC100002 & Riou & 2012 & 2 & 307 & 22.76667 & 259.0814 & 95.54314 \\
\hline EC100002 & Riou & 2014 & 1 & 544 & 42.36667 & 560.7254 & 115.1856 \\
\hline EC100054 & Frioul & 2012 & 1 & 317 & 22.46667 & 335.7444 & 118.0449 \\
\hline EC100054 & Frioul & 2012 & 2 & 223 & 23.33333 & 102.0563 & 17.26958 \\
\hline EC100054 & Frioul & 2012 & 3 & 379 & 21.83333 & 123.5627 & 43.27236 \\
\hline EC100104 & Riou & 2015 & 1 & 347 & 22.7 & 344.462 & 90.98925 \\
\hline EC100104 & Riou & 2015 & 2 & 279 & 18.93333 & 237.5836 & 76.64678 \\
\hline EC100156 & Riou & 2012 & 1 & 107 & 18.16667 & 74.70529 & 26.8197 \\
\hline EC100156 & Riou & 2012 & 2 & 218 & 19.16667 & 116.7197 & 31.65386 \\
\hline EC100156 & Riou & 2012 & 3 & 336 & 21 & 138.7979 & 50.91555 \\
\hline EC100160 & Riou & 2012 & 1 & 423 & 22.4 & 99.63473 & 26.54514 \\
\hline EC100160 & Riou & 2012 & 2 & 258 & 17.1 & 168.0411 & 34.38288 \\
\hline EC100183 & Riou & 2015 & 1 & 310 & 16.73333 & 150.7264 & 60.51673 \\
\hline EC100253 & Riou & 2015 & 1 & 264 & 17.03333 & 174.5967 & 68.18407 \\
\hline EC102691 & Riou & 2014 & 1 & 433 & 21.86667 & 158.9545 & 34.90184 \\
\hline EC102692 & Riou & 2014 & 1 & 636 & 46.96667 & 495.5599 & 84.38068 \\
\hline EC102698 & Riou & 2014 & 1 & 259 & 18.73333 & 152.3522 & 49.09335 \\
\hline NB02 & Riou & 2011 & 1 & 211 & 19.76667 & 145.5024 & 23.07429 \\
\hline NB02 & Riou & 2011 & 2 & 22 & 6.7666667 & 13.02388 & 2.097616 \\
\hline NB02 & Riou & 2011 & 3 & 269 & 16.93333 & 138.1201 & 42.86953 \\
\hline NB06 & Riou & 2012 & 1 & 230 & 18.2 & 162.8009 & 37.6337 \\
\hline NB06 & Riou & 2012 & 2 & 319 & 21.13333 & 126.9835 & 28.01322 \\
\hline NB06 & Riou & 2012 & 3 & 418 & 22.4 & 88.22749 & 18.16903 \\
\hline NB07 & Riou & 2014 & 1 & 471 & 18.2 & 83.71739 & 21.39259 \\
\hline NB08 & Riou & 2014 & 1 & 108 & 26.46667 & 294.8945 & 47.0458 \\
\hline NB08 & Riou & 2014 & 2 & 362 & 20.33333 & 101.7575 & 23.6823 \\
\hline NB09 & Riou & 2014 & 1 & 326 & 20.13333 & 140.1232 & 49.31408 \\
\hline NB10 & Riou & 2014 & 1 & 279 & 20.66667 & 159.4168 & 41.84232 \\
\hline NB11 & Riou & 2014 & 1 & 243 & 25.23333 & 298.2127 & 96.93353 \\
\hline NB11 & Riou & 2014 & 2 & 94 & 17.86667 & 102.0556 & 23.6134 \\
\hline NB12 & Riou & 2015 & 1 & 329 & 18.66667 & 280.2737 & 124.3417 \\
\hline NB13 & Riou & 2015 & 1 & 171 & 19 & 162.264 & 60.2429 \\
\hline NB13 & Riou & 2015 & 2 & 102 & 4.166667 & 9.352807 & 3.394749 \\
\hline NB13 & Riou & 2015 & 3 & 335 & 22.4 & 98.93079 & 19.69591 \\
\hline NB13 & Riou & 2015 & 4 & 277 & 17.33333 & 330.5388 & 94.25448 \\
\hline NB14 & Riou & 2015 & 1 & 277 & 17.8 & 176.8317 & 53.54744 \\
\hline NB15 & Riou & 2015 & 1 & 80 & 17 & 255.3445 & 102.2782 \\
\hline NB16 & Riou & 2015 & 1 & 405 & 21.7 & 203.2518 & 29.24086 \\
\hline NB16 & Riou & 2015 & 2 & 423 & 24.1 & 272.6973 & 29.55321 \\
\hline NB17 & Riou & 2015 & 1 & 349 & 21.7 & 320.6357 & 73.82406 \\
\hline NB17 & Riou & 2015 & 2 & 269 & 20.06667 & 230.7422 & 82.62435 \\
\hline NB17 & Riou & 2015 & 3 & 171 & 23.46667 & 204.3194 & 59.18303 \\
\hline NB18 & Riou & 2015 & 1 & 313 & 23.5 & 270.2717 & 58.78955 \\
\hline NB18 & Riou & 2015 & 2 & 25 & 3.2 & 8.57647 & 1.871632 \\
\hline NB19 & Riou & 2015 & 1 & 359 & 21.8 & 215.4816 & 46.68042 \\
\hline NB20 & Riou & 2015 & 1 & 292 & 17.06667 & 55.43941 & 13.44915 \\
\hline NB21 & Riou & 2015 & 1 & 237 & 17.16667 & 230.0234 & 49.71648 \\
\hline NB22 & Riou & 2015 & 1 & 284 & 21.53333 & 305.2421 & 59.42231 \\
\hline NB23 & Riou & 2015 & 1 & 266 & 16.96667 & 157.3242 & 38.13538 \\
\hline NB23 & Riou & 2015 & 2 & 426 & 24.26667 & 253.7867 & 53.44138 \\
\hline
\end{tabular}


To corroborate the degree of trophic specialization found in the resource selection patterns and their inter-annual variations, we assessed the individual trophic position of shearwaters using stable isotope analyses of the first primary feather (P1) of each individual. Considering the moult pattern of Scopoli's shearwaters, P1 feathers collected in August reflect diet during the previous chick-rearing period (Ramos et al. 2009). Therefore, feathers collected on GPStracked shearwaters during chick-rearing at year $n$ described their diet during the chickrearing period of year $n-1$. A total of $134 \mathrm{P} 1$ feathers were collected during the biotelemetry fieldwork ( $\mathrm{n}=31$ in 2011, $\mathrm{n}=33$ in 2012, $\mathrm{n}=20$ in 2014, $\mathrm{n}=20$ in 2015 and $\mathrm{n}=30$ in 2016).

We collected both GPS data and P1 samples in 2016, but did not considered GPS data collected in 2016 in our analyses. Relative abundance of stable isotopes of nitrogen $\left({ }^{15} \mathrm{~N}:{ }^{14} \mathrm{~N}\right.$, thereafter ' $\delta{ }^{15} \mathrm{~N}$ ') and carbon $\left({ }^{13} \mathrm{C}:{ }^{12} \mathrm{C}\right.$, thereafter ' $\delta{ }^{13} \mathrm{C}$ ') were determined on about $0.4 \mathrm{mg}$ subsamples of P1 feathers by continuous-flow isotope-ratio spectrometry (see Péron et al. [2013] for more details on sample preparation and calculation of isotopic ratios). $\delta^{15} \mathrm{~N}$ values equation as described by Hobson and Bond (2012) for seabirds:

$$
T P_{i}=3+\left(\delta^{15} N_{i}-\Delta d_{\text {feather }}-\delta^{15} N_{\text {copepods }}\right) / 3.4
$$
where $\delta^{15} N_{i}$ is the stable nitrogen isotope ratio for individual $i$ in its $\mathrm{P} 1$ feather, $\Delta d_{\text {feather }}$ is the mean diet-tissue discrimination factor between feather and prey muscle protein for comparable species because no data is available for adult Procellariforms $\left(3.7 \%\right.$ for $\delta^{15} N$, 
Meier et al. 2017), $\delta^{15} N_{\text {copepods }}(4.7 \%$ ) is the average value measured on copepods in the Gulf of Lions based on samples collected during the PELMED campaign in 2014, with an assumed trophic level of 2. We found a similar value for the $\delta^{15} N_{\text {copepods }}$ than in 2008 in the Gulf of Lions (4.5\%; Costalago et al. 2012). We considered a constant trophic enrichment factor of 3.4\%o (Post 2002).

To gain additional insights into diet specialization of Scopoli's shearwaters, we related the isotopic signature of individuals to those of their potential prey. The isotopic signatures of European anchovy, sardine and sprat were determined yearly between 2010 and 2015 based on sample collected during PELMED surveys covering our study area ( $\mathrm{n}$ ranged between 18 and 61 for anchovies, $\mathrm{n}$ ranged between 36 and 51 for sardines, $\mathrm{n}$ ranged between 32 and 57 for sprats; Brosset et al. 2016; Mialet et al. 2017). No data was available for sprat in 2015 and we used the isotopic values found in 2014 for this species in 2015 . We also considered isotopic values estimated for zooplankton in $2014(\mathrm{n}=174$ samples, Brosset et al. 2016) and copepods only (calanoids) in $2014\left(\delta^{15} N=4.74+/-0.77\right.$ [mean $+/-\mathrm{SD}$ ], $\delta^{13} C=-22.59+/-$ $0.63, \mathrm{n}=134$ samples, unpublished data) in the Gulf of Lions by IFREMER. Finally, isotopic signatures of European common squids (Loligo vulgaris), European flying squids (Todarodes sagittatus) and euphausiids (Meganyctiphanes norvegica) were taken from oceanographic surveys carried out in 2006-2007 in the Western Mediterranean (Cardona et al. 2012). Importantly, inference on diet of shearwaters from $\delta^{15} \mathrm{~N}$ values were valuable because 1) the average $\delta^{15} \mathrm{~N}$ isotopic signatures in zooplankton/copepods (4.75\%o/4.74\%o) were clearly different (at least $\sim 3.3 \%$, i.e. about one trophic level) from $\delta^{15} \mathrm{~N}$ in the three fish species (anchovy: 8.03\%o, sardine: 8.31\%o and sprat: 8.34\%o) in 2014 and standard deviation was small for each prey type, 2) the isotopic landscape is relatively homogeneous in space and time (Fig. S4.2). We found a low spatial variability among $\delta^{15} \mathrm{~N}$ values within the Gulf of Lion for fish species and zooplankton in 2014 and for fish species in other years (Fig. S4.2). 
We fitted a linear mixed model assessing the relationship between $\delta^{15} \mathrm{~N}$ values for each prey type (response variable) and a set of independent variables: longitude, latitude, fish length or zooplankton size class, and added a nested random intercept for fish (year/station) or a random intercept for zooplankton (station) to control for non-independence among multiple samples from the same year and/or the same station. Models indicated a slight decrease in isotopic values from West to East for anchovy (beta_longitude $=-0.36,95 \% \mathrm{CI}=-0.54 ;-0.17$ ) and sardine (beta_longitude $=-0.21,95 \% \mathrm{CI}=-0.36 ;-0.05$ ), but $\delta^{15} \mathrm{~N}$ values remained very different between fish and zooplankton throughout the longitudinal gradient. No longitudinal trend was found for sprat and zooplankton and no latitudinal trend occurred for any species. These results were supported by the low standard deviation in $\delta^{15} \mathrm{~N}$ for any species at each year. Similarly, we also found a very low inter-annual variability among the $\delta^{15} \mathrm{~N}$ values for any fish species in our study, with average values ranging between $7.15 \%$ and $8.03 \%$ for anchovy, $7.81 \%$ and $8.5 \%$ for sardines, and $7.65 \%$ and $8.34 \%$ for sprats (see also Brosset $e t$ al. 2016). We have no multi-year data for zooplankton/copepod but we expect that if $\delta^{15} \mathrm{~N}$ values for zooplankton/copepod changed significantly among years, small pelagic fish (anchovy, sardine and sprat) preying on zooplankton/copepod should have also changed in their $\delta^{15} \mathrm{~N}$ values among years, which is not the case. We thus are confident with the fact that $\delta^{15} \mathrm{~N}$ values for zooplankton/copepod should be relatively stable during our study period. This is reinforced by the fact that $\delta^{15} \mathrm{~N}$ values remained stable over time (2004, 2005 and 2014) in the Gulf of Lion (Brosset et al. 2016).

We found heterogeneity in the trophic position of individuals within and across years, while most birds had low trophic position, with a mean trophic position of $3.39+/-0.03$ (mean +/- SE, Fig. S4.1). In 2010 and 2011, shearwaters showed individual dietary specialization with their trophic position ranging from 2.9 to 4.7 , corresponding to a diet exclusively based on zooplankton, euphausiids and copepods, or on small pelagic fish and 
squid (Fig. S4.1, Fig. 6 in the main text). The following years had lower individual heterogeneity. The trophic position and contribution of fish in the diet in 2013 seemed to increase related to other years $(\mathrm{P}<0.02)$, but we have to be cautious with this interpretation because $\delta^{15} N_{\text {copepods }}$ was considered constant among years based on an estimation in 2014 (i.e. constant baseline). An increase of the $\delta^{15} N_{\text {copepods }}$ value in 2013 could imply higher trophic position values for shearwaters in 2013. However, $\delta^{15} N_{\text {copepods }}$ seemed to be relatively stable over years with similar values in 2008 and 2014, and isotopic signature of shearwaters well matched isotopic signature of small pelagic fish in 2013 (Fig. 6 in the main text). Shearwaters became more specialized on prey of lower trophic levels in 2014 with few variations among individuals (Fig. S4.1, Fig. 6 in the main text). Mean trophic position of individuals was not related to sex and age $\left(\mathrm{F}_{6,93}=2.24, \mathrm{r}^{2}=0.07, \mathrm{P}<0.05\right)$.

\section{References}

Brosset, P. et al. (2016). Linking small pelagic dietary shifts with ecosystem changes in the Gulf of Lions. Mar. Ecol. Prog. Ser., 554, 157-171.

Cardona, L., Álvarez de Quevedo, I., Borrell, A. \& Aguilar, A. (2012). Massive Consumption of Gelatinous Plankton by Mediterranean Apex Predators. PLoS ONE, 7, e31329.

Costalago, D., Navarro, J., Álvarez-Calleja, I. \& Palomera, I. (2012). Ontogenic and seasonal changes in the feeding habits and trophic levels of two small pelagic fish species. Mar. Ecol. Prog. Ser., 460, 169-181.

Hobson, K.A. \& Bond, A.L. (2012). Extending an indicator: year-round information on seabird trophic ecology from multiple-tissue stable-isotope analyses. Mar. Ecol. Prog. Ser., $461,233-243$.

Meier, R.E. et al. (2017). Tracking, feather moult and stable isotopes reveal foraging behaviour of a critically endangered seabird during the non-breeding season. Divers. Distrib., 
304 Mialet, B. (2017). Bilan des essais et optimisation du suivi mutualisé « réseaux trophiques et 305 contaminants » sur les campagnes halieutiques DCF 2014- 2015. Rapport pour le projet 306 DCSMM. http://archimer.ifremer.fr/doc/00373/48447/

307 Péron, C. et al. (2013). Importance of coastal Marine Protected Areas for the conservation of 308 pelagic seabirds: the case of vulnerable yelkouan shearwaters in the Mediterranean Sea. Biol. 309 Conserv., 168, 210-221.

310 Post, D.M. (2002) Using stable isotopes to estimate trophic position: models, methods, and 311 assumptions. Ecology, 83,703-718.

312 Ramos, R., González-Solís, J. \& Ruiz, X. (2009). Linking isotopic and migratory patterns in a 313 pelagic seabird. Oecologia, 160, 97-105. 

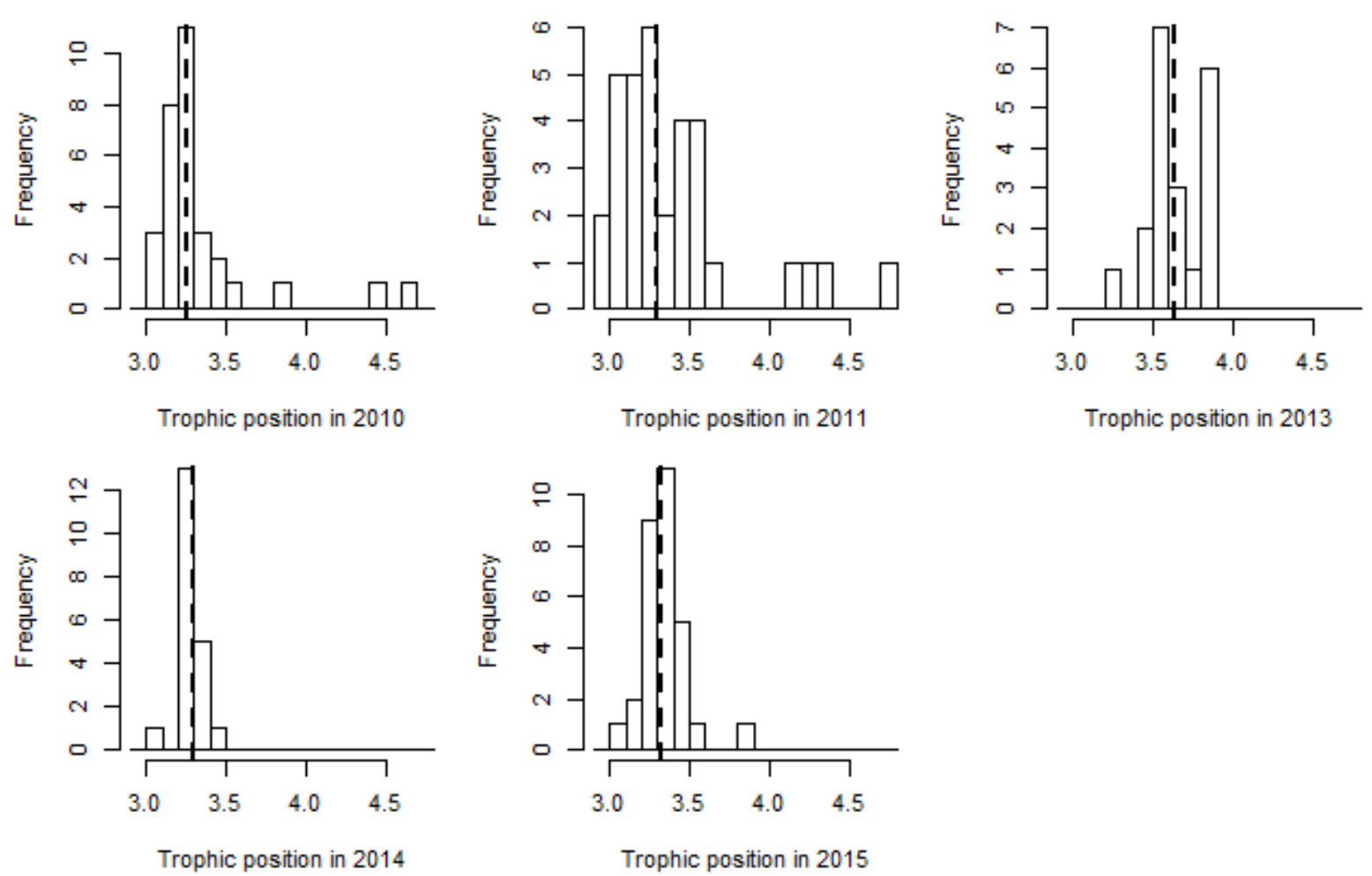

315 Figure S4.1. Annual distributions of inter-individual heterogeneity of trophic position of

316 Scopoli's shearwaters in the Gulf of Lions (Western Mediterranean) during the chick-rearing period between 2010 and 2015. Dotted lines represent median values within distributions. 

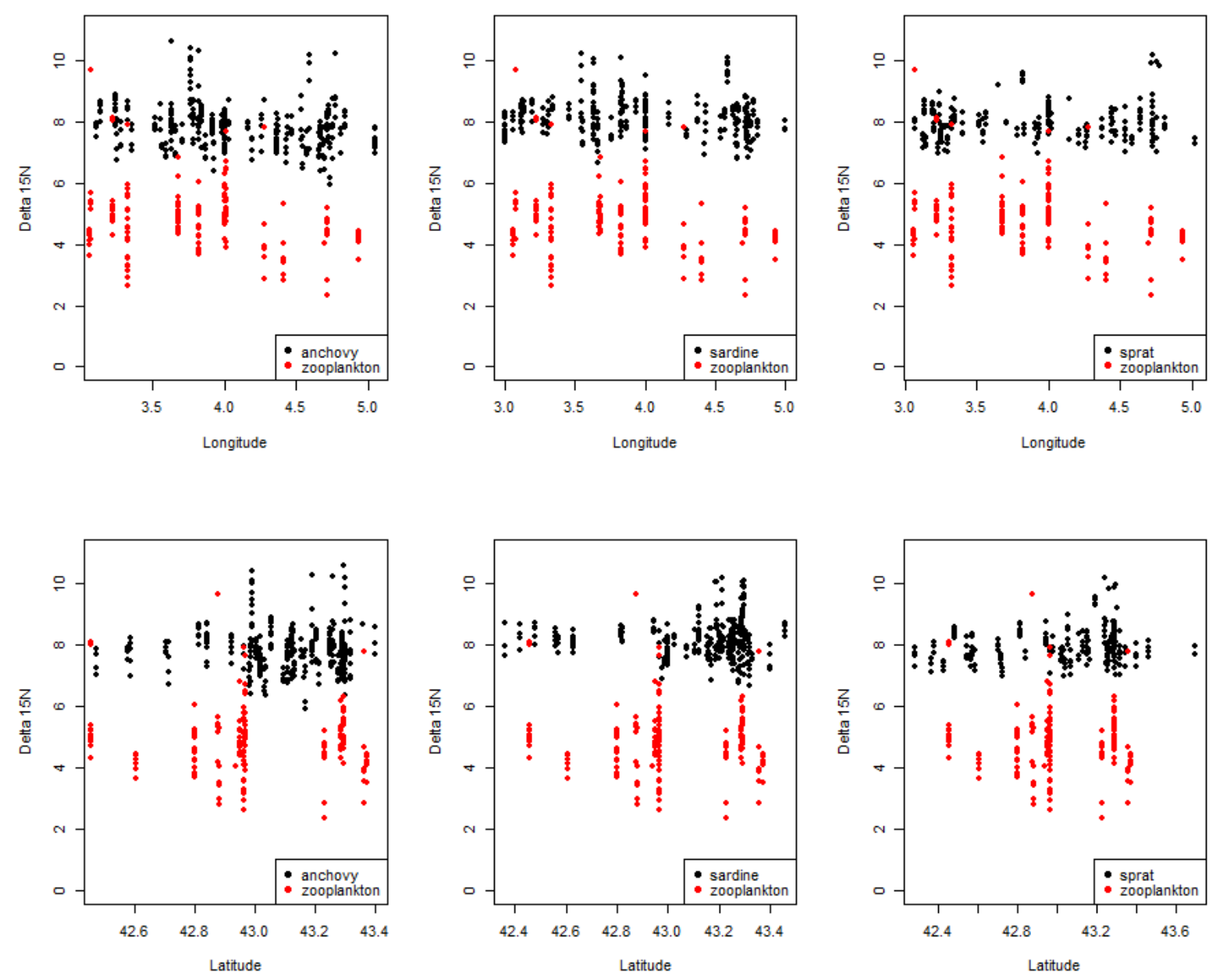

Figure S4.2. Spatial trends in the $\delta^{15} \mathrm{~N}$ isotopic values along longitudinal and latitudinal

320 gradients for three pelagic fish species (black circles) in July 2010 to 2015 and for

zooplankton in July 2014 (red circles) within the Gulf of Lion (Western Mediterranean). $\delta^{15} \mathrm{~N}$ 


\section{Supporting Information S5. Determining within-individual consistency in resource}

\section{selection}

We quantified individual specialization in resource selection (i.e. within-individual consistency in resource selection) with an adjusted repeatability index $R_{k}$ for each shearwater $k$. We adapted the population-level repeatability index $R$ developed for logistic regression with random coefficients (Johnson 2014; Nakagawa et al. 2017) that took the form:

$R=\frac{\sigma_{x, b e t w e e n}^{2}}{\sigma_{x, \text { between }}^{2}+\sigma_{x, \text { within }}^{2}+\sigma_{\varepsilon}^{2}}$

$\sigma_{x, \text { between }}^{2}=\left(\sum_{k} \sum_{i} \operatorname{var}\left(\gamma_{0 k}^{(\text {bird })}+\gamma_{x k}^{(\text {bird })} x_{i j k}\right)\right) / n$

$\sigma_{x, \text { within }}^{2}=\left(\sum_{j k} \sum_{i} \operatorname{var}\left(\gamma_{0 j k}^{(t r i p)}+\gamma_{x j k}^{(t r i p)} x_{i j k}\right)\right) / n$

$\sigma_{\varepsilon}^{2}=\frac{1}{p(1-p)}$

$p \sim \operatorname{logit}^{-1}\left(\beta_{0}{\sqrt{1+\left(\frac{16 \sqrt{3}}{15 \pi}\right)^{2} \times\left(\sigma_{x, \text { between }}^{2}+\sigma_{x, \text { within }}^{2}+\sigma_{e}^{2}\right)}}^{-1}\right)$

where $\sigma_{x, \text { between }}^{2}$ and $\sigma_{x, \text { within }}^{2}$ are the between- and within-individual variances (bird and trip level, respectively) estimated within resource selection function with a random effect for the prey-related variable $x, \sigma_{\varepsilon}^{2}$ is global observation-level (GPS location level) variance at the individual level given a logit link, $\gamma_{0 k}^{(b i r d)}$ and $\gamma_{x k}^{(b i r d)}$ are the random intercepts and the random coefficients of $x$, respectively, for shearwater $k$ at the individual level, $\gamma_{0 j k}^{(\text {trip })}$ and $\gamma_{x j k}^{(t r i p)}$ are the random intercepts and the random coefficients of $x$, respectively, for trip $j$ and shearwater $k$ at the trip level, $n$ the total number of observations, $p$ is the expected proportion of successes on the observed scale, and $\sigma_{e}^{2}$ is the fixed-effect variance. 
partitioning $\sigma_{\varepsilon}^{2}$ at the individual level, as usually done for linear models (Potier et al. 2015;

347

Wakefield et al. 2015). In a mixed RSF for foraging location $i$, trip $j$ and shearwater $k, R_{k}$ took the form:

$R_{k}=\frac{\sigma_{x, \text { between }}^{2}}{\sigma_{x, \text { between }}^{2}+\sigma_{x, \text { within }}^{2}+\sigma_{\varepsilon k}^{2}}$,

$\sigma_{\varepsilon k}^{2}=\frac{1}{p_{k}\left(1-p_{k}\right)}$

$p_{k} \sim \operatorname{logit}^{-1}\left(\beta_{0}{\sqrt{1+\left(\frac{16 \sqrt{3}}{15 \pi}\right)^{2} \times\left(\sigma_{x k, \text { between }}^{2}+\sigma_{x k, \text { within }}^{2}+\sigma_{e k}^{2}\right)}}^{-1}\right)$

where $\sigma_{\varepsilon k}^{2}$ is the partitioned observation-level variance for the $k^{\text {th }}$ bird, $p_{k}$ is the expected

proportion of successes on the observed scale for the $k^{\text {th }}$ bird, $\sigma_{x k \text {,between }}^{2}$ and $\sigma_{x k \text {,within }}^{2}$ are the between- and within-individual variance attributable to the $k^{\text {th }}$ bird, respectively, and $\sigma_{e k}^{2}$

357 is the fixed-effect variance for the $k^{\text {th }}$ bird.

$R_{k}$ values range between 0 and $1 . R_{k}$ values close to 1 imply high specialization (i.e. consistency) in resource selection for shearwater $k$. Low $R_{k}$ values can arise from a relatively high heterogeneity in resource selection among foraging trips or locations of shearwater $k$ (i.e. high within-individual or partitioned observation-level variance). Analyses were performed with the $r p t R$ package (Stoffel et al. 2017) of the R software (R Development Core Team 2016).

\section{References}

366 Johnson, P.C.D. (2014) Extension of Nakagawa \& Schielzeth's R ${ }^{2}$ GLMm to random slopes models. Methods Ecol. Evol., 5, 944-946. 
368 Nakagawa, S., Johnson, P.C.D. \& Schielzeth, H. (2017). The coefficient of determination R2 369 and intra-class correlation coefficient from generalized linear mixed-effects models revisited 370 and expanded. J. R. Soc. Interface, 14, 20170213.

371 Potier, S., Carpentier, A., Grémillet, D., Leroy, B. \& Lescroël, A. (2015). Individual

372 repeatability of foraging behaviour in a marine predator, the great cormorant, Phalacrocorax 373 carbo. Anim. Behav., 103, 83-90.

374 R Development Core Team 2016. R: A Language and Environment for Statistical Computing.

375 R Foundation for Statistical Computing, Vienna.

376 Stoffel, M.A., Nakagawa, S. \& Schielzeth, H. (2017). rptR: Repeatability estimation and

377 variance decomposition by generalized linear mixed-effects models. Methods Ecol. Evol., 8, 378 1639-1644.

379 Wakefield, E.D. et al. (2015). Long-term individual foraging site fidelity - why some gannets 380 don't change their spots. Ecology, 96, 3058-3074. 
Table S6.1. Mixed-effects logistic regression models for the resource selection of Scopoli's shearwater in the Gulf of Lions (Western Mediterranean) during the chick-rearing period between 2010 and 2015, estimated with GPS foraging locations ( $\mathrm{n}=56,945$ locations) with random intercepts and coefficients for trip ( $\mathrm{n}=182$ trips) and bird levels $(\mathrm{n}=75$ shearwaters).

We showed the marginal selection coefficients $(\beta)$ with their standard errors (SE) and 95\% confidence intervals (CI), the variance of random effects at the bird (VAR $\mathrm{Vird}_{\text {) }}$ ) and trip levels (VAR ${ }_{\text {trip). }}$. Models were assessed independently for each prey-related variable (12 models have converged) and summarized in the table. We accounted for multiple comparisons by adjusting our 95\% CI with a Benjamini-Yekutieli correction at alpha $=0.0014$ and z-value $=$ 3.19 .

\begin{tabular}{llllll}
\hline Variable & B & SE & Adjusted 95\% CI & VAR $_{\text {bird }}$ & VAR $_{\text {trip }}$ \\
\hline Anchovy adult biomass & & & & & \\
Intercept & $-2.45^{*}$ & 0.11 & $-2.80 ;-2.10$ & 0.02 & 0.20 \\
Biomass & -0.26 & 0.10 & $-0.58 ; 0.06$ & 0.22 & 1.02
\end{tabular}

Anchovy juvenile biomass

$\begin{array}{llllll}\text { Intercept } & 2.34^{*} & 0.09 & 2.05 ; 2.63 & 0.14 & 0.25 \\ \text { Biomass } & -1.07^{*} & 0.10 & -1.39 ;-0.75 & 1.31 & 0.96\end{array}$

Sardine adult biomass

$\begin{array}{llllll}\text { Intercept } & -2.34^{*} & 0.10 & -2.66 ;-2.02 & 0.12 & 0.29 \\ \text { Biomass } & -2.04^{*} & 0.09 & -2.33 ;-1.75 & 0.67 & 5.65\end{array}$

Sardine juvenile biomass

$\begin{array}{llllll}\text { Intercept } & -3.03^{*} & 0.08 & -3.29 ;-2.77 & 0.32 & 0.81 \\ \text { Biomass } & -14.70^{*} & 0.09 & -14.98 ;-14.41 & 34.41 & 210.43\end{array}$


Sprat adult biomass

$\begin{array}{llllll}\text { Intercept } & -2.59^{*} & 0.09 & -2.88 ;-2.30 & 0.06 & 0.22 \\ \text { Biomass } & -0.01 & 0.07 & -0.23 ; 0.21 & 0.12 & 0.94\end{array}$

Sprat juvenile biomass

$\begin{array}{llllll}\text { Intercept } & -2.22^{*} & 0.08 & -2.48 ;-1.96 & 0.08 & 0.27 \\ \text { Biomass } & -0.77^{*} & 0.07 & -0.99 ;-0.55 & 0.06 & 1.06\end{array}$

Zooplankton-preferred abundance

$\begin{array}{llllll}\text { Intercept } & -3.02^{*} & 0.17 & -3.56 ;-2.48 & 0.06 & 0.42 \\ \text { Abundance } & 0.30^{*} & 0.09 & 0.01 ; 0.59 & 0.16 & 0.82\end{array}$

Zooplankton-other abundance

$\begin{array}{llllll}\text { Intercept } & -2.31^{*} & 0.15 & -2.79 ;-1.83 & 0.15 & 0.34 \\ \text { Abundance } & 0.29^{*} & 0.09 & 0.003 ; 0.58 & 0.22 & 0.79\end{array}$

Anchovy adult predictability

$\begin{array}{llllll}\text { Intercept } & -8.29^{*} & 0.30 & -9.25 ;-7.33 & 0.63 & 3.40 \\ \text { Var(biomass) } & -11.36^{*} & 0.69 & -13.56 ;-9.15 & 171.90 & 430.57\end{array}$

Sprat adult predictability

$\begin{array}{llllll}\text { Intercept } & -7.80^{*} & 0.15 & -8.28 ;-7.32 & 2.35 & 1.16 \\ \text { Var(biomass) } & -2.70^{*} & 0.12 & -3.08 ;-2.32 & 0.90 & 24.89\end{array}$

Zooplankton-preferred predictability
Intercept
$-2.15^{*}$
$0.11 \quad-2.50 ;-1.80$
0.02
0.20
Var(abundance)
0.29
$0.18 \quad-0.28 ; 0.86$
0.85
3.97

Zooplankton-other predictability

$\begin{array}{llllll}\text { Intercept } & -2.21^{*} & 0.12 & -2.59 ;-1.83 & 0.01 & 0.34 \\ \text { Var(abundance) } & -0.06 & 0.16 & -0.57 ; 0.45 & 0.32 & 4.04\end{array}$


Table S6.2. Variance components used to estimate the within-individual consistency in

395 resource selection of shearwaters within the Gulf of Lions (Western Mediterranean) during

396 the chick-rearing period between 2011 and 2015. We show the between-individual variance

$397\left(\sigma_{x, \text { between }}^{2}\right)$, the within-individual variance $\left(\sigma_{x, \text { within }}^{2}\right)$ and the distribution (mean \pm SE) of all

398 the partitioned observation-level variance of each bird $k\left(\sigma_{\varepsilon k}^{2}\right)$ used in the analyses.

399

\begin{tabular}{|c|c|c|c|}
\hline Model & $\sigma_{x, \text { between }}^{2}$ & $\sigma_{x, \text { within }}^{2}$ & $\sigma_{\varepsilon k}^{2}$ \\
\hline Anchovy adult biomass & 0.234 & 1.224 & $9.589 \pm 0.102$ \\
\hline Anchovy juvenile biomass & 1.449 & 1.217 & $7.200 \pm 0.110$ \\
\hline Sardine adult biomass & 0.784 & 5.936 & $3.139 \pm 0.145$ \\
\hline Sardine juvenile biomass & 34.726 & 211.235 & $4.671 \pm 0.127$ \\
\hline Sprat adult biomass & 0.175 & 1.163 & $11.245 \pm 0.136$ \\
\hline Sprat juvenile biomass & 0.139 & 1.331 & $7.980 \pm 0.079$ \\
\hline Zooplankton-preferred abundance & 0.223 & 1.239 & $13.930 \pm 0.148$ \\
\hline Zooplankton-other abundance & 0.369 & 1.133 & $8.735 \pm 0.072$ \\
\hline Anchovy adult predictability & 172.535 & 433.963 & $36.178 \pm 5.766$ \\
\hline Sprat adult predictability & 3.249 & 26.049 & $49.715 \pm 4.830$ \\
\hline Zooplankton-preferred predictability & 0.868 & 4.173 & $7.557 \pm 0.197$ \\
\hline Zooplankton-other predictability & 0.319 & 4.378 & $7.114 \pm 0.192$ \\
\hline
\end{tabular}




\begin{tabular}{lll}
\hline Variable & Zooplankton-fish trips & Zooplankton-only trips \\
\hline Anchovy adult biomass & $0.31[0.20 ; 0.42]^{*}$ & $-0.95[-1.13 ;-0.76]^{*}$ \\
Anchovy juvenile biomass & $-0.85[-0.99 ;-0.71]^{*}$ & $-1.32[-1.49 ;-1.15]^{*}$ \\
Sardine adult biomass & $-1.03[-1.36 ;-0.70]^{*}$ & $-3.21[-3.71 ;-2.70]^{*}$ \\
Sardine juvenile biomass & $-9.08[-10.91 ;-7.25]^{*}$ & $-19.85[-23.16 ;-16.54]^{*}$ \\
Sprat adult biomass & $0.62[0.49 ; 0.75]^{*}$ & $-0.75[-0.89 ;-0.62]^{*}$ \\
Sprat juvenile biomass & $-0.26[-0.40 ;-0.12]^{*}$ & $-1.37[-1.58 ;-1.16]^{*}$ \\
Zooplankton-preferred abundance & $0.24[0.08 ; 0.41]^{*}$ & $0.37[0.19 ; 0.54]^{*}$ \\
Zooplankton-other abundance & $0.50[0.35 ; 0.65]^{*}$ & $0.05[-0.13 ; 0.23]$ \\
Anchovy adult predictability & $-5.17[-8.19 ;-2.14]^{*}$ & $-14.20[-19.67 ;-8.74]^{*}$ \\
Sprat adult predictability & $-0.87[-1.45 ;-0.29]^{*}$ & $-4.42[-5.49 ;-3.36]^{*}$ \\
Zooplankton-preferred predictability & $0.16[-0.22 ; 0.53]$ & $0.47[0.11 ; 0.84]^{*}$ \\
Zooplankton-other predictability & $0.24[-0.10 ; 0.57]$ & $-0.38[-0.83 ; 0.06]$ \\
\hline O5\% Cl exclude 0. & & \\
\hline
\end{tabular}

Table S6.3. Resource selection for the two foraging trip tactics of shearwaters within the Gulf of Lions (Western Mediterranean) during the chick-rearing period between 2011 and 2015.

Mean selection coefficient $(\bar{\beta})$ are shown with their $95 \%$ confidence interval $(\mathrm{CI})$.

404 
Table S6.4. Spearman rank correlations $\left(r_{s}\right)$ and their significance $(\mathrm{P})$ in parentheses between

407 individual foraging site fidelity (IFSF) and individual specialization in resource selection

408 (ISRS), and between IFSF and resource selection for Scopoli's shearwater $(n=47$

409 individuals), in the Gulf of Lions (Western Mediterranean) during four chick-rearing periods

410 between 2011 and 2015 and each prey-related variable. P-values are adjusted with Benjamini-

411 Yekutieli correction to account for the 24 multiple comparisons.

412

\begin{tabular}{lll}
\hline Model & IFSF versus ISRS & IFSF versus resource selection \\
\hline Anchovy adult biomass & $-0.04(1.00)$ & $-0.08(1.00)$ \\
Anchovy juvenile biomass & $0.17(1.00)$ & $-0.10(1.00)$ \\
Sardine adult biomass & $0.13(1.0)$ & $0.26(1.00)$ \\
Sardine juvenile biomass & $-0.03(1.0)$ & $0.27(1.00)$ \\
Sprat adult biomass & $-0.11(1.0)$ & $0.07(1.00)$ \\
Sprat juvenile biomass & $0.02(1.00)$ & $0.33(1.00)$ \\
Zooplankton-preferred abundance & $-0.27(1.0)$ & $-0.17(1.00)$ \\
Zooplankton-other abundance & $-0.43(0.90)$ & $-0.16(1.00)$ \\
Anchovy adult predictability & $-0.13(1.0)$ & $0.14(1.00)$ \\
Sprat adult predictability & $0.28(1.0)$ & $0.24(1.00)$ \\
Zooplankton-preferred predictability & $-0.17(1.00)$ & $0.13(1.00)$ \\
Zooplankton-other predictability & $-0.14(1.00)$ & $-0.002(1.00)$ \\
\hline
\end{tabular}


Table S6.5. Proportions of the different foraging trip tactics of GPS-tracked shearwaters each year within the Gulf of Lions (Western Mediterranean) during the chick-rearing period. We tested for annual variations in the relative importance of selection tactics ( $\mathrm{n}=182$ trips) using mixed logistic regression with individuals ( $\mathrm{n}=75$ shearwaters) as random intercept and year as predictor. We found inter-annual variability in the probability to use zooplankton-fish over zooplankton-only trips. In 2011, shearwaters mainly (66\%) used zooplankton-fish specialist trips, while zooplankton-only specialist trips became predominant (63\%) in 2014. The probability to use a zooplankton-fish trip over a zooplankton-only trip was significantly higher in 2011 than in 2014 (z-test $=-2.508, \mathrm{P}=0.01)$. Interestingly, isotopic analyses confirmed that shearwaters had low individual trophic position in 2014 , relatively homogeneous among birds, and that their individual dietary specialization were poorly based on small pelagic fish this year (Supporting Information S4, Fig. S4.1, S4.2). Contrary to other years, selection patterns were more balanced among trips in 2012 and 2015 and the probability to use a zooplankton-fish trip over a zooplankton-only trip did not differ statistically from other years.

\begin{tabular}{llll}
\hline Year & Zooplankton-fish trip & Zooplankton-only trip & $\mathrm{Nb}$ trip \\
\hline 2011 & 0.66 & 0.34 & 50 \\
2012 & 0.55 & 0.45 & 73 \\
2014 & 0.37 & 0.63 & 30 \\
2015 & 0.52 & 0.48 & 29 \\
\hline
\end{tabular}



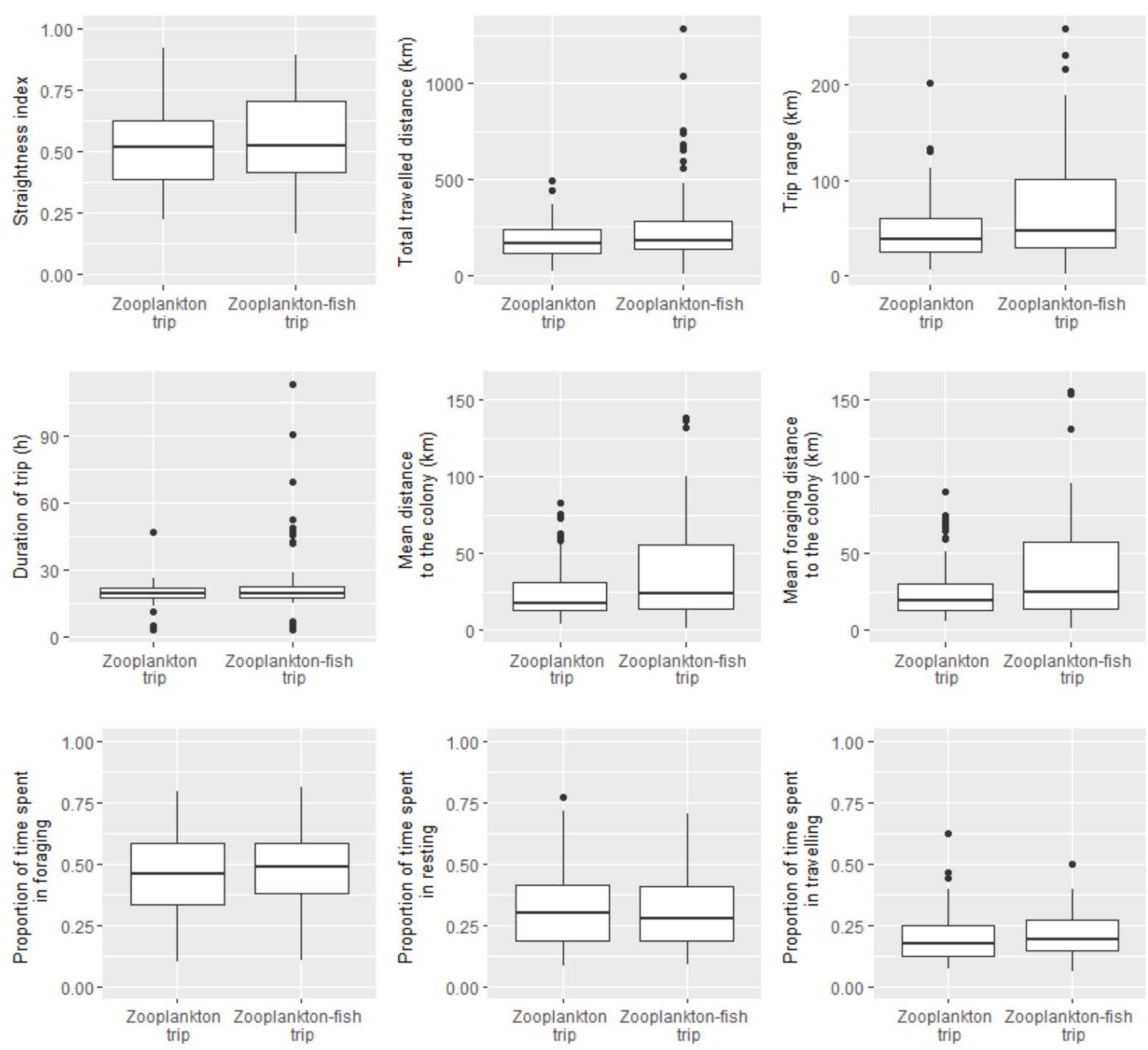

431 Figure S6.1. Foraging trip features of the different foraging trip tactics (zooplankton-only

432 specialist trip and zooplankton-fish specialist trip) of Scopoli's shearwaters within the Gulf of

433 Lions (Western Mediterranean) during the chick-rearing period between 2011 and 2015. We

434 characterized differences between features of trip tactics considering tortuosity with a

435 straightness index (i.e. [2 x trip range] / total travelled distance), trip duration, mean distance

436 to the colony, mean distance to the colony for foraging, and proportion of time spent in

437 foraging, resting or travelling. We fitted linear or logistic mixed models depending the

438 dependent variable with the trip tactics (i.e. groups of trips from the cluster analysis) and year

439 as predictors. We used individuals as random intercept to accommodate for multiple trips. We

440 calculated $95 \%$ confidence intervals with a bootstrap procedure. Relative to zooplankton-only 
441 specialist trips, zooplankton-fish specialist trips had higher trip duration $(24.2 \mathrm{~h}$ versus $19.8 \mathrm{~h}$,

$442 \mathrm{t}$-test $=2.106, \mathrm{P}<0.03)$, total travelled distance $(247 \mathrm{~km}$ versus $183 \mathrm{~km}, \mathrm{t}$-test $=2.237, \mathrm{P}<$

$4430.03)$, trip range $(67 \mathrm{~km}$ versus $49 \mathrm{~km}$, $\mathrm{t}$-test $=2.221, \mathrm{P}<0.03)$, mean distance to the colony

$444(36 \mathrm{~km}$ versus $25 \mathrm{~km}$, t-test $=2.654, \mathrm{P}<0.01)$, mean distance to the colony for foraging

445 locations $(38 \mathrm{~km}$ versus $26 \mathrm{~km}$, $\mathrm{t}$-test $=2.401, \mathrm{P}<0.02)$, but tortuosity (mean straightness

446 index $=0.55$ versus 0.52 , z-test $=-0.031, \mathrm{P}=0.98)$ and proportion of time spent in resting

447 (0.30 versus 0.32 , $\mathrm{z}$-test $=-0.685, \mathrm{P}=0.49)$, foraging $(0.48$ versus 0.46 , $\mathrm{z}$-test $=1.556, \mathrm{P}=$

$4480.12)$ or travelling $(0.21$ versus 0.21 , z-test $=-0.303, P=0.76)$ were similar between trip

449 tactics. 

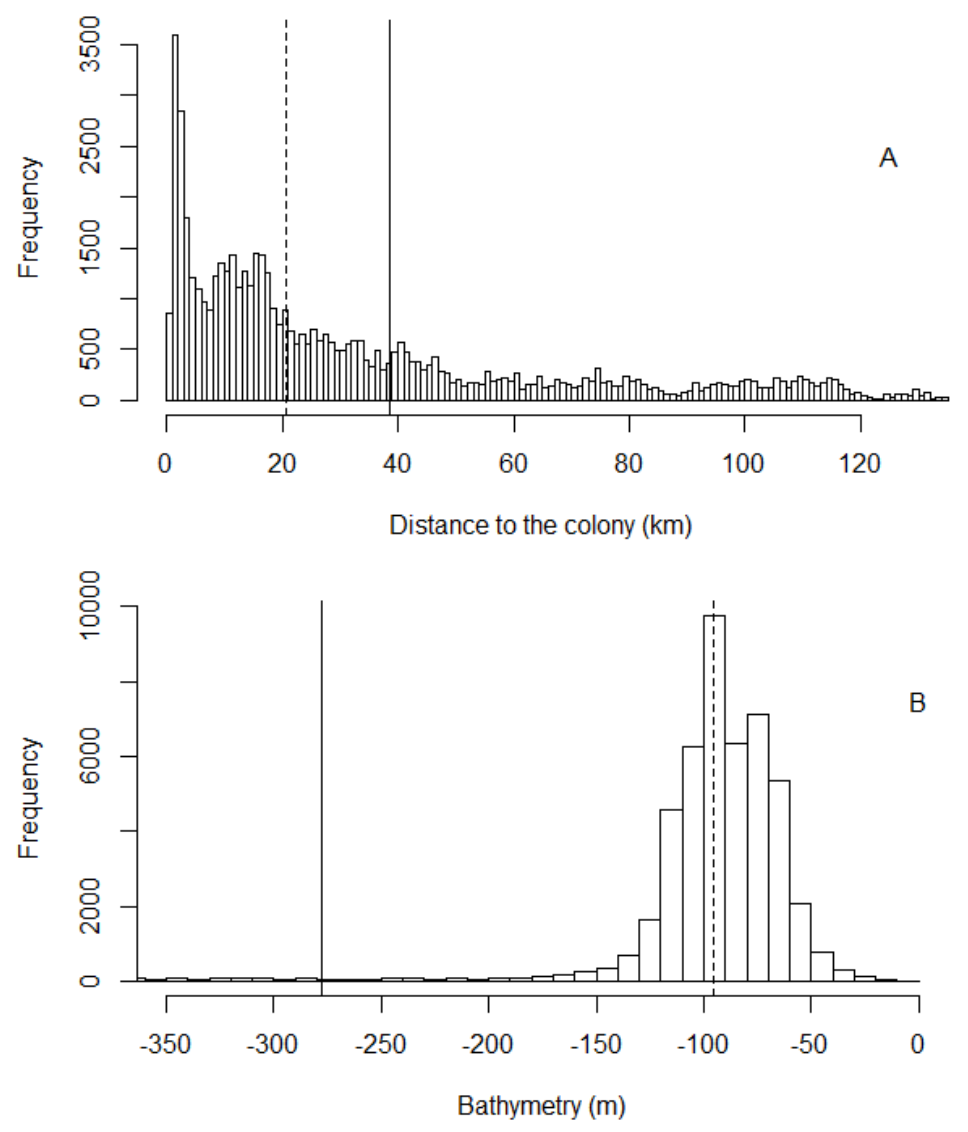

450

451 Figure S6.2. Distribution of foraging locations as a function of distance to the colony (A) and 452 bathymetry (B). The distributions are truncated at $130 \mathrm{~km}(95 \%$ of data are shown, the tail of 453 the distribution reach $260 \mathrm{~km})$ and $-350 \mathrm{~m}(84 \%$ of data are shown, the tail of the distribution 454 reach -2380 m). Mean (solid line) and median (dashed line) values of the distributions are 455 showed. 


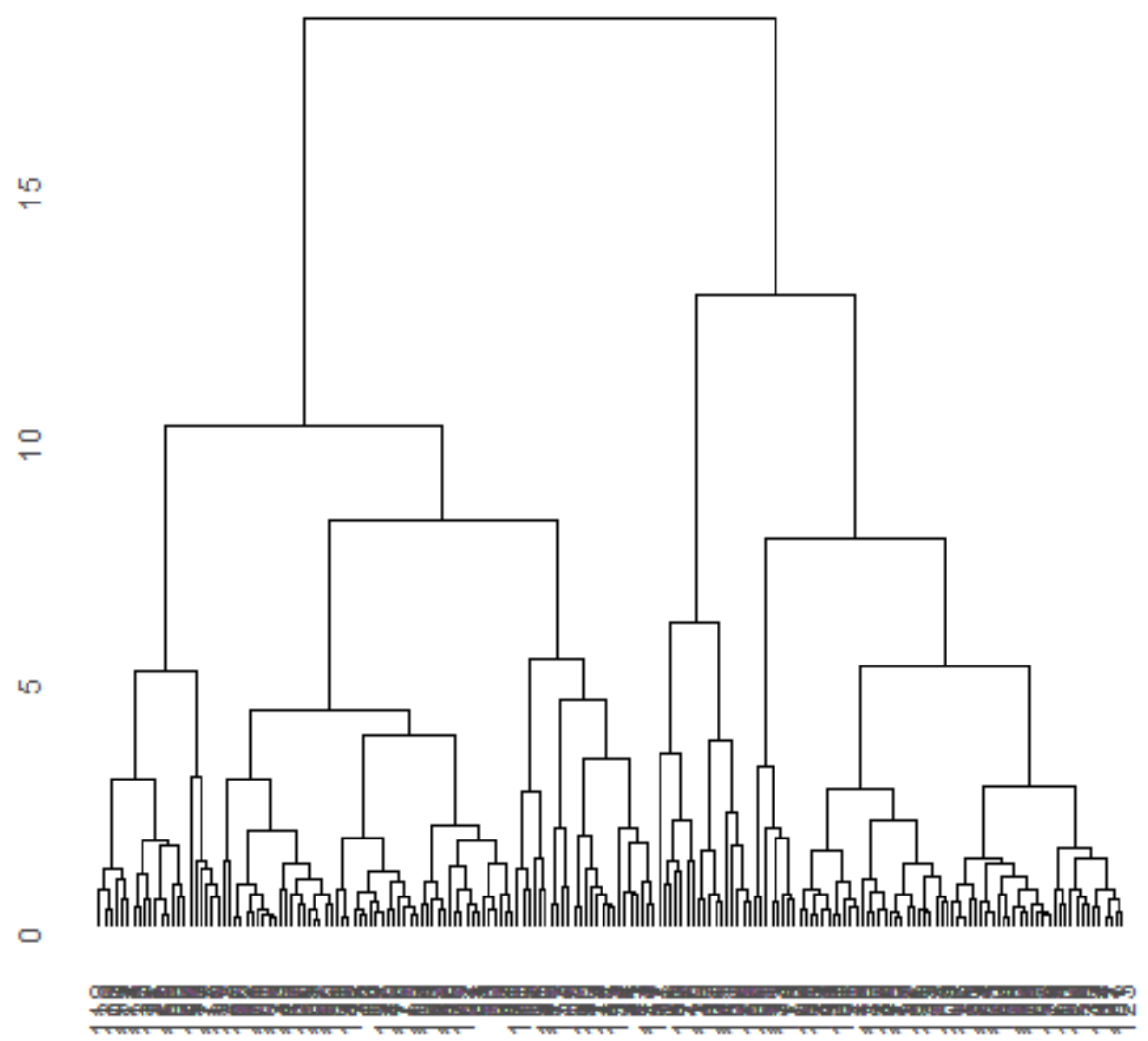

456

457 Figure S6.3. Dendrogram for the cluster analysis based on selection coefficients for 182

458 foraging trips of shearwaters in the Gulf of Lions (Western Mediterranean) occurring during

459 the chick-rearing period between 2011 and 2015. We considered two different clusters

460 corresponding to two foraging trip tactics. 